\title{
Design and Synthesis of LM146, a Potent Inhibitor of PB1 with Improved Selectivity Profile over SMARCA2
}

Supporting Information

Léa Mélin, $†$ Emily Gesner,§ Sarah Attwell,§ Olesya A. Kharenko,§ Edward H. van der Horst, $\S$ Henrik C. Hansen, $\S$ Alexandre Gagnon*†

† Département de chimie, Université du Québec à Montréal, C.P. 8888, Succ. Centre-Ville, Montréal, Québec, H3C 3P8, Canada

$\S$ Zenith Epigenetics Ltd, Suite 300, 4820 Richard Road SW, Calgary, AB, T3E 6L1, Canad 


\section{TABLE OF CONTENT}

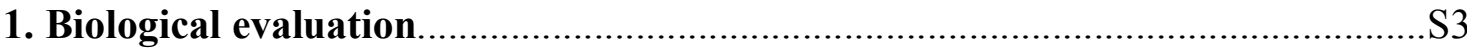

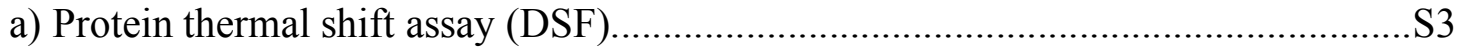

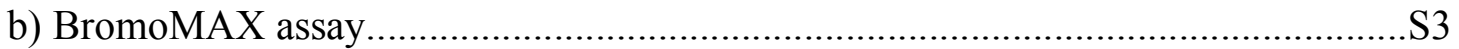

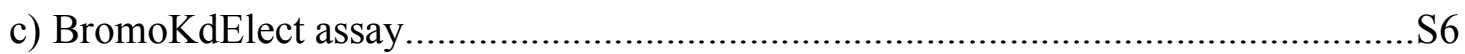

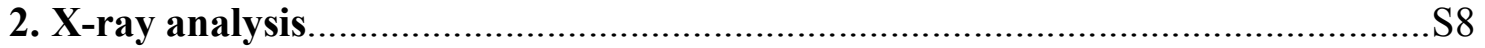




\section{Biological evaluation}

\section{a) Protein thermal shift assay (DSF)}

N-terminally His-tagged recombinant bromodomains PB1(2) (Reaction Biology RD-11-218), PB1(4) (Reaction Biology RD-11-215), PB1(5) (Reaction Biology RD-11-216), and SMARCA2A (Reaction Biology RD-11-212) were incubated at a concentration of $10 \mu \mathrm{M}$ with $100 \mu \mathrm{M}$ of compound at a final DMSO concentration of $0.2 \%$ in the presence of $5 \times$ SYPRO orange protein stain (Life Technologies S-6650) for $30 \mathrm{~min}$ at $25^{\circ} \mathrm{C}$ in $50 \mathrm{mM} \mathrm{NaCl} / 50 \mathrm{mM}$ HEPES buffer, $\mathrm{pH}$ 7.4. Melt curve experiments were run on an Applied Biosystems ViiA7 realtime PCR instrument. Melting temperatures $\left(\mathrm{T}_{\mathrm{m}}\right)$ were calculated using Applied Biosystems Protein Thermal Shift Software v1.3. This assay was performed at Zenith Epigenetics Ltd, Calgary, Canada.

\section{b) BromoMAX assay}

Protocol description. T7 phage strains displaying bromodomains were grown in parallel in 24well blocks in an E. coli host derived from the BL21 strain. E. coli were grown to log-phase and infected with T7 phage from a frozen stock (multiplicity of infection $=0.4$ ) and incubated with shaking at $32^{\circ} \mathrm{C}$ until lysis (90-150 minutes). The lysates were centrifuged (5,000 x g) and filtered $(0.2 \mu \mathrm{m})$ to remove cell debris. Streptavidin-coated magnetic beads were treated with biotinylated small molecule or acetylated peptide ligands for 30 minutes at room temperature to generate affinity resins for bromodomain assays. The liganded beads were blocked with excess biotin and washed with blocking buffer (SeaBlock (Pierce), 1 \% BSA, $0.05 \%$ Tween 20, 1 mM DTT) to remove unbound ligand and to reduce non-specific phage binding. Binding reactions were assembled by combining bromodomains, liganded affinity beads, and test compounds in $1 \mathrm{x}$ binding buffer (16\% SeaBlock, 0.32x PBS, 0.02\%BSA, $0.04 \%$ Tween 20, $0.004 \%$ Sodium azide, $7.9 \mathrm{mM}$ DTT). Test compounds were prepared as $1000 \mathrm{X}$ stocks in $100 \%$ DMSO and subsequently diluted 1:25 in monoethylene glycol (MEG). The compounds were then diluted directly into the assays such that the final concentrations of DMSO and MEG were $0.1 \%$ and $2.4 \%$, respectively. All reactions were performed in polypropylene 384 -well plates in a final volume of $0.02 \mathrm{ml}$. The assay plates were incubated at room temperature with shaking for 1 hour and the affinity beads were washed with wash buffer (1x PBS, 0.05\% Tween 20). The beads were then re-suspended in elution buffer (1x PBS, 0.05\% Tween 20, $2 \mu \mathrm{M}$ nonbiotinylated affinity ligand) and incubated at room temperature with shaking for 30 minutes. The bromodomain concentration in the eluates was measured by qPCR. 
\%Ctrl Calculation. LM146 was screened at $10 \mu \mathrm{M}$, and results for primary screen binding interactions are reported as '\% Ctrl', where lower numbers indicate stronger hits in the matrix in Table S1.

$\% \mathrm{Ctrl}=100 \times \frac{\text { test compound signal-positive control signal }}{\text { negative control signal-positive control signal }}$

With test compound $=\mathbf{L M 1 4 6}$, negative control $=$ DMSO $(100 \% \mathrm{Ctrl})$ and positive control $=$ control compound $(0 \% \mathrm{Ctrl})$.

\section{Relationship between Binding Constant Distributions (Kds) \& Single Concentration}

Primary Screen Values. Based on screening data from thousands of profiled compounds, a proportional relationship between primary screening results and corresponding compound/target affinities may be described. Evident in the correlation graph below is a range of binding constants ( $\mathrm{Kd}$ values) for the indicated ranges of POC values with tighter binding (higher affinity) interactions associated with lower POC values and weaker binding (lower affinity) associated with higher POC values. This distribution of binding constants is characteristic of single concentration primary screens and underscores the importance of following up observed 'hits' or apparent high affinity interactions with quantitative binding constant determinations.

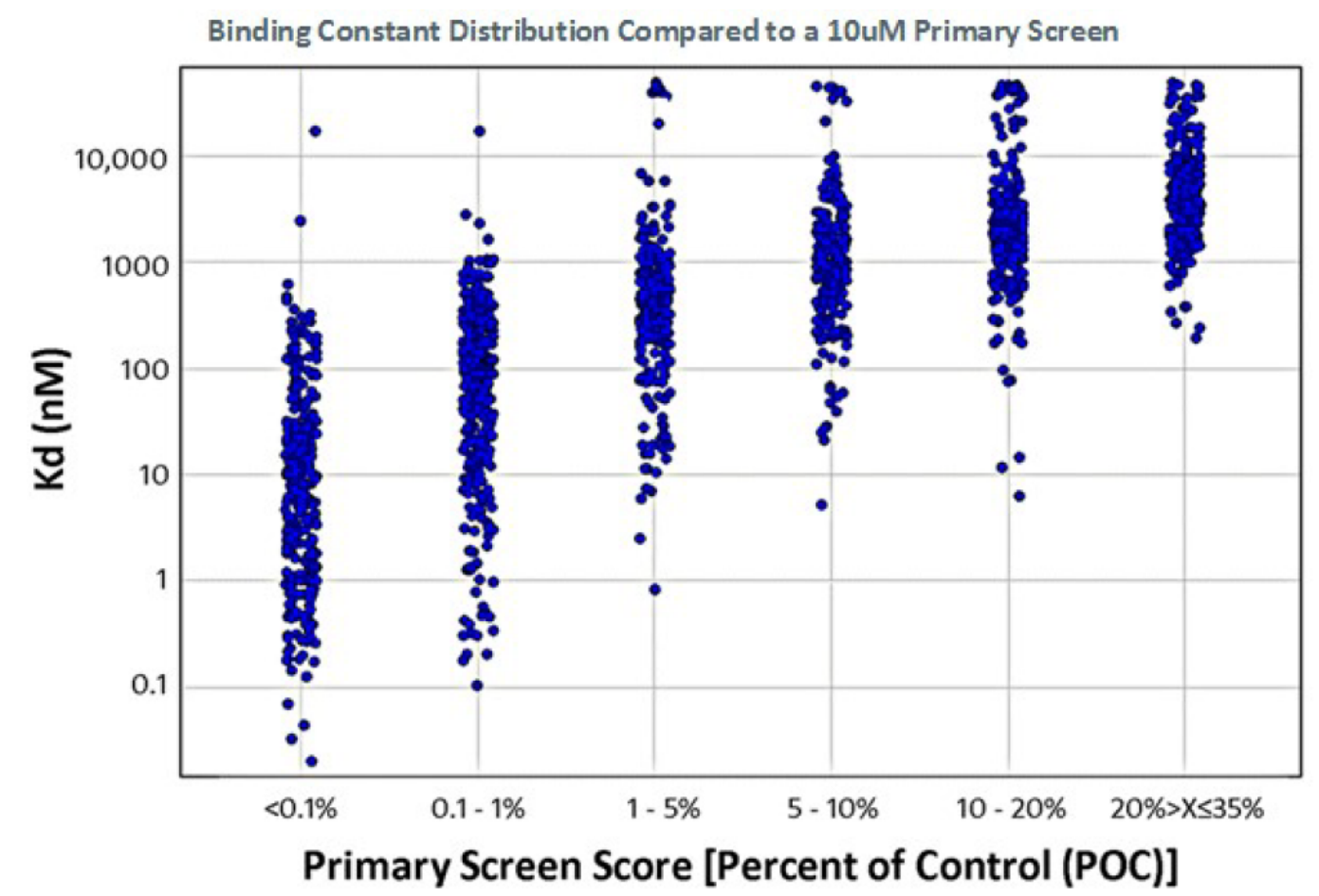

Figure S1. Data correlation between primary screening (10 $\mu \mathrm{M}$ concentration) and binding constants (Kd values). Binding constants are correlated with primary screening results, where lower POC values are associated with low $\mathrm{Kd}$ values (higher affinity interactions). 


\section{Additional data.}

Table S1. Matrix of bromoMAX screen for LM146 at $10 \mu \mathrm{M}$
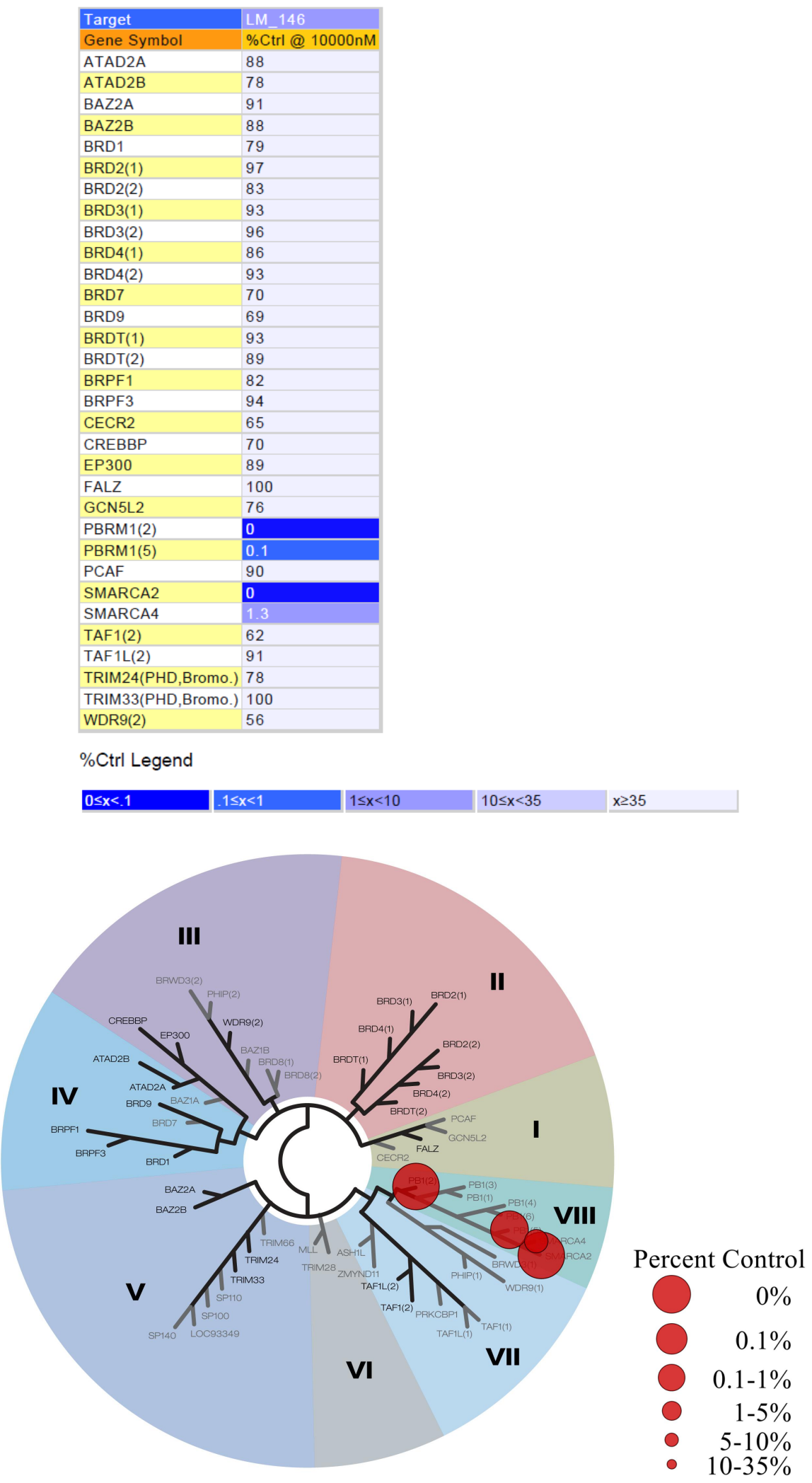

Figure S2. TREEspot ${ }^{\mathrm{TM}}$ bromodomain phylogenic tree for LM146. 


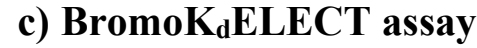

Protocol description. T7 phage strains displaying bromodomains were grown in parallel in 24well blocks in an E. coli host derived from the BL21 strain. E. coli were grown to log-phase and infected with T7 phage from a frozen stock (multiplicity of infection $=0.4$ ) and incubated with shaking at $32^{\circ} \mathrm{C}$ until lysis (90-150 minutes). The lysates were centrifuged (5,000 x g) and filtered $(0.2 \mu \mathrm{m})$ to remove cell debris. Streptavidin-coated magnetic beads were treated with biotinylated small molecule or acetylated peptide ligands for 30 minutes at room temperature to generate affinity resins for bromodomain assays. The liganded beads were blocked with excess biotin and washed with blocking buffer (SeaBlock (Pierce), $1 \%$ BSA, $0.05 \%$ Tween 20, $1 \mathrm{mM}$ DTT) to remove unbound ligand and to reduce non-specific phage binding. Binding reactions were assembled by combining bromodomains, liganded affinity beads, and test compounds in $1 \mathrm{x}$ binding buffer (17\% SeaBlock, 0.33x PBS, $0.04 \%$ Tween 20, 0.02\% BSA, $0.004 \%$ Sodium azide, $7.4 \mathrm{mM}$ DTT). Test compounds were prepared as $1000 \mathrm{X}$ stocks in $100 \%$ DMSO. Kds were determined using an 11-point 3-fold compound dilution series with one DMSO control point. All compounds for Kd measurements are distributed by acoustic transfer (non-contact dispensing) in 100\% DMSO. The compounds were then diluted directly into the assays such that the final concentration of DMSO was $0.09 \%$. All reactions performed in polypropylene 384-well plates. Each was a final volume of $0.02 \mathrm{ml}$. The assay plates were incubated at room temperature with shaking for 1 hour and the affinity beads were washed with wash buffer (1x PBS, $0.05 \%$ Tween 20). The beads were then re-suspended in elution buffer (1x PBS, $0.05 \%$ Tween 20, $2 \mu \mathrm{M}$ non-biotinylated affinity ligand) and incubated at room temperature with shaking for 30 minutes. The bromodomain concentration in the eluates was measured by qPCR. This assay was performed at Eurofins DiscoverX, San Diego, USA.

Compound handling. An 11-point 3-fold serial dilution of each test compound was prepared in $100 \%$ DMSO at 1000x final test concentration. All compounds for Kd measurements are distributed by acoustic transfer (non-contact dispensing) in 100\% DMSO. The compounds were then diluted directly into the assays such that the final concentration of DMSO was $0.09 \%$. Most Kds were determined using a compound top concentration $=10,000 \mathrm{nM}$. If the initial $\mathrm{Kd}$ determined was $<0.169 \mathrm{nM}$ (the lowest concentration tested), the measurement was repeated with a serial dilution starting at a lower top concentration.

Binding constants (Kds). Binding constants (Kds) were calculated with a standard doseresponse curve using the Hill equation: 


$$
\text { Response }=\text { Background }+\frac{\text { Signal }- \text { Background }}{1+\frac{\text { Kd(Hill Slope })}{\text { Dose }(\text { Hill Slope })}}
$$

The Hill Slope was set to -1 . Curves were fitted using a non-linear least square fit with the Levenberg-Marquardt algorithm.
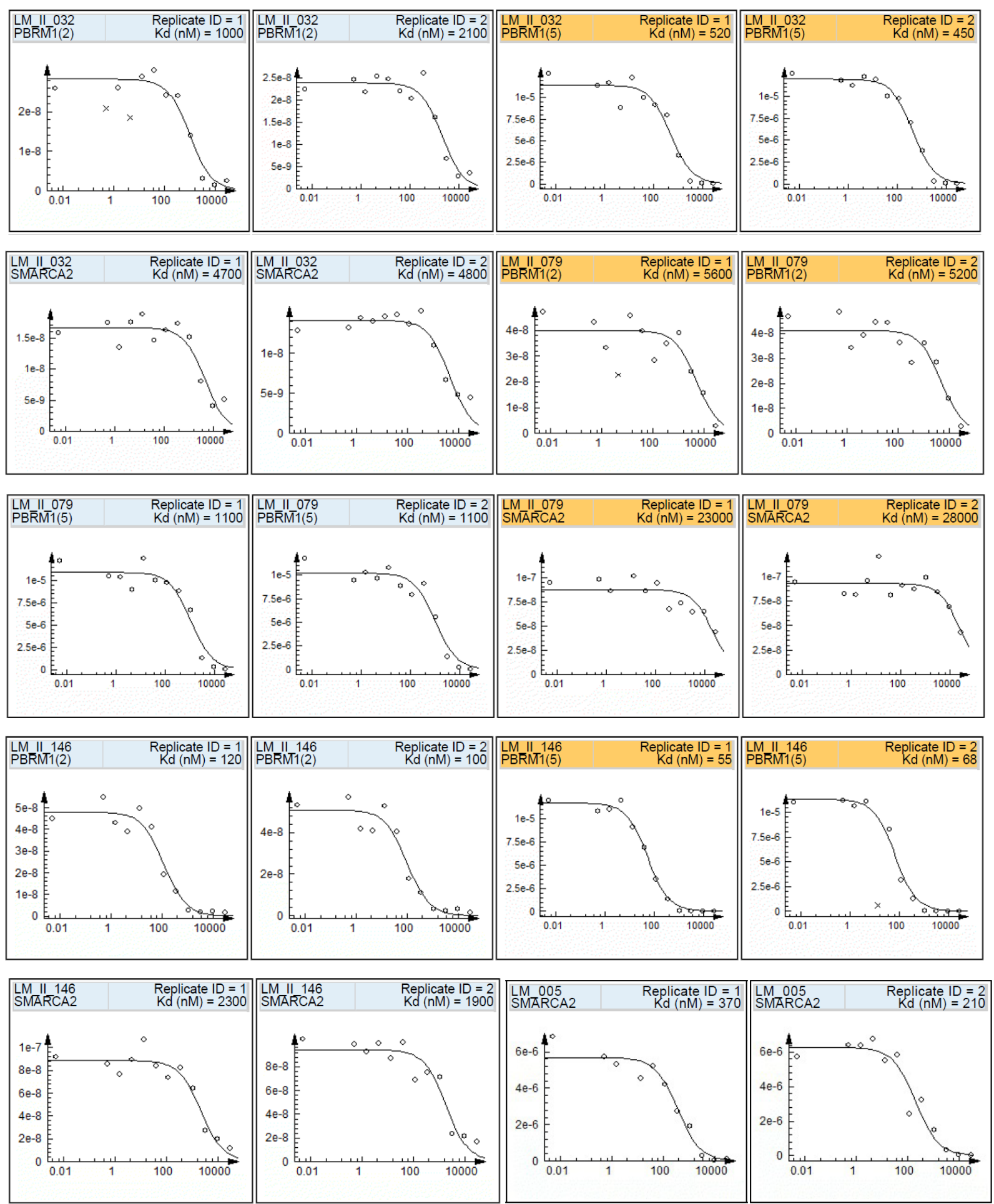


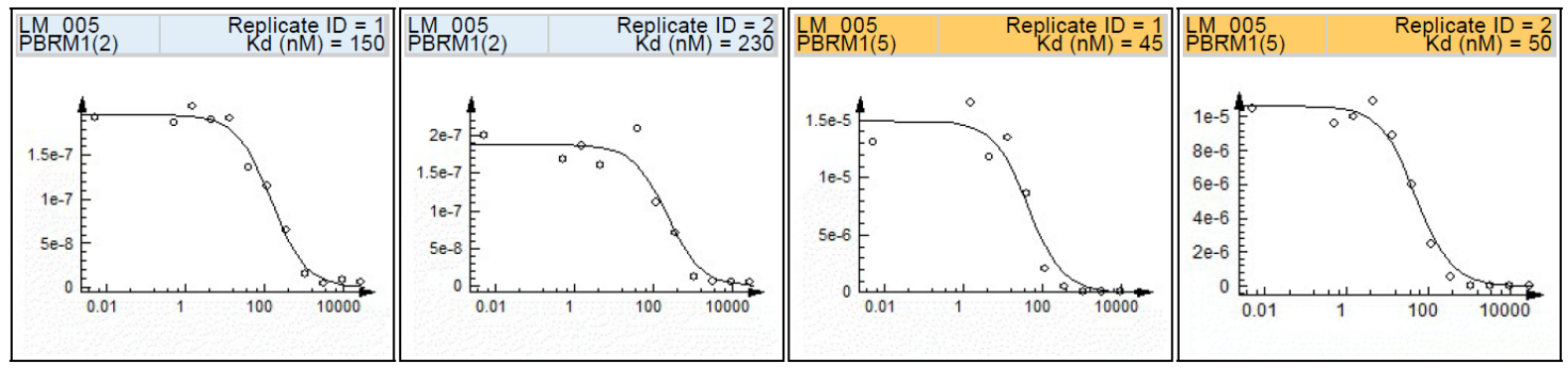

Figure S3. Additional Curve Images. The amount of bromodomain measured by qPCR (Signal; y-axis) is plotted against the corresponding compound concentration in $\mathrm{nM}$ in $\log 10$ scale (x-axis). Data points marked with an "x" were not used for Kd determination. LM_II_032 stands for compound 18, LM_II_079 = compound 21, LM_II_146 $=\mathbf{2 4}=\mathbf{L M 1 4 6}$ and LM_005 $=\mathbf{3}$.

\section{X-ray analysis}

Protocol description. The data for LM146, crystallized from chloroform, were collected from a shock-cooled single crystal at $150 \mathrm{~K}$ on a Bruker Venture Metaljet $\kappa$-geometry diffractometer with a Metal Jet using Helios MX Mirror Optics as monochromator and a Bruker CMOS Photon III detector. The diffractometer was equipped with an Oxford Cryostream 700 low temperature device and used Ga $K \alpha$ radiation $(\lambda=1.34139 \AA)$. All data were integrated with SAINT and a multi-scan absorption correction using TWINABS was applied. The structure was solved by dual methods using XT and refined by full-matrix least-squares methods against $\mathrm{F}^{2}$ by XL. Structure solution and refinement were performed within the graphical User Interface of OLEX2. All non-hydrogen atoms were refined with anisotropic displacement parameters. The hydrogen atoms were refined isotropically on calculated positions using a riding model with their $U_{\text {iso }}$ values constrained to 1.5 times the $U_{\text {eq }}$ of their pivot atoms for terminal $\mathrm{sp}^{3}$ carbon atoms and 1.2 times for all other carbon atoms. Disordered moieties were refined using bond lengths restraints and displacement parameter restraints. This report and the CIF file were generated using FinalCif. The crystal structure was deposited in the Cambridge Crystallographic Data Centre CCDC (number 2070470). 


\section{Additional data.}

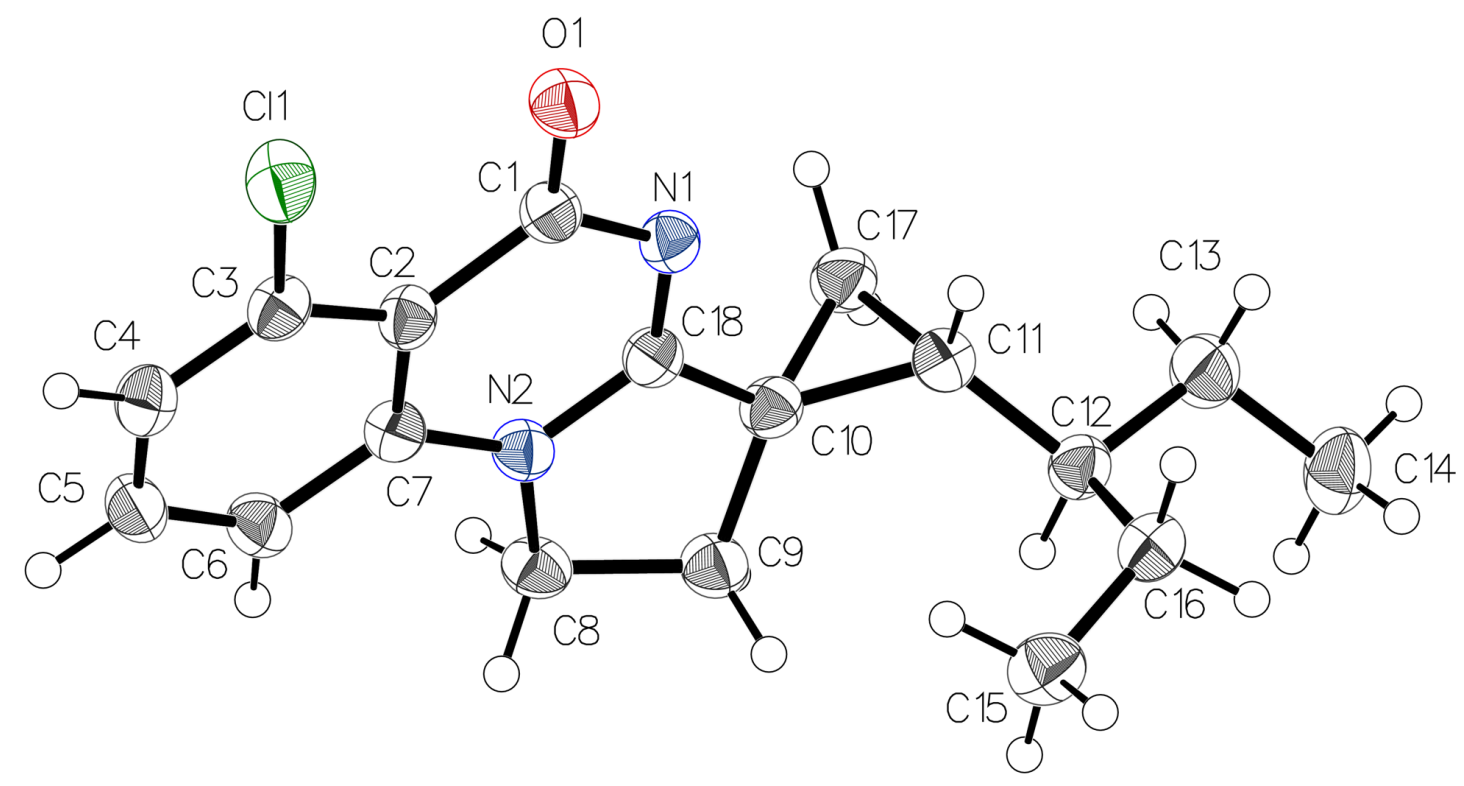

Figure S4. Thermal atomic displacement ellipsoid plot (Ortep) for LM146. Ellipsoids are drawn at the 50\% probability level and hydrogen atoms are shown as spheres of arbitrary size. Cambridge Crystallographic Data Centre CCDC number 2070470. 
Table S2. Crystal data and structure refinement for LM146

\begin{tabular}{|c|c|}
\hline Empirical formula & $\mathrm{C}_{18} \mathrm{H}_{21} \mathrm{ClN}_{2} \mathrm{O}$ \\
\hline Formula weight & 316.82 \\
\hline Temperature [K] & 150 \\
\hline Crystal system & monoclinic \\
\hline Space group (number) & $P 2_{1} / c(14)$ \\
\hline$a[\AA]$ & $24.3485(10)$ \\
\hline$b[\AA]$ & $8.5492(3)$ \\
\hline$c[\AA]$ & $7.4732(3)$ \\
\hline$\alpha\left[^{\circ}\right]$ & 90 \\
\hline$\beta\left[^{\circ}\right]$ & $94.710(2)$ \\
\hline$v\left[{ }^{\circ}\right]$ & 90 \\
\hline Volume $\left[\AA^{3}\right]$ & $1550.37(10)$ \\
\hline$Z$ & 4 \\
\hline$\rho_{\text {calc }}\left[\mathrm{g} / \mathrm{cm}^{3}\right]$ & 1.357 \\
\hline$\mu\left[\mathrm{mm}^{-1}\right]$ & 1.449 \\
\hline$F(000)$ & 672 \\
\hline Crystal size $\left[\mathrm{mm}^{3}\right]$ & $0.27 \times 0.08 \times 0.04$ \\
\hline Crystal color & clear light colorless \\
\hline Crystal shape & plate \\
\hline Radiation & Ga $K_{\alpha}(\lambda=1.34139 \AA)$ \\
\hline $2 \theta$ range $\left[{ }^{\circ}\right]$ & 6.34 to $121.31(0.77 \AA)$ \\
\hline \multirow[t]{3}{*}{ Index ranges } & $0 \leq h \leq 31$ \\
\hline & $0 \leq \mathrm{k} \leq 11$ \\
\hline & $-9 \leq 1 \leq 9$ \\
\hline Reflections collected & 3545 \\
\hline \multirow[t]{3}{*}{ Independent reflections } & 3545 \\
\hline & $R_{\text {int }}=0.0755$ \\
\hline & $R_{\text {sigma }}=0.0463$ \\
\hline Completeness to & $99.5 \%$ \\
\hline \multicolumn{2}{|l|}{$\theta=53.594^{\circ}$} \\
\hline Data / Restraints / & $3545 / 0 / 202$ \\
\hline \multicolumn{2}{|l|}{ Parameters } \\
\hline Goodness-of-fit on $F^{2}$ & 1.035 \\
\hline Final $R$ indexes & $R_{1}=0.0580$ \\
\hline$[I \geq 2 \sigma(I)]$ & $w R_{2}=0.1636$ \\
\hline Final $R$ indexes & $R_{1}=0.0648$ \\
\hline [all data] & $w R_{2}=0.1735$ \\
\hline Largest peak/hole $\left[\mathrm{e} \AA^{3}\right]$ & $0.65 /-0.29$ \\
\hline
\end{tabular}


Table S3. Atomic coordinates and $U_{\text {eq }}\left[\AA^{2}\right]$ for $\mathbf{L M 1 4 6}$

\begin{tabular}{|c|c|c|c|c|}
\hline Atom & $x$ & $y$ & $z$ & $U_{\text {eq }}$ \\
\hline $\mathrm{Cl} 1$ & $0.90977(3)$ & $-0.08631(7)$ & $0.53827(12)$ & $0.0433(2)$ \\
\hline 01 & $0.80626(8)$ & $-0.0153(2)$ & $0.3434(3)$ & $0.0373(5)$ \\
\hline N1 & $0.76591(8)$ & $0.2230(2)$ & $0.3167(3)$ & $0.0294(5)$ \\
\hline N2 & $0.81603(8)$ & $0.4465(3)$ & $0.4192(3)$ & $0.0290(4)$ \\
\hline $\mathrm{C} 1$ & $0.80971(10)$ & $0.1255(3)$ & $0.3711(4)$ & $0.0293(5)$ \\
\hline $\mathrm{C} 2$ & $0.86032(10)$ & $0.1992(3)$ & $0.4630(4)$ & $0.0291(5)$ \\
\hline C3 & $0.90749(10)$ & $0.1167(3)$ & $0.5330(4)$ & $0.0301(5)$ \\
\hline C4 & $0.95419(10)$ & $0.1924(3)$ & $0.6040(4)$ & $0.0338(6)$ \\
\hline $\mathrm{H} 4$ & 0.985416 & 0.133772 & 0.649495 & 0.041 \\
\hline C5 & $0.95560(10)$ & $0.3554(3)$ & $0.6091(4)$ & $0.0348(6)$ \\
\hline H5 & 0.988148 & 0.407422 & 0.655902 & 0.042 \\
\hline C6 & $0.91040(10)$ & $0.4415(3)$ & $0.5470(4)$ & $0.0329(5)$ \\
\hline H6 & 0.911306 & 0.552535 & 0.551994 & 0.039 \\
\hline $\mathrm{C7}$ & $0.86282(10)$ & $0.3632(3)$ & $0.4762(4)$ & $0.0294(5)$ \\
\hline $\mathrm{C} 8$ & $0.80931(10)$ & $0.6182(3)$ & $0.4292(4)$ & $0.0318(5)$ \\
\hline $\mathrm{H} 8 \mathrm{~A}$ & 0.828537 & 0.671743 & 0.334888 & 0.038 \\
\hline $\mathrm{H} 8 \mathrm{~B}$ & 0.823391 & 0.658861 & 0.548262 & 0.038 \\
\hline C9 & $0.74669(10)$ & $0.6387(3)$ & $0.3982(4)$ & $0.0336(6)$ \\
\hline H9A & 0.729941 & 0.650614 & 0.513787 & 0.040 \\
\hline H9B & 0.737387 & 0.731539 & 0.322622 & 0.040 \\
\hline C10 & $0.72677(10)$ & $0.4900(3)$ & $0.3033(4)$ & $0.0296(5)$ \\
\hline C11 & $0.66688(10)$ & $0.4392(3)$ & $0.2733(4)$ & $0.0310(5)$ \\
\hline H11 & 0.661070 & 0.323802 & 0.282636 & 0.037 \\
\hline C12 & $0.61972(10)$ & $0.5372(3)$ & $0.3310(4)$ & $0.0314(5)$ \\
\hline $\mathrm{H} 12$ & 0.633418 & 0.646157 & 0.354062 & 0.038 \\
\hline C13 & $0.57303(12)$ & $0.5425(4)$ & $0.1791(4)$ & $0.0422(7)$ \\
\hline $\mathrm{H} 13 \mathrm{~A}$ & 0.588803 & 0.573807 & 0.066486 & 0.051 \\
\hline $\mathrm{H} 13 \mathrm{~B}$ & 0.557656 & 0.435953 & 0.161186 & 0.051 \\
\hline C14 & $0.52622(12)$ & $0.6544(4)$ & $0.2132(5)$ & $0.0467(7)$ \\
\hline $\mathrm{H} 14 \mathrm{~A}$ & 0.500691 & 0.661544 & 0.105130 & 0.070 \\
\hline H14B & 0.541386 & 0.758203 & 0.243173 & 0.070 \\
\hline $\mathrm{H} 14 \mathrm{C}$ & 0.506519 & 0.615313 & 0.313334 & 0.070 \\
\hline C15 & $0.63886(13)$ & $0.4934(4)$ & $0.6690(4)$ & $0.0408(7)$ \\
\hline $\mathrm{H} 15 \mathrm{~A}$ & 0.673741 & 0.441229 & 0.649927 & 0.061 \\
\hline H15B & 0.623074 & 0.447041 & 0.773287 & 0.061 \\
\hline $\mathrm{H} 15 \mathrm{C}$ & 0.645523 & 0.605075 & 0.690639 & 0.061 \\
\hline C16 & $0.59922(11)$ & $0.4729(4)$ & $0.5049(4)$ & $0.0373(6)$ \\
\hline $\mathrm{H} 16 \mathrm{~A}$ & 0.564160 & 0.525662 & 0.526302 & 0.045 \\
\hline $\mathrm{H} 16 \mathrm{~B}$ & 0.591279 & 0.360002 & 0.488605 & 0.045 \\
\hline C17 & $0.69778(10)$ & $0.4882(3)$ & $0.1154(4)$ & $0.0337(6)$ \\
\hline $\mathrm{H} 17 \mathrm{~A}$ & 0.688129 & 0.590170 & 0.058336 & 0.040 \\
\hline H17B & 0.708272 & 0.405627 & 0.031918 & 0.040 \\
\hline C18 & $0.77040(9)$ & $0.3723(3)$ & $0.3465(3)$ & $0.0274(5)$ \\
\hline
\end{tabular}

Table S4. Bond lengths and angles for LM146

\begin{tabular}{ll} 
Atom-Atom & Length $[\AA]$ \\
\hline $\mathrm{Cl} 1-\mathrm{C} 3$ & $1.737(3)$ \\
$\mathrm{O} 1-\mathrm{C} 1$ & $1.223(3)$ \\
$\mathrm{N} 1-\mathrm{C} 1$ & $1.388(3)$ \\
$\mathrm{N} 1-\mathrm{C} 18$ & $1.298(3)$ \\
$\mathrm{N} 2-\mathrm{C} 7$ & $1.381(3)$ \\
$\mathrm{N} 2-\mathrm{C} 8$ & $1.479(3)$
\end{tabular}




\begin{tabular}{|c|c|}
\hline N2-C18 & $1.354(3)$ \\
\hline $\mathrm{C} 1-\mathrm{C} 2$ & $1.499(3)$ \\
\hline C2-C3 & $1.411(3)$ \\
\hline $\mathrm{C} 2-\mathrm{C} 7$ & $1.407(4)$ \\
\hline C3-C4 & $1.377(4)$ \\
\hline $\mathrm{C} 4-\mathrm{H} 4$ & 0.9500 \\
\hline C4-C5 & $1.394(4)$ \\
\hline $\mathrm{C} 5-\mathrm{H} 5$ & 0.9500 \\
\hline C5-C6 & $1.372(4)$ \\
\hline $\mathrm{C} 6-\mathrm{H} 6$ & 0.9500 \\
\hline C6-C7 & $1.404(3)$ \\
\hline $\mathrm{C} 8-\mathrm{H} 8 \mathrm{~A}$ & 0.9900 \\
\hline $\mathrm{C} 8-\mathrm{H} 8 \mathrm{~B}$ & 0.9900 \\
\hline $\mathrm{C} 8-\mathrm{C} 9$ & $1.533(3)$ \\
\hline С9-H9A & 0.9900 \\
\hline C9-H9B & 0.9900 \\
\hline C9-C10 & $1.515(4)$ \\
\hline C10-C11 & $1.520(3)$ \\
\hline C10-C17 & $1.519(4)$ \\
\hline C10-C18 & $1.480(3)$ \\
\hline $\mathrm{C} 11-\mathrm{H} 11$ & 1.0000 \\
\hline C11-C12 & $1.512(4)$ \\
\hline C11-C17 & $1.509(4)$ \\
\hline $\mathrm{C} 12-\mathrm{H} 12$ & 1.0000 \\
\hline C12-C13 & $1.540(4)$ \\
\hline C12-C16 & $1.532(4)$ \\
\hline $\mathrm{C} 13-\mathrm{H} 13 \mathrm{~A}$ & 0.9900 \\
\hline C13-H13B & 0.9900 \\
\hline C13-C14 & $1.525(4)$ \\
\hline $\mathrm{C} 14-\mathrm{H} 14 \mathrm{~A}$ & 0.9800 \\
\hline C14-H14B & 0.9800 \\
\hline $\mathrm{C} 14-\mathrm{H} 14 \mathrm{C}$ & 0.9800 \\
\hline $\mathrm{C} 15-\mathrm{H} 15 \mathrm{~A}$ & 0.9800 \\
\hline C15-H15B & 0.9800 \\
\hline $\mathrm{C} 15-\mathrm{H} 15 \mathrm{C}$ & 0.9800 \\
\hline C15-C16 & $1.507(4)$ \\
\hline $\mathrm{C} 16-\mathrm{H} 16 \mathrm{~A}$ & 0.9900 \\
\hline C16-H16B & 0.9900 \\
\hline C17-H17A & 0.9900 \\
\hline C17-H17B & 0.9900 \\
\hline Atom-Atom-Atom & Angle $\left[{ }^{\circ}\right]$ \\
\hline $\mathrm{C} 18-\mathrm{N} 1-\mathrm{C} 1$ & $119.2(2)$ \\
\hline $\mathrm{C} 7-\mathrm{N} 2-\mathrm{C} 8$ & $126.0(2)$ \\
\hline C18-N2-C7 & $120.7(2)$ \\
\hline C18-N2-C8 & $113.3(2)$ \\
\hline O1-C1-N1 & $120.1(2)$ \\
\hline $\mathrm{O} 1-\mathrm{C} 1-\mathrm{C} 2$ & $122.2(2)$ \\
\hline $\mathrm{N} 1-\mathrm{C} 1-\mathrm{C} 2$ & $117.7(2)$ \\
\hline $\mathrm{C} 3-\mathrm{C} 2-\mathrm{C} 1$ & $125.0(2)$ \\
\hline $\mathrm{C} 7-\mathrm{C} 2-\mathrm{C} 1$ & $118.7(2)$ \\
\hline $\mathrm{C} 7-\mathrm{C} 2-\mathrm{C} 3$ & $116.3(2)$ \\
\hline $\mathrm{C} 2-\mathrm{C} 3-\mathrm{Cl} 1$ & $122.08(19)$ \\
\hline $\mathrm{C} 4-\mathrm{C} 3-\mathrm{Cl} 1$ & $115.95(19)$ \\
\hline C4-C3-C2 & $122.0(2)$ \\
\hline $\mathrm{C} 3-\mathrm{C} 4-\mathrm{H} 4$ & 120.1 \\
\hline C3-C4-C5 & $119.9(2)$ \\
\hline
\end{tabular}




\begin{tabular}{|c|c|}
\hline $\mathrm{C} 5-\mathrm{C} 4-\mathrm{H} 4$ & 120.1 \\
\hline $\mathrm{C} 4-\mathrm{C} 5-\mathrm{H} 5$ & 119.7 \\
\hline $\mathrm{C} 6-\mathrm{C} 5-\mathrm{C} 4$ & $120.6(2)$ \\
\hline $\mathrm{C} 6-\mathrm{C} 5-\mathrm{H} 5$ & 119.7 \\
\hline $\mathrm{C} 5-\mathrm{C} 6-\mathrm{H} 6$ & 120.5 \\
\hline $\mathrm{C} 5-\mathrm{C} 6-\mathrm{C} 7$ & $119.1(2)$ \\
\hline $\mathrm{C} 7-\mathrm{C} 6-\mathrm{H} 6$ & 120.5 \\
\hline $\mathrm{N} 2-\mathrm{C} 7-\mathrm{C} 2$ & $117.6(2)$ \\
\hline $\mathrm{N} 2-\mathrm{C} 7-\mathrm{C} 6$ & $120.3(2)$ \\
\hline $\mathrm{C} 6-\mathrm{C} 7-\mathrm{C} 2$ & $122.1(2)$ \\
\hline $\mathrm{N} 2-\mathrm{C} 8-\mathrm{H} 8 \mathrm{~A}$ & 111.2 \\
\hline $\mathrm{N} 2-\mathrm{C} 8-\mathrm{H} 8 \mathrm{~B}$ & 111.2 \\
\hline N2-C8-C9 & $102.63(19)$ \\
\hline $\mathrm{H} 8 \mathrm{~A}-\mathrm{C} 8-\mathrm{H} 8 \mathrm{~B}$ & 109.2 \\
\hline C9-C8-H8A & 111.2 \\
\hline $\mathrm{C} 9-\mathrm{C} 8-\mathrm{H} 8 \mathrm{~B}$ & 111.2 \\
\hline С8-C9-H9A & 110.8 \\
\hline C8-C9-H9B & 110.8 \\
\hline H9A-C9-H9B & 108.9 \\
\hline C10-C9-C8 & $104.5(2)$ \\
\hline C10-C9-H9A & 110.8 \\
\hline C10-C9-H9B & 110.8 \\
\hline C9-C10-C11 & $125.1(2)$ \\
\hline C9-C10-C17 & $123.2(2)$ \\
\hline C17-C10-C11 & $59.56(17)$ \\
\hline C18-C10-C9 & $105.8(2)$ \\
\hline C18-C10-C11 & $120.0(2)$ \\
\hline C18-C10-C17 & $117.8(2)$ \\
\hline $\mathrm{C} 10-\mathrm{C} 11-\mathrm{H} 11$ & 114.3 \\
\hline C12-C11-C10 & $122.8(2)$ \\
\hline $\mathrm{C} 12-\mathrm{C} 11-\mathrm{H} 11$ & 114.3 \\
\hline C17-C11-C10 & $60.17(17)$ \\
\hline C17-C11-H11 & 114.3 \\
\hline C17-C11-C12 & $120.5(2)$ \\
\hline $\mathrm{C} 11-\mathrm{C} 12-\mathrm{H} 12$ & 108.4 \\
\hline C11-C12-C13 & $109.8(2)$ \\
\hline C11-C12-C16 & $110.6(2)$ \\
\hline $\mathrm{C} 13-\mathrm{C} 12-\mathrm{H} 12$ & 108.4 \\
\hline $\mathrm{C} 16-\mathrm{C} 12-\mathrm{H} 12$ & 108.4 \\
\hline C16-C12-C13 & $111.3(2)$ \\
\hline $\mathrm{C} 12-\mathrm{C} 13-\mathrm{H} 13 \mathrm{~A}$ & 108.7 \\
\hline C12-C13-H13B & 108.7 \\
\hline $\mathrm{H} 13 \mathrm{~A}-\mathrm{C} 13-\mathrm{H} 13 \mathrm{~B}$ & 107.6 \\
\hline C14-C13-C12 & $114.3(3)$ \\
\hline C14-C13-H13A & 108.7 \\
\hline C14-C13-H13B & 108.7 \\
\hline C13-C14-H14A & 109.5 \\
\hline C13-C14-H14B & 109.5 \\
\hline C13-C14-H14C & 109.5 \\
\hline $\mathrm{H} 14 \mathrm{~A}-\mathrm{C} 14-\mathrm{H} 14 \mathrm{~B}$ & 109.5 \\
\hline $\mathrm{H} 14 \mathrm{~A}-\mathrm{C} 14-\mathrm{H} 14 \mathrm{C}$ & 109.5 \\
\hline $\mathrm{H} 14 \mathrm{~B}-\mathrm{C} 14-\mathrm{H} 14 \mathrm{C}$ & 109.5 \\
\hline $\mathrm{H} 15 \mathrm{~A}-\mathrm{C} 15-\mathrm{H} 15 \mathrm{~B}$ & 109.5 \\
\hline $\mathrm{H} 15 \mathrm{~A}-\mathrm{C} 15-\mathrm{H} 15 \mathrm{C}$ & 109.5 \\
\hline $\mathrm{H} 15 \mathrm{~B}-\mathrm{C} 15-\mathrm{H} 15 \mathrm{C}$ & 109.5 \\
\hline C16-C15-H15A & 109.5 \\
\hline C16-C15-H15B & 109.5 \\
\hline
\end{tabular}




\begin{tabular}{ll} 
C16-C15-H15C & 109.5 \\
C12-C16-H16A & 108.6 \\
C12-C16-H16B & 108.6 \\
C15-C16-C12 & $114.7(2)$ \\
C15-C16-H16A & 108.6 \\
C15-C16-H16B & 108.6 \\
H16A-C16-H16B & 107.6 \\
C10-C17-H17A & 117.7 \\
C10-C17-H17B & 117.7 \\
C11-C17-C10 & $60.27(17)$ \\
C11-C17-H17A & 117.7 \\
C11-C17-H17B & 117.7 \\
H17A-C17-H17B & 114.9 \\
N1-C18-N2 & $125.8(2)$ \\
N1-C18-C10 & $125.6(2)$ \\
N2-C18-C10 & $108.6(2)$ \\
\hline
\end{tabular}

Table S5. Torsion angles for LM146

\begin{tabular}{ll} 
Atom-Atom-Atom-Atom & Torsion Angle [ $\left.{ }^{\circ}\right]$ \\
\hline Cl1-C3-C4-C5 & $-178.6(2)$ \\
O1-C1-C2-C3 & $-2.8(4)$ \\
O1-C1-C2-C7 & $174.7(3)$ \\
N1-C1-C2-C3 & $177.3(3)$ \\
N1-C1-C2-C7 & $-5.2(4)$ \\
N2-C8-C9-C10 & $-21.7(3)$ \\
C1-N1-C18-N2 & $3.9(4)$ \\
C1-N1-C18-C10 & $-177.4(2)$ \\
C1-C2-C3-Cl1 & $-6.0(4)$ \\
C1-C2-C3-C4 & $175.1(3)$ \\
C1-C2-C7-N2 & $6.4(4)$ \\
C1-C2-C7-C6 & $-174.7(3)$ \\
C2-C3-C4-C5 & $0.4(4)$ \\
C3-C2-C7-N2 & $-176.0(2)$ \\
C3-C2-C7-C6 & $2.9(4)$ \\
C3-C4-C5-C6 & $1.3(4)$ \\
C4-C5-C6-C7 & $-0.8(4)$ \\
C5-C6-C7-N2 & $177.5(3)$ \\
C5-C6-C7-C2 & $-1.4(4)$ \\
C7-N2-C8-C9 & $-164.9(3)$ \\
C7-N2-C18-N1 & $-2.7(4)$ \\
C7-N2-C18-C10 & $178.4(2)$ \\
C7-C2-C3-Cl1 & $176.5(2)$ \\
C7-C2-C3-C4 & $-2.4(4)$ \\
C8-N2-C7-C2 & $177.1(2)$ \\
C8-N2-C7-C6 & $-1.8(4)$ \\
C8-N2-C18-N1 & $177.5(2)$ \\
C8-N2-C18-C10 & $-1.4(3)$ \\
C8-C9-C10-C11 & $168.1(3)$ \\
C8-C9-C10-C17 & $-118.1(3)$ \\
C8-C9-C10-C18 & $21.6(3)$ \\
C9-C10-C11-C12 & $2.2(4)$ \\
C9-C10-C11-C17 & $111.3(3)$ \\
C9-C10-C17-C11 & $-114.3(3)$ \\
C9-C10-C18-N1 & $168.0(3)$ \\
C9-C10-C18-N2 & $-13.1(3)$ \\
& \\
&
\end{tabular}




\begin{tabular}{ll} 
C10-C11-C12-C13 & $134.9(3)$ \\
C10-C11-C12-C16 & $-101.9(3)$ \\
C11-C10-C18-N1 & $19.5(4)$ \\
C11-C10-C18-N2 & $-161.7(2)$ \\
C11-C12-C13-C14 & $-172.9(3)$ \\
C11-C12-C16-C15 & $69.3(3)$ \\
C12-C11-C17-C10 & $112.7(3)$ \\
C13-C12-C16-C15 & $-168.4(3)$ \\
C16-C12-C13-C14 & $64.4(3)$ \\
C17-C10-C11-C12 & $-109.1(3)$ \\
C17-C10-C18-N1 & $-49.6(4)$ \\
C17-C10-C18-N2 & $129.3(2)$ \\
C17-C11-C12-C13 & $62.8(3)$ \\
C17-C11-C12-C16 & $-174.0(2)$ \\
C18-N1-C1-O1 & $-179.7(3)$ \\
C18-N1-C1-C2 & $0.2(4)$ \\
C18-N2-C7-C2 & $-2.7(4)$ \\
C18-N2-C7-C6 & $178.3(3)$ \\
C18-N2-C8-C9 & $14.9(3)$ \\
C18-C10-C11-C12 & $144.4(3)$ \\
C18-C10-C11-C17 & $-106.5(3)$ \\
C18-C10-C17-C11 & $110.3(3)$ \\
\hline
\end{tabular}



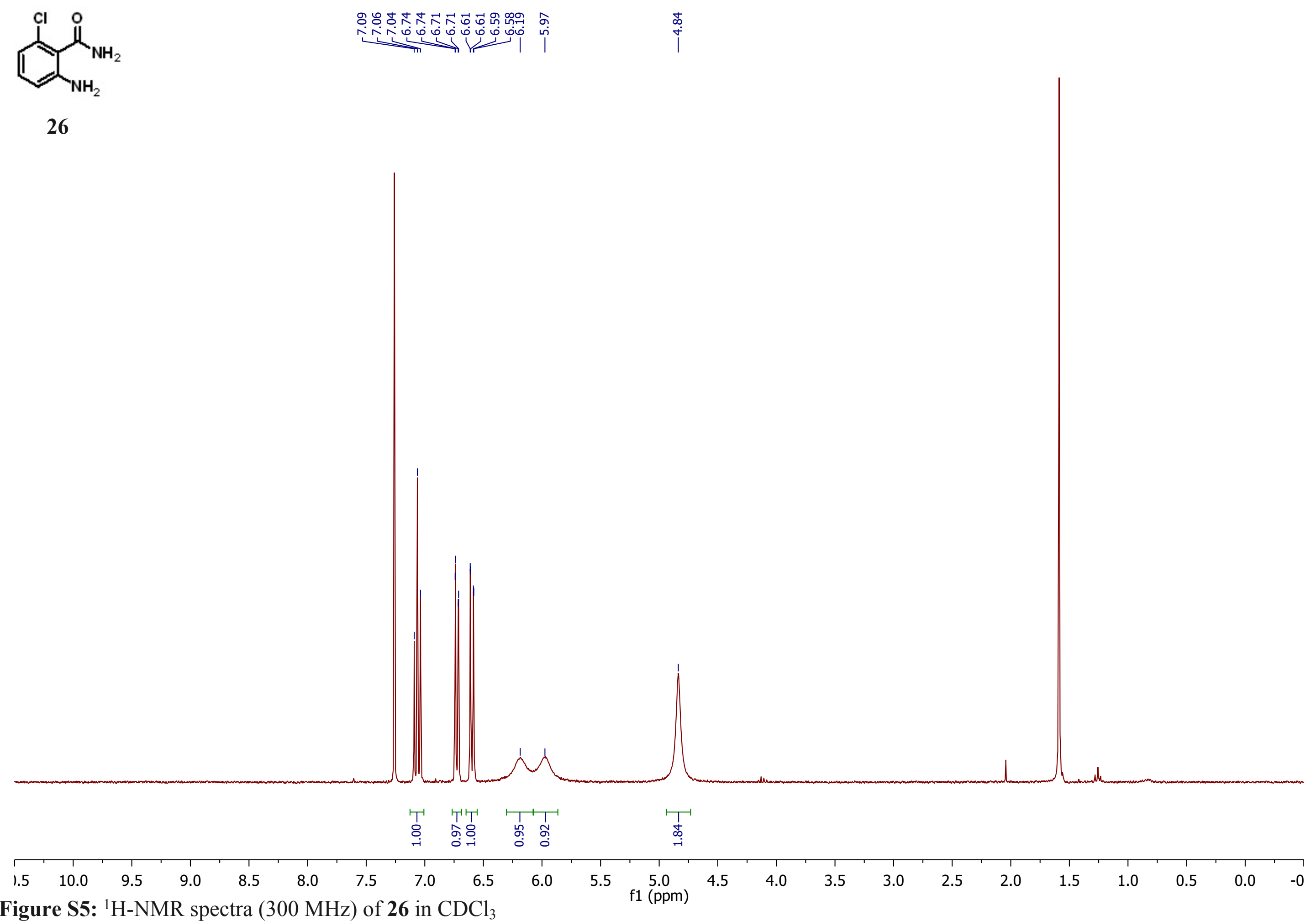

Figure S5: ${ }^{1} \mathrm{H}-\mathrm{NMR}$ spectra $(300 \mathrm{MHz})$ of $\mathbf{2 6}$ in $\mathrm{CDCl}_{3}$ 

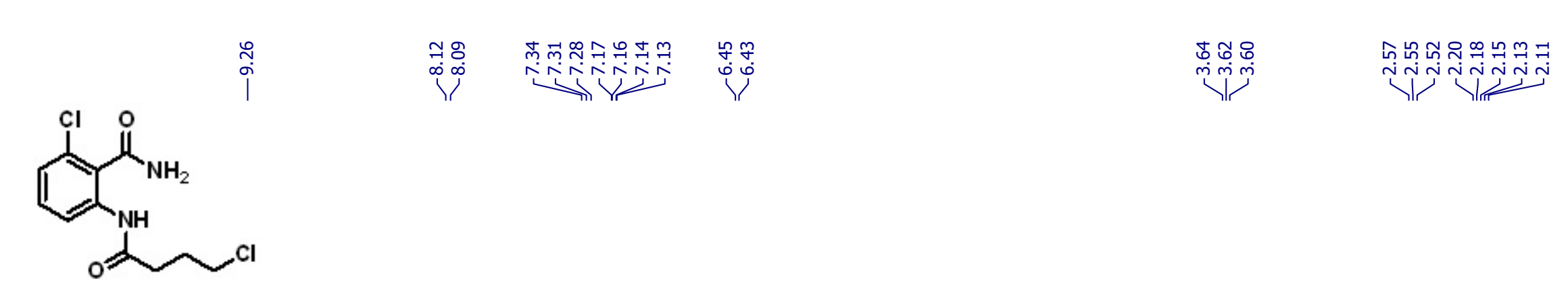

27

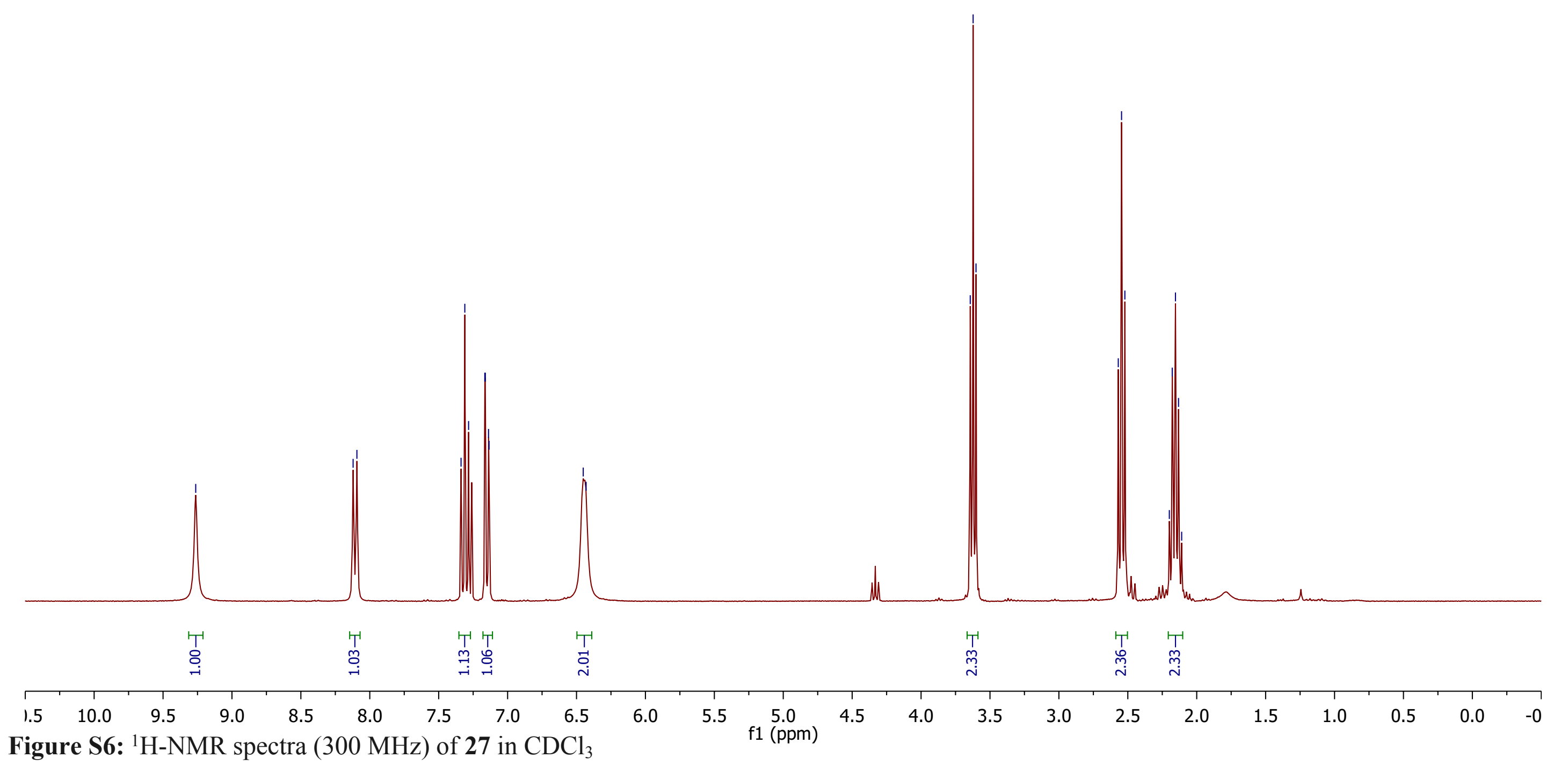



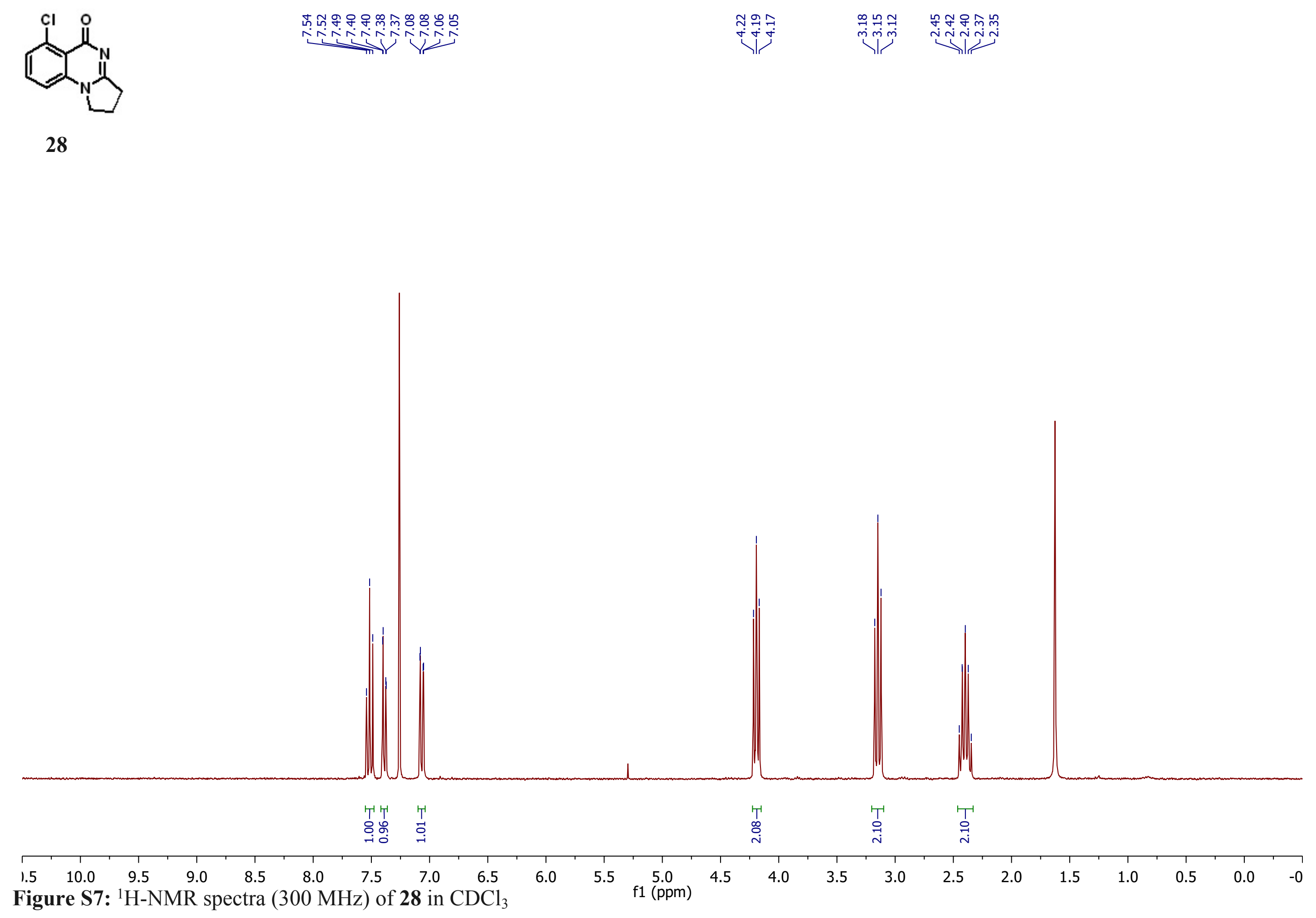

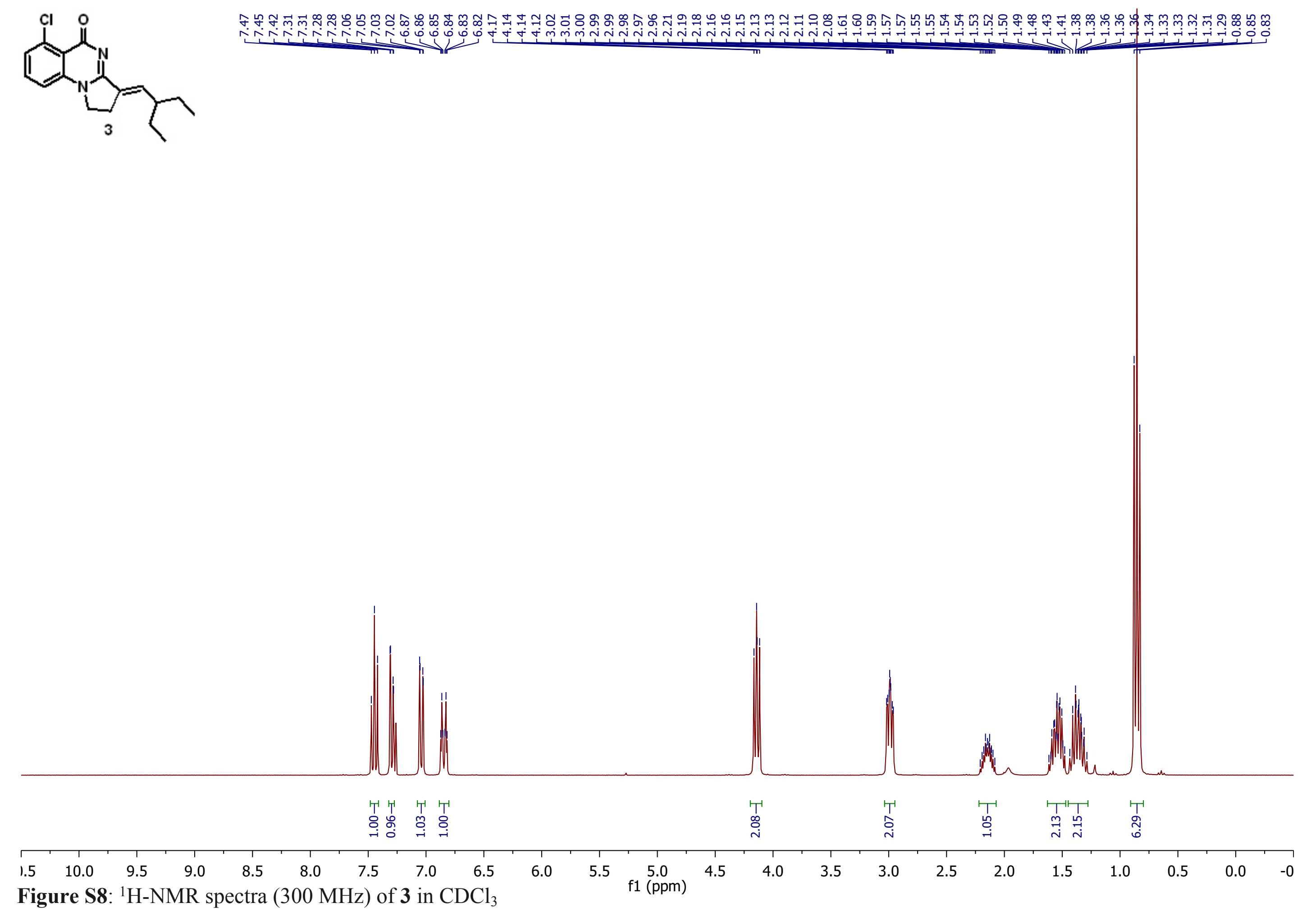


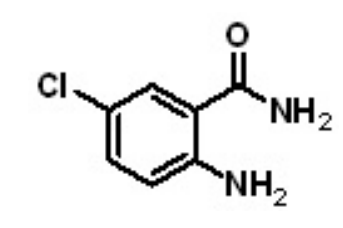

29

.

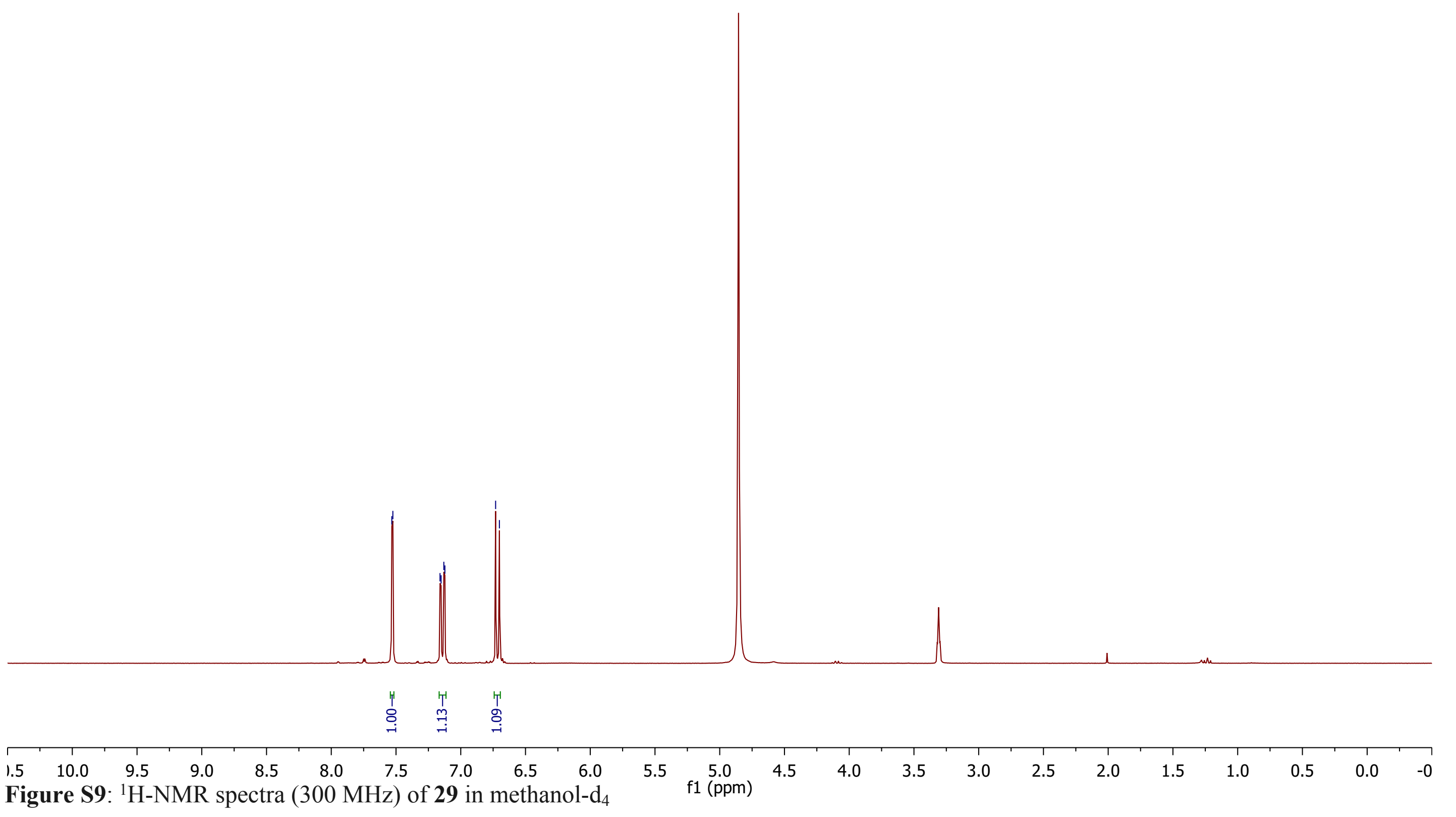


<smiles>NC(=O)c1cc(Cl)ccc1NC(=O)CCCCl</smiles>

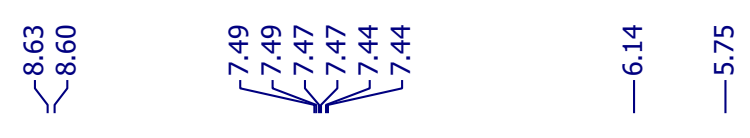

\section{ํํำ}

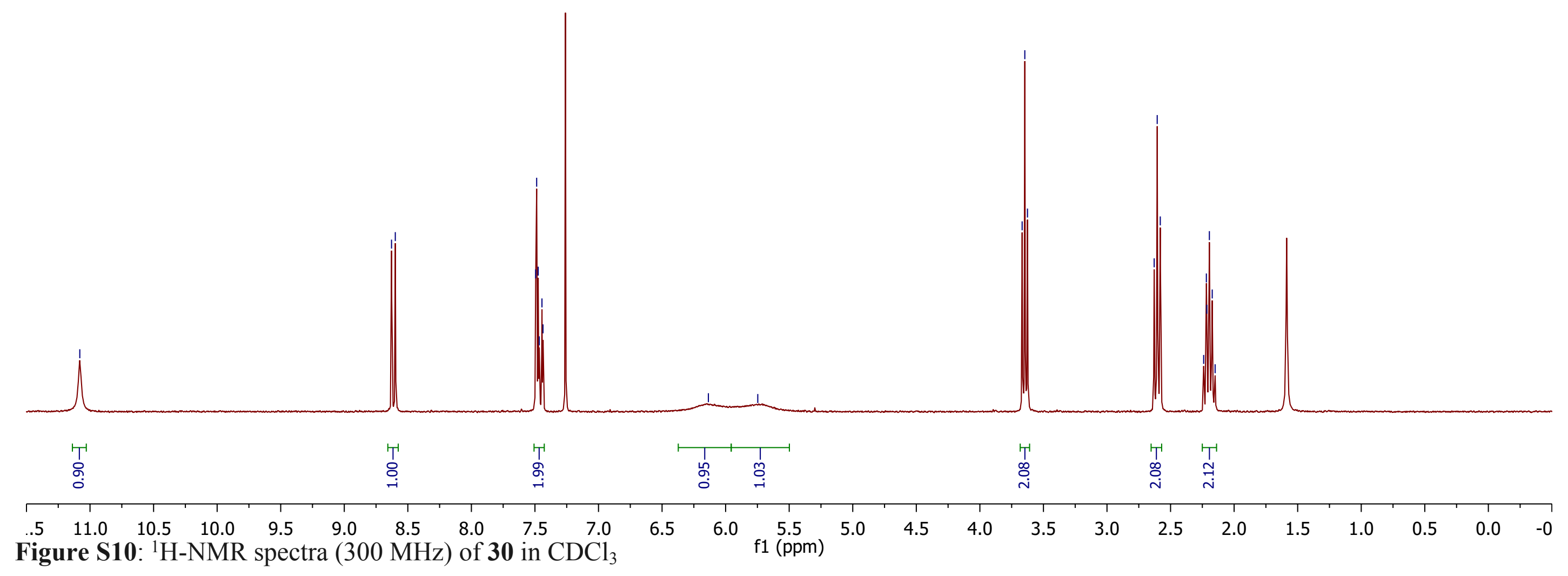



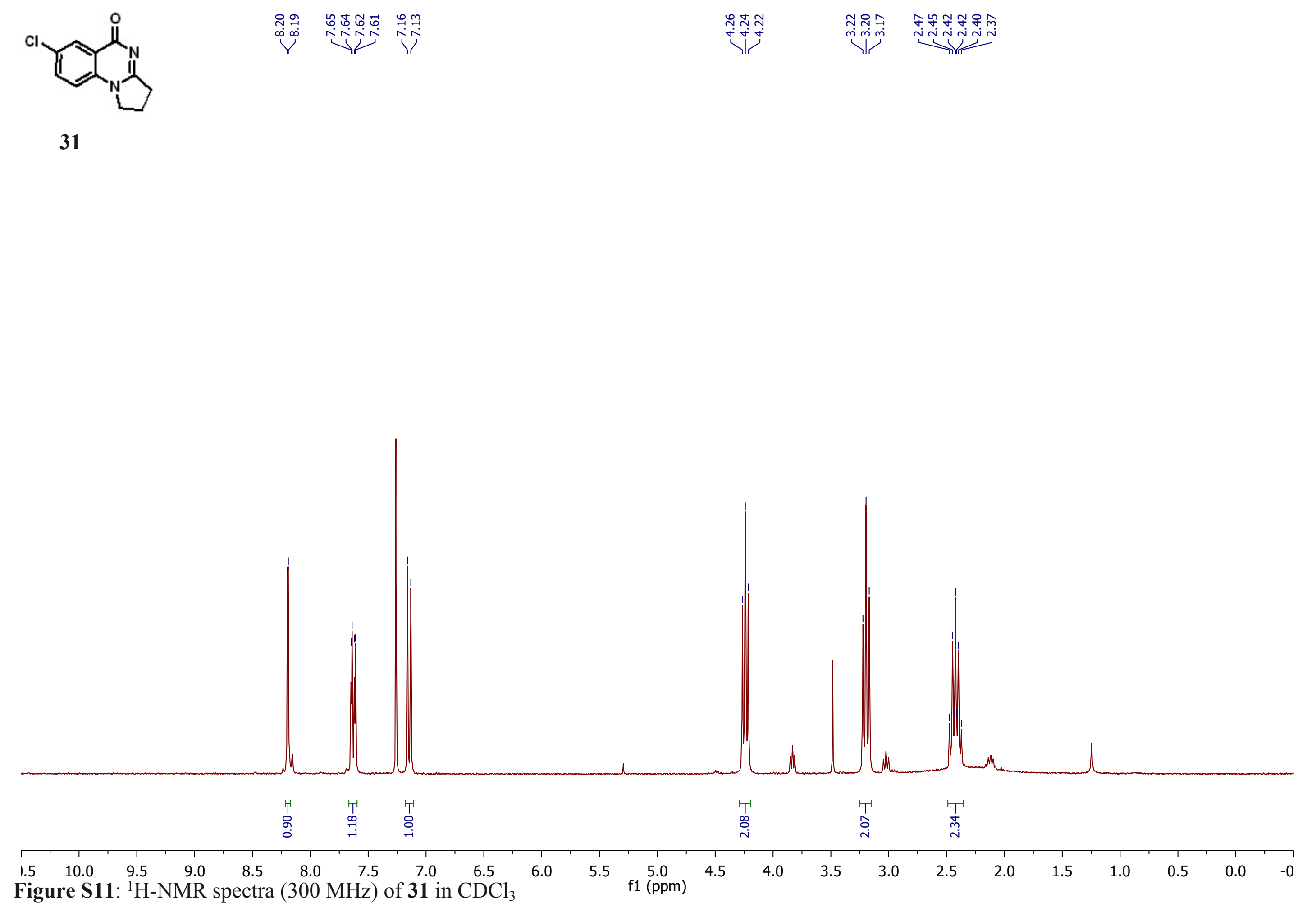


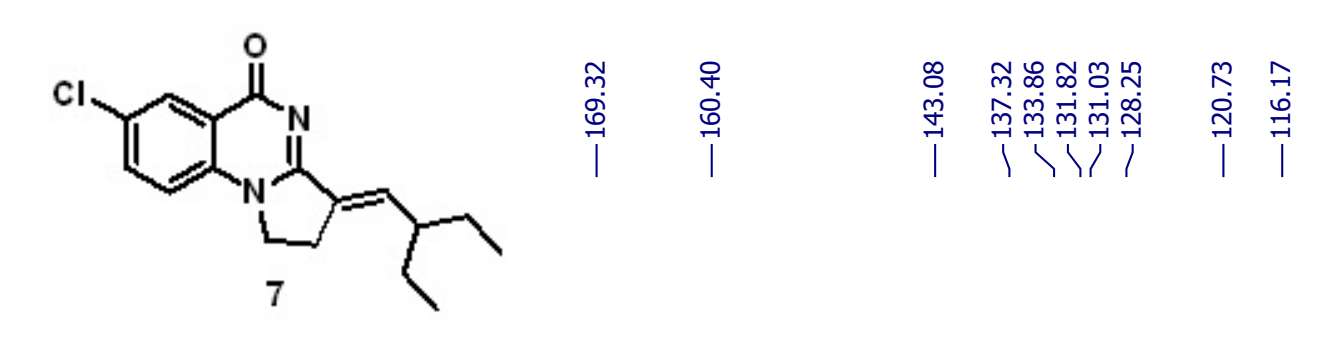

।

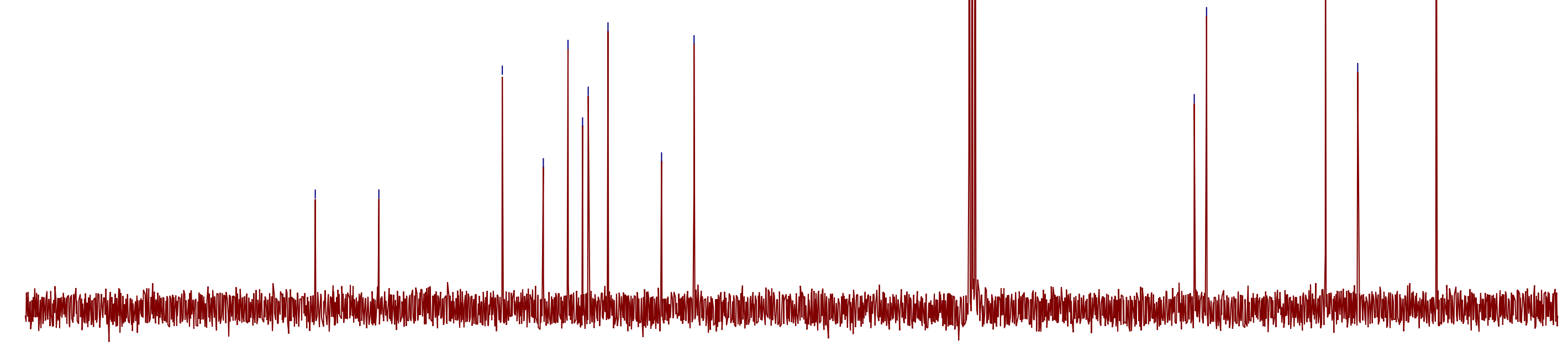

\begin{tabular}{|c|c|c|c|c|c|c|c|c|c|c|c|c|c|c|c|c|c|c|c|c|c|}
\hline$\Gamma$ & & 1 & T & $T$ & & 1 & 1 & 1 & 1 & $T$ & 1 & $T$ & 1 & $T$ & $T$ & $T$ & $T$ & $T$ & $T$ & $T$ & $T$ \\
\hline 210 & 200 & 190 & 180 & 170 & 160 & 150 & 140 & 130 & 120 & 110 & 100 & 90 & 80 & 70 & 60 & 50 & 40 & 30 & 20 & 10 & 0 \\
\hline
\end{tabular}

Figure S13: ${ }^{13} \mathrm{C}-\mathrm{NMR}$ spectra $(75 \mathrm{MHz})$ of 7 in $\mathrm{CDCl}_{3}$ 


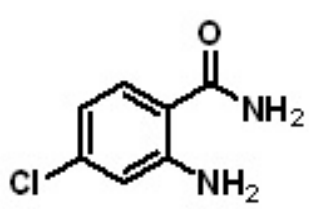

32 

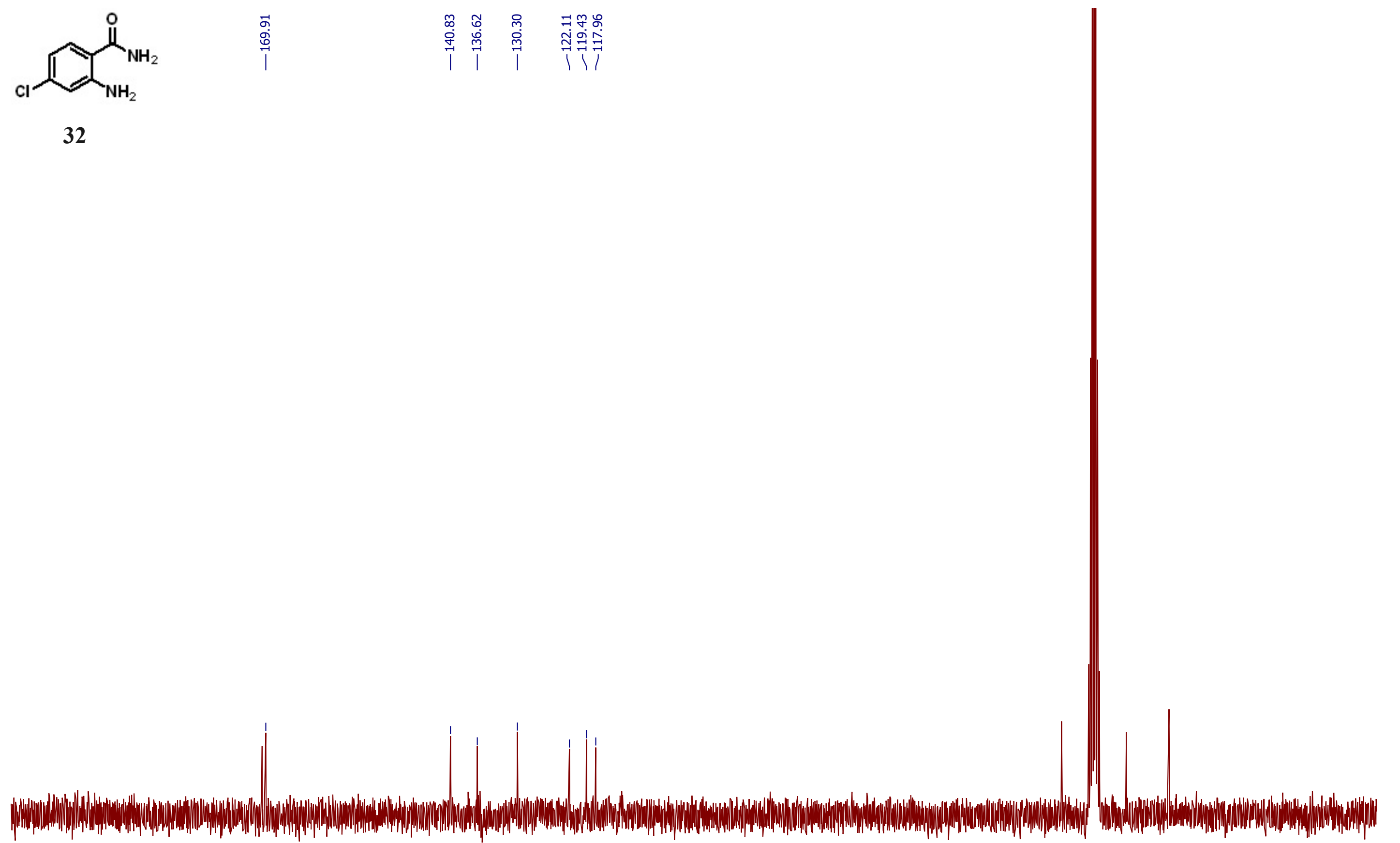

$\begin{array}{lllll}200 & 190 & 180 & 170 & 160\end{array}$

Figure S15: ${ }^{13} \mathrm{C}-\mathrm{NMR}$ spectra $(75 \mathrm{MHz})$ of 32 in DMSO-d 6 

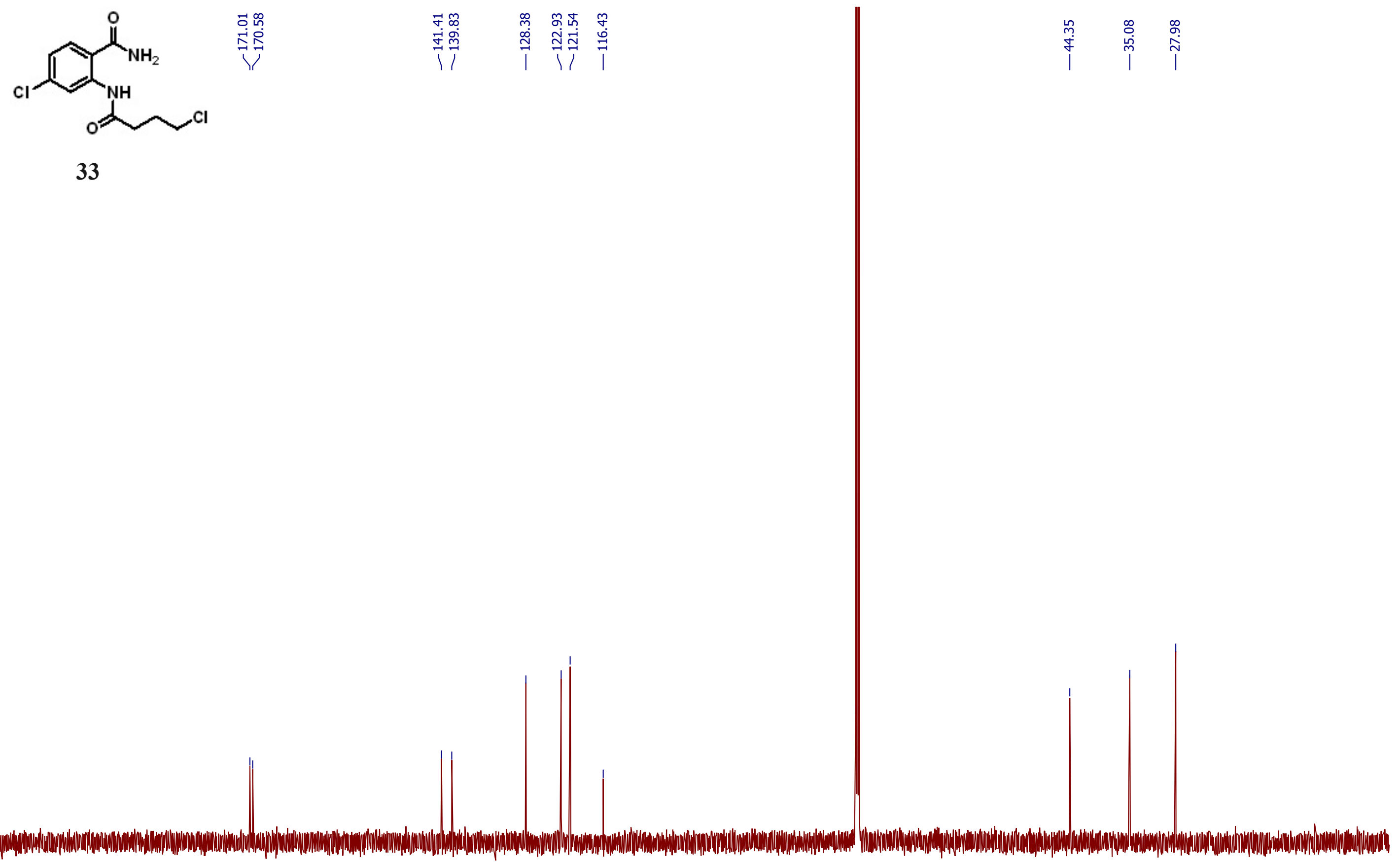

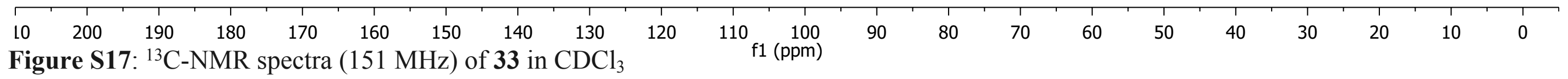



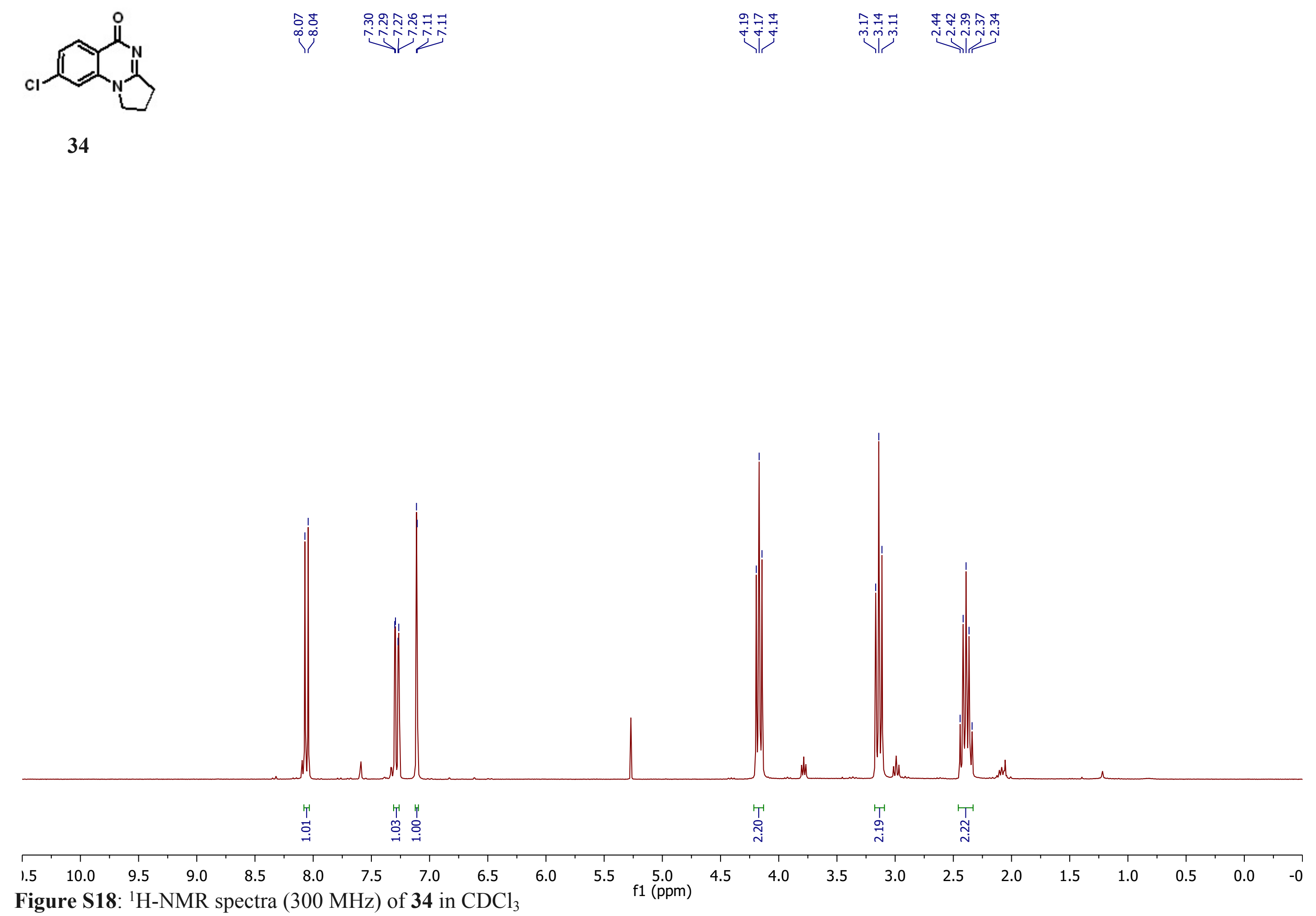

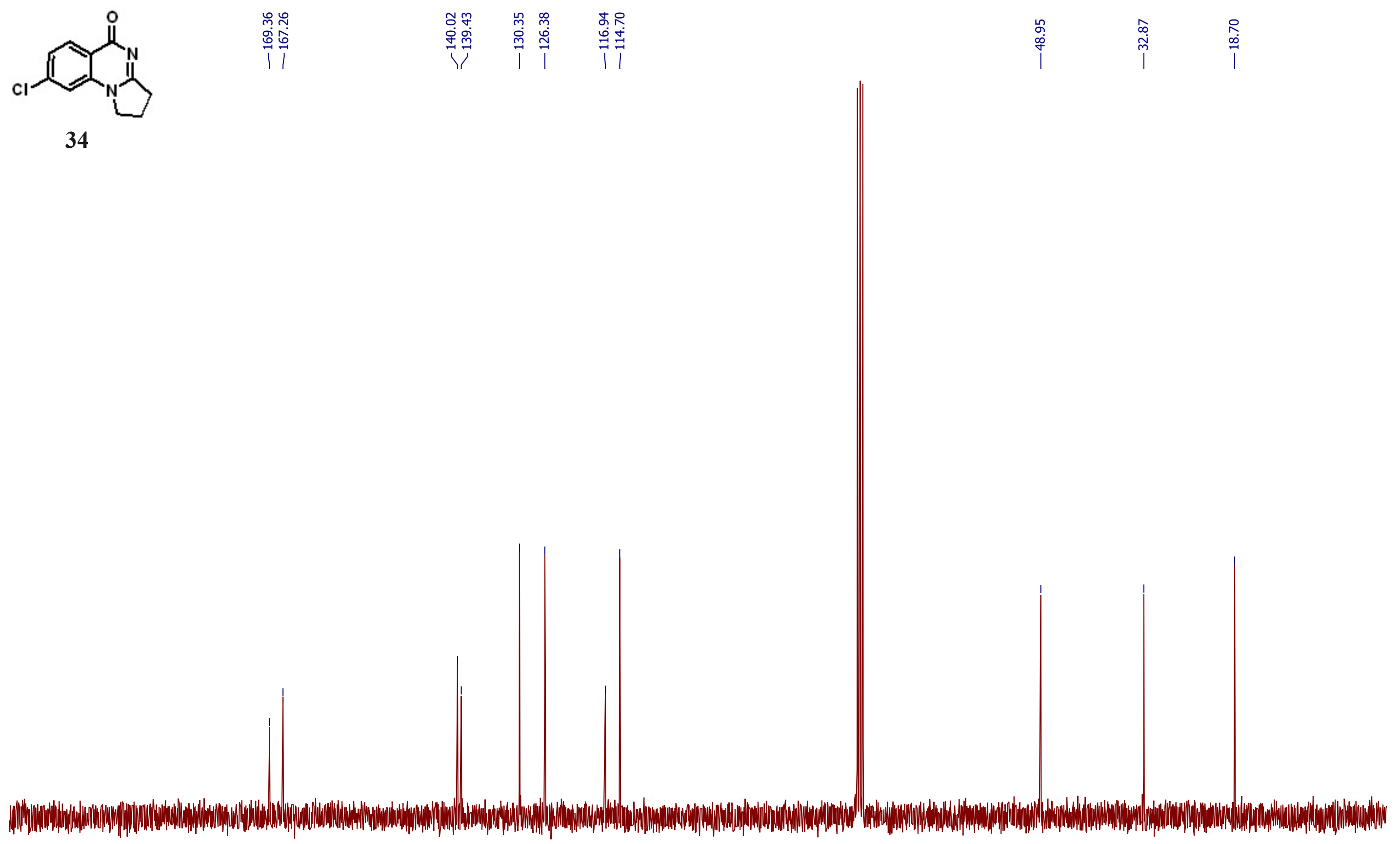

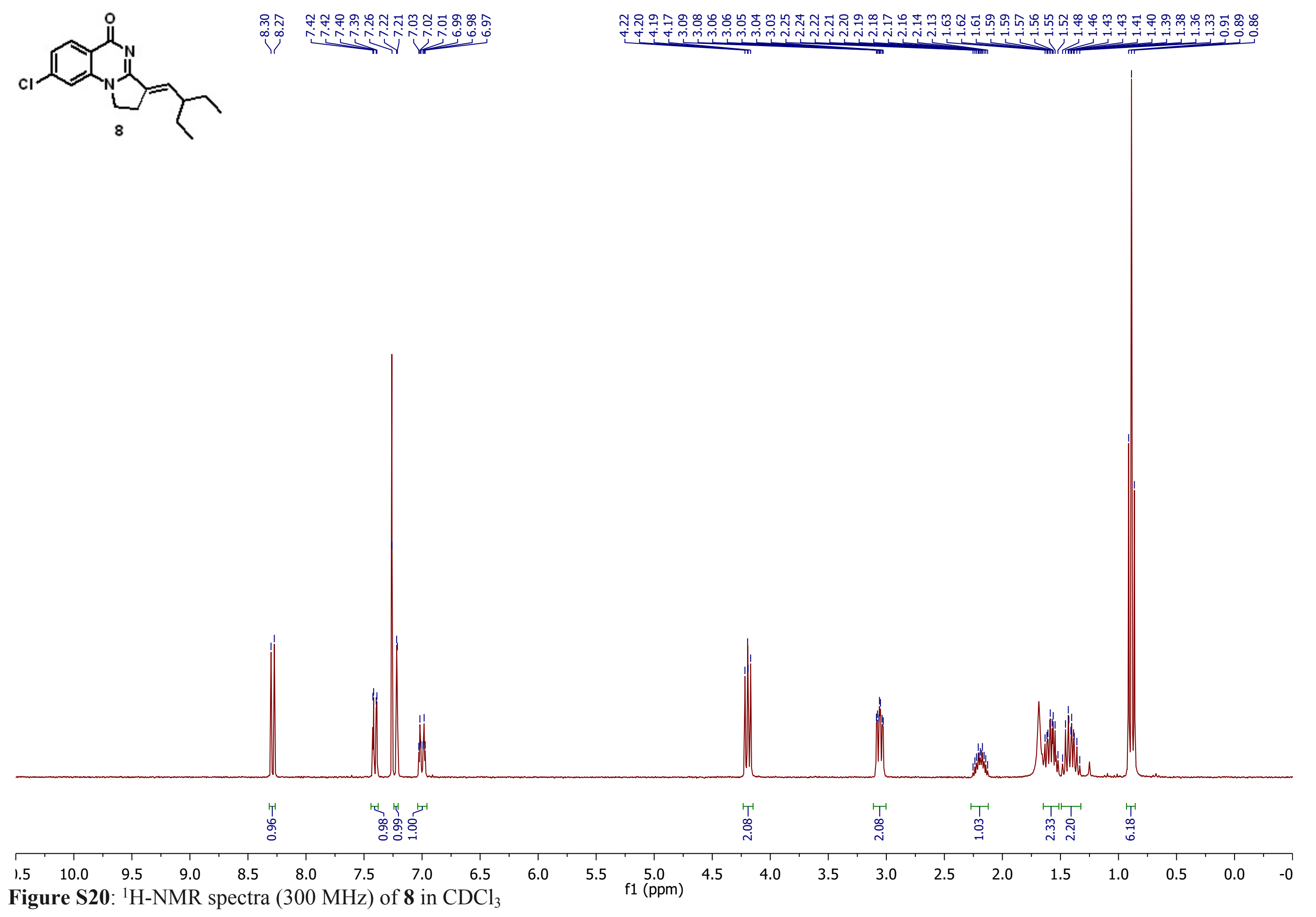


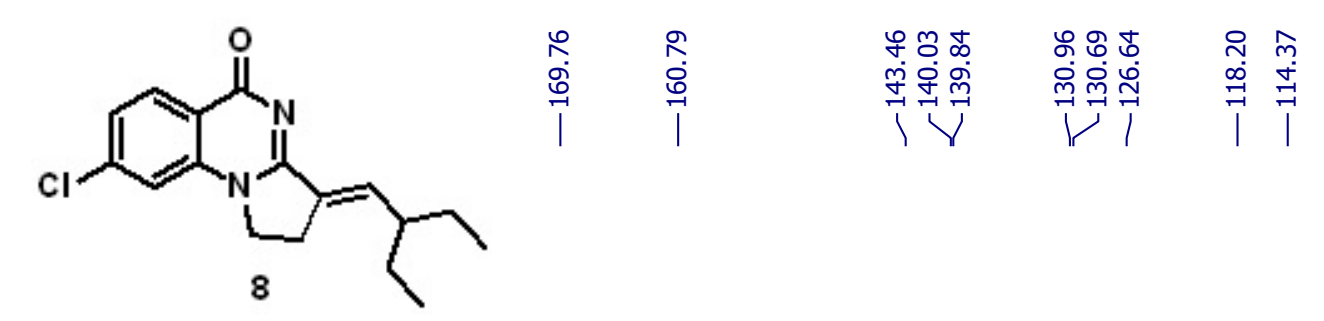

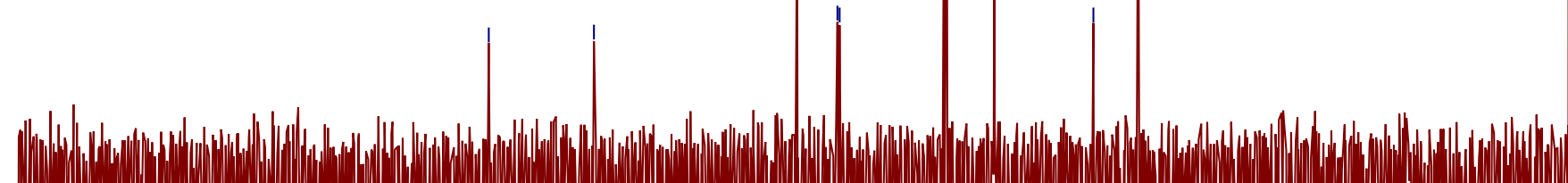

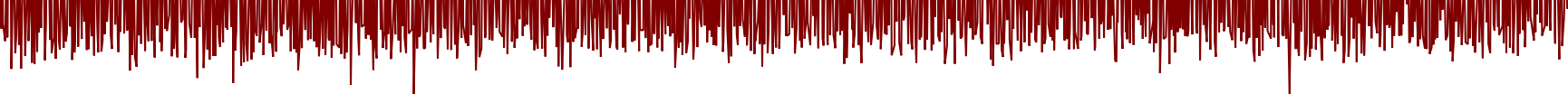

$200 \quad 190 \quad 180$ 


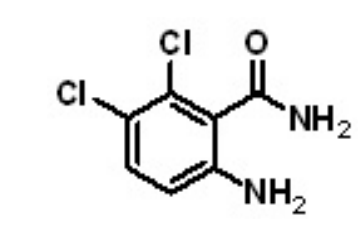



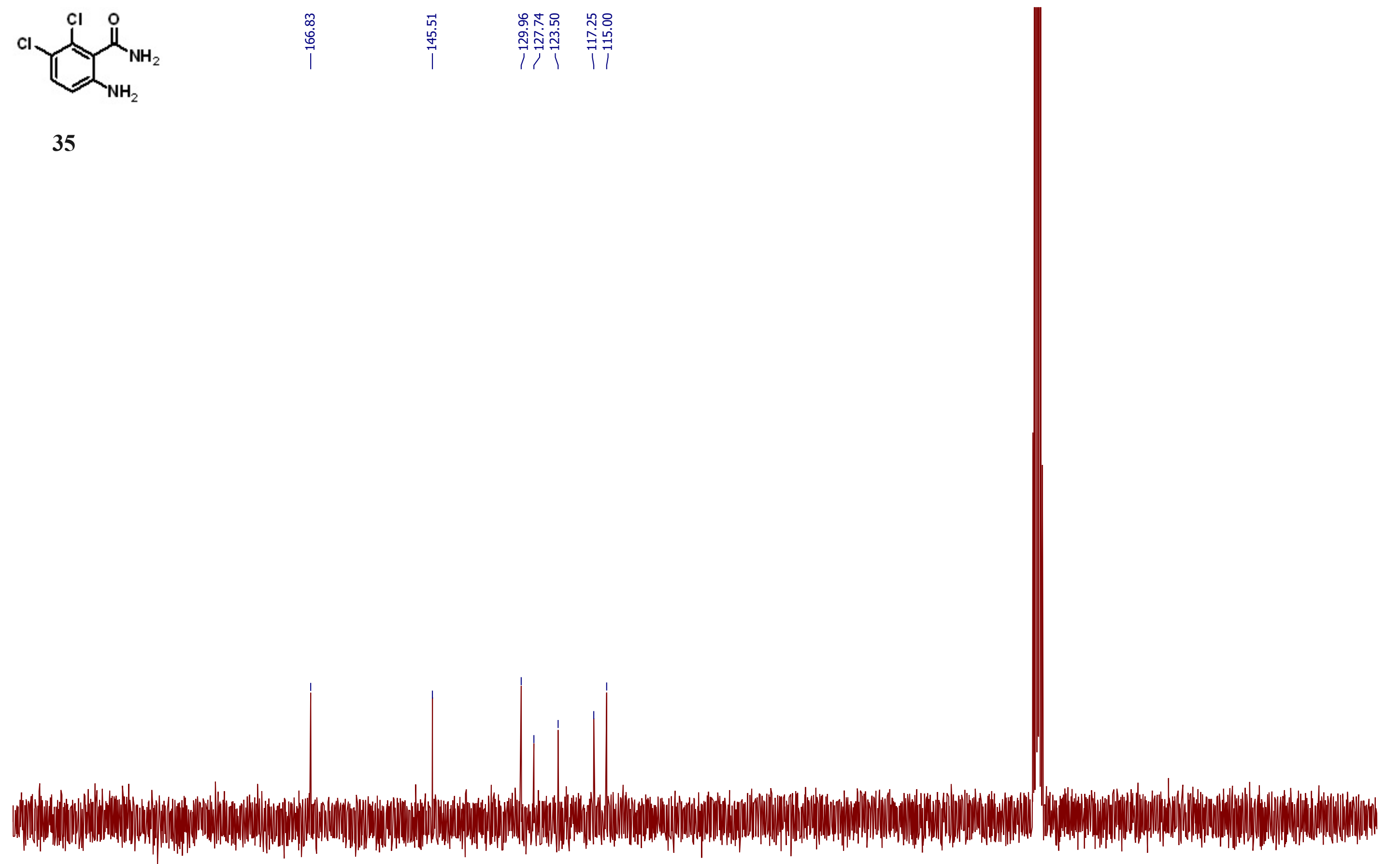

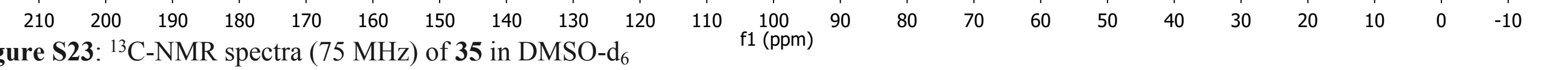



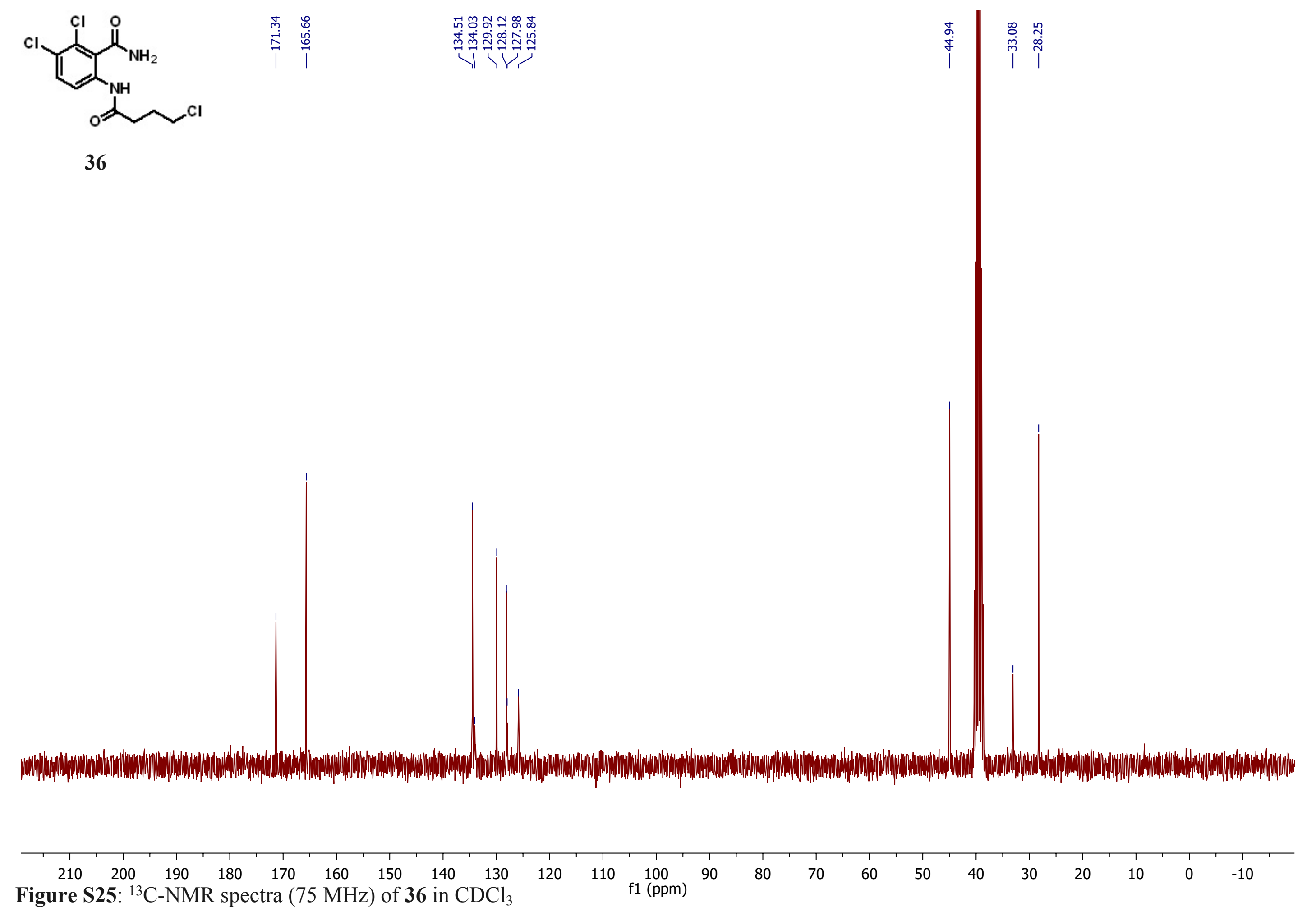

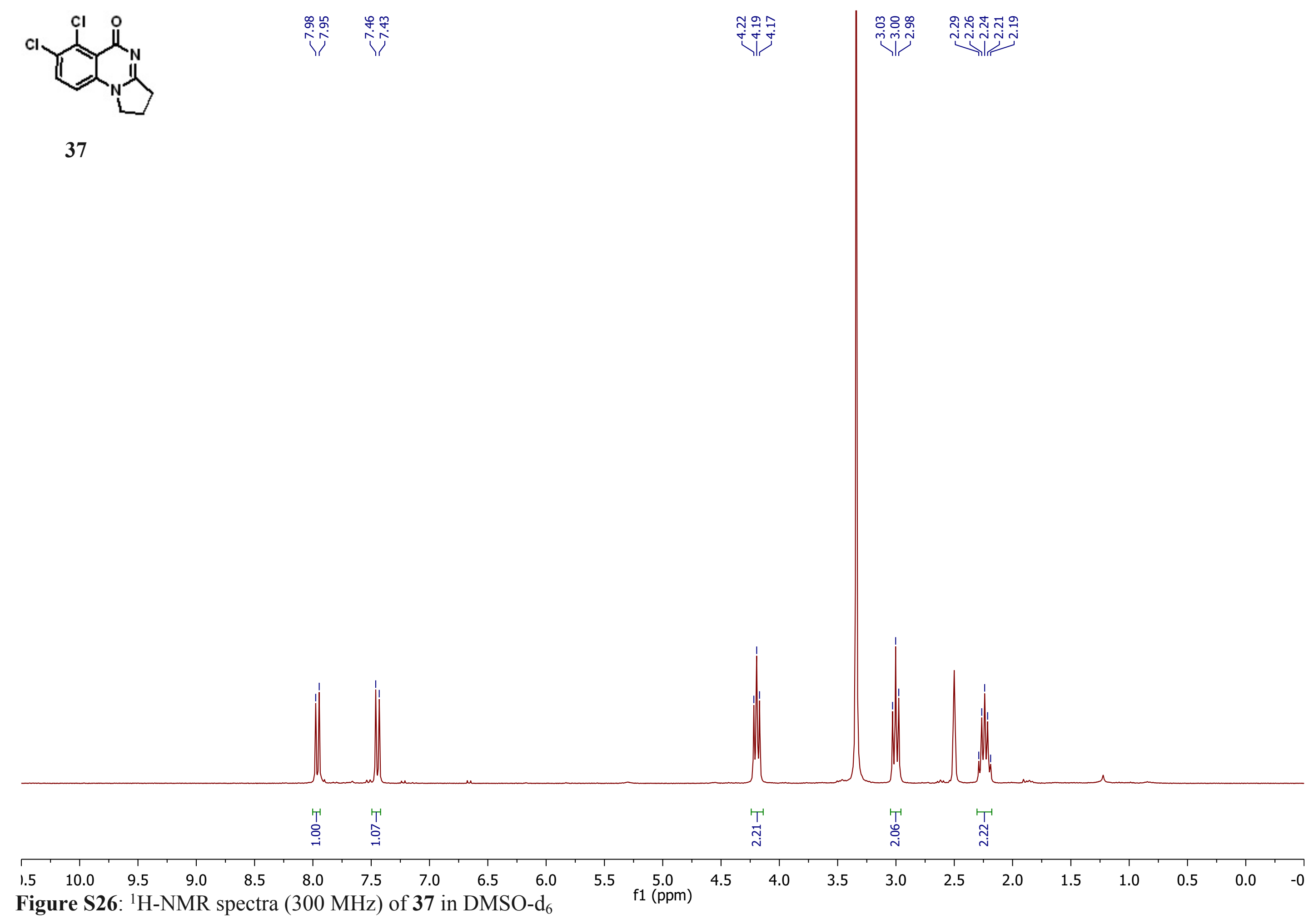


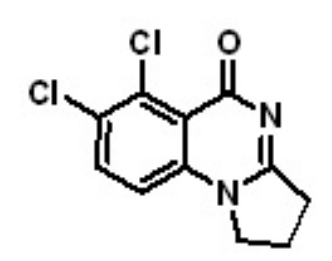

37

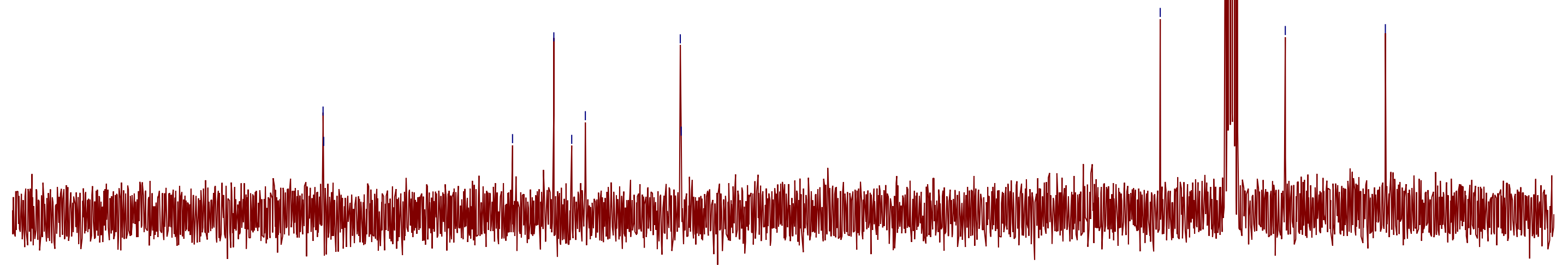
Figure S27: ${ }^{13} \mathrm{C}-\mathrm{NMR}$ spectra $(75 \mathrm{MHz})$ of $\mathbf{3 7}$ in $\mathrm{DMSO}-\mathrm{d}_{6}$

110

100
$\mathrm{f} 1(\mathrm{ppm})$

$90 \quad 80$

70

60

50

40

30

20 

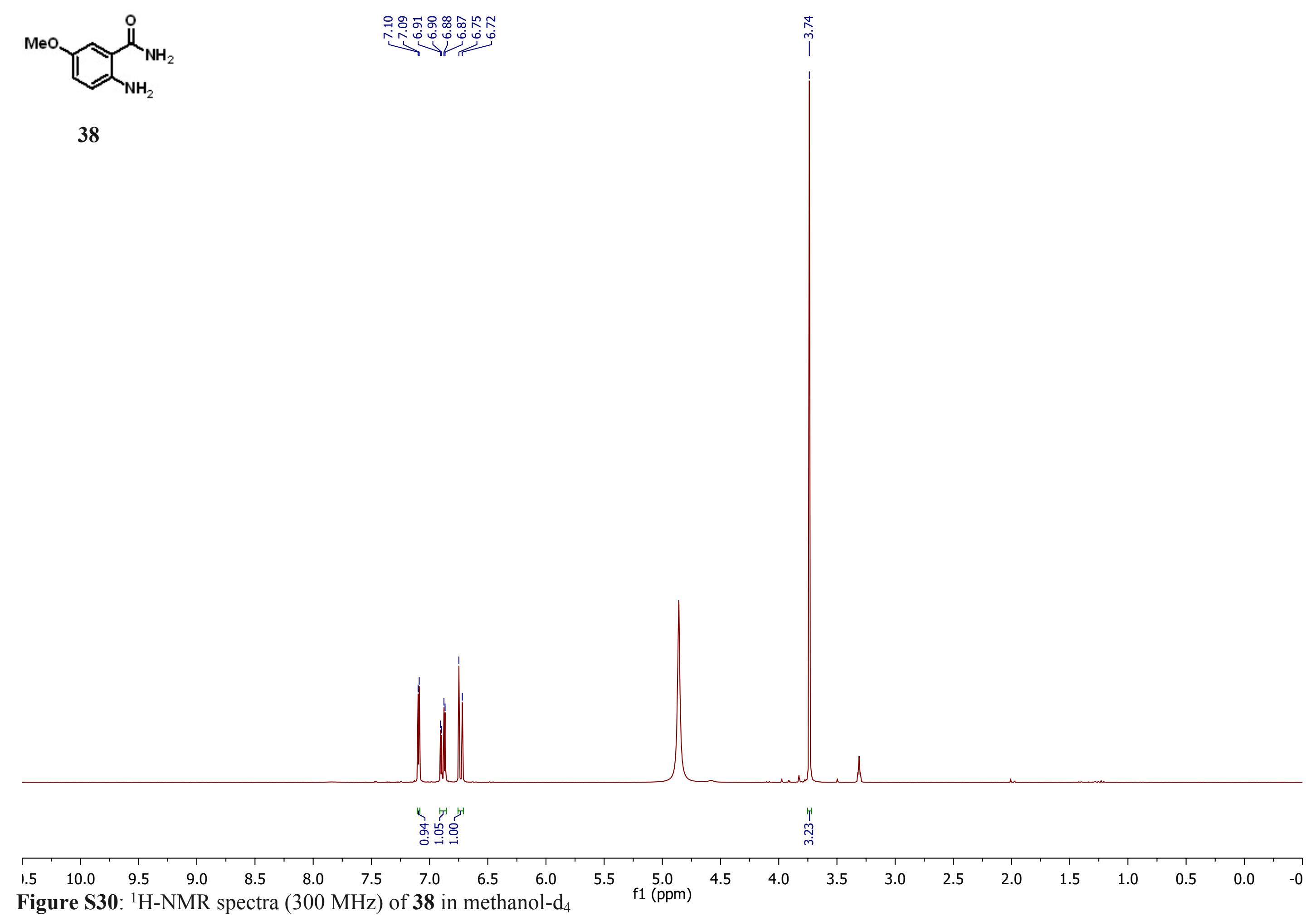
<smiles>COc1ccc(NC(=O)CCCCl)c(C(N)=O)c1</smiles>

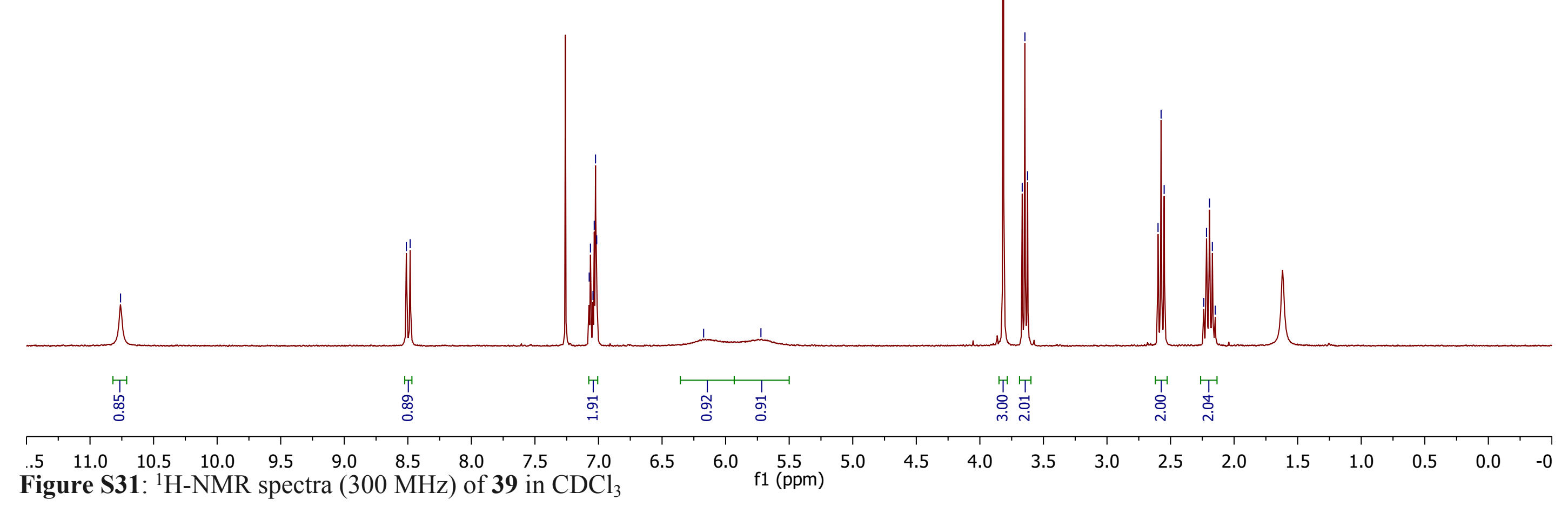



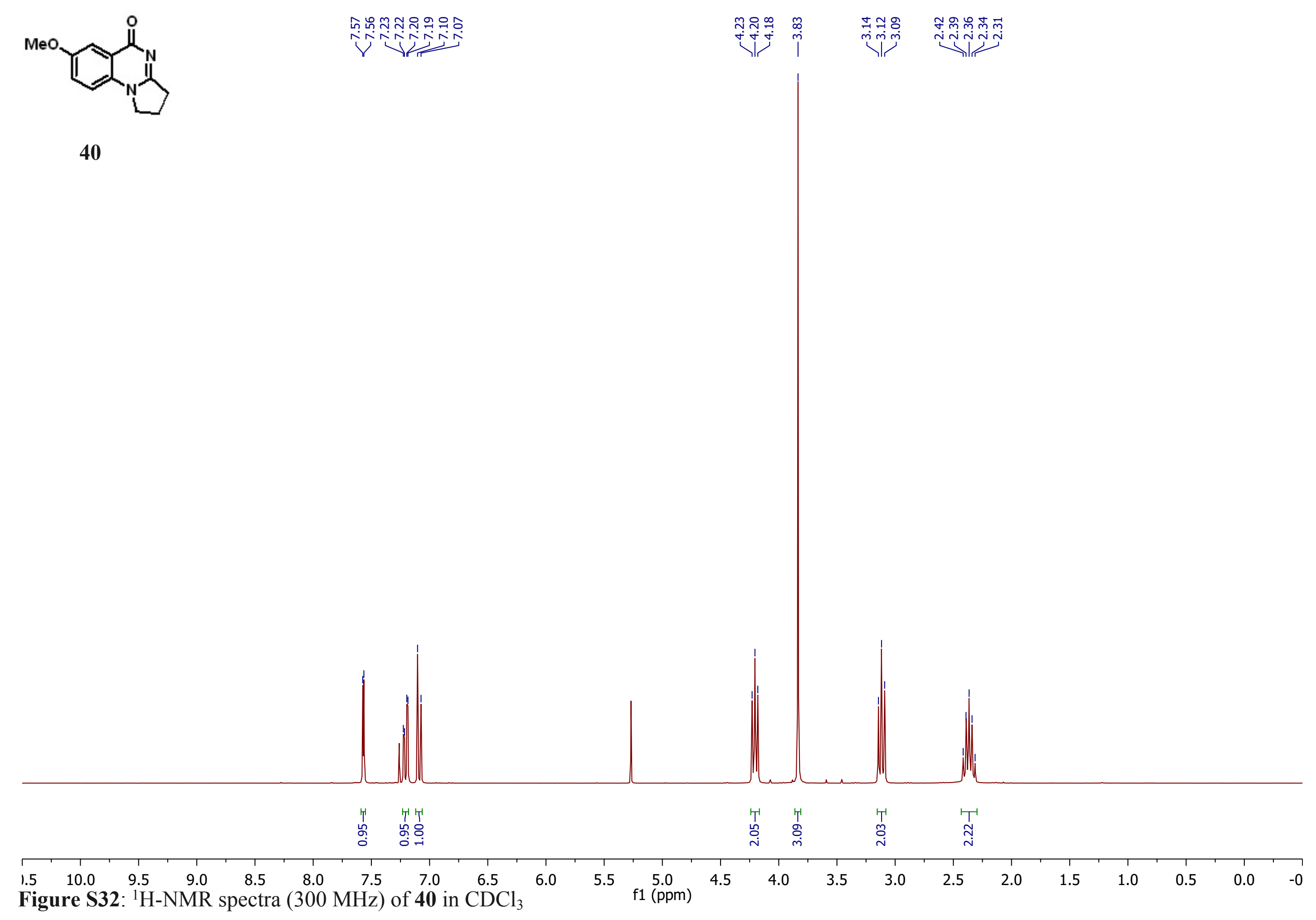


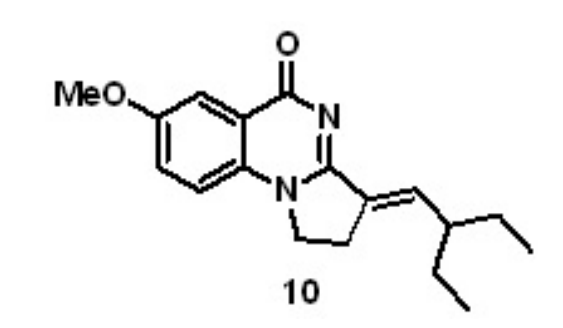

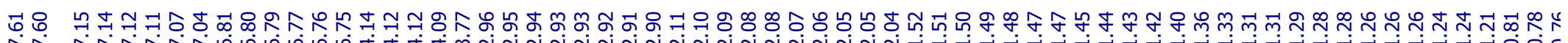

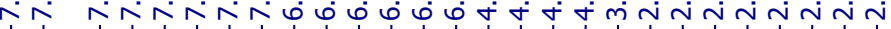

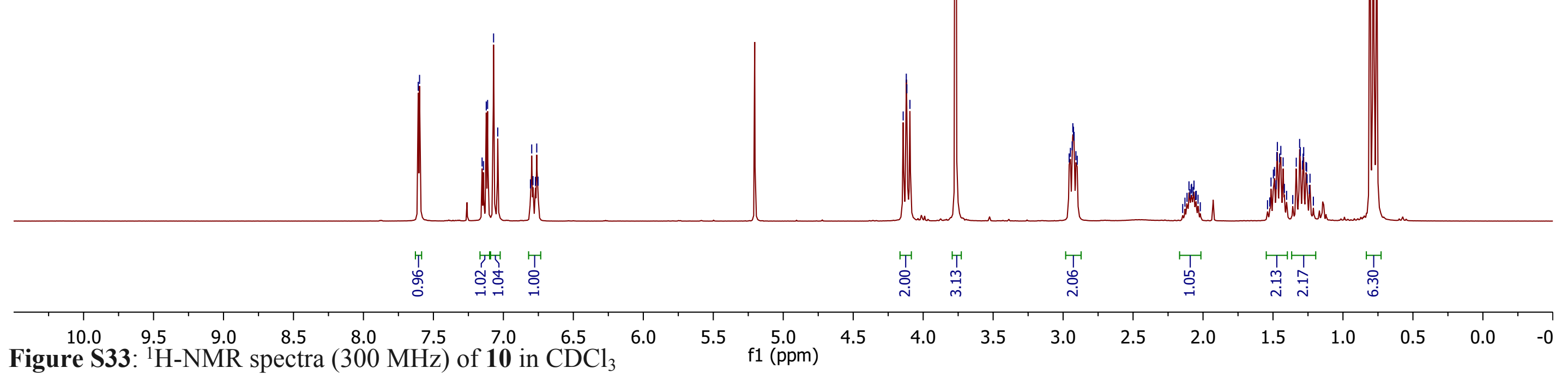




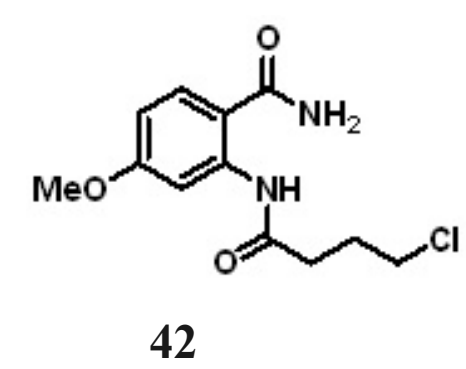

42

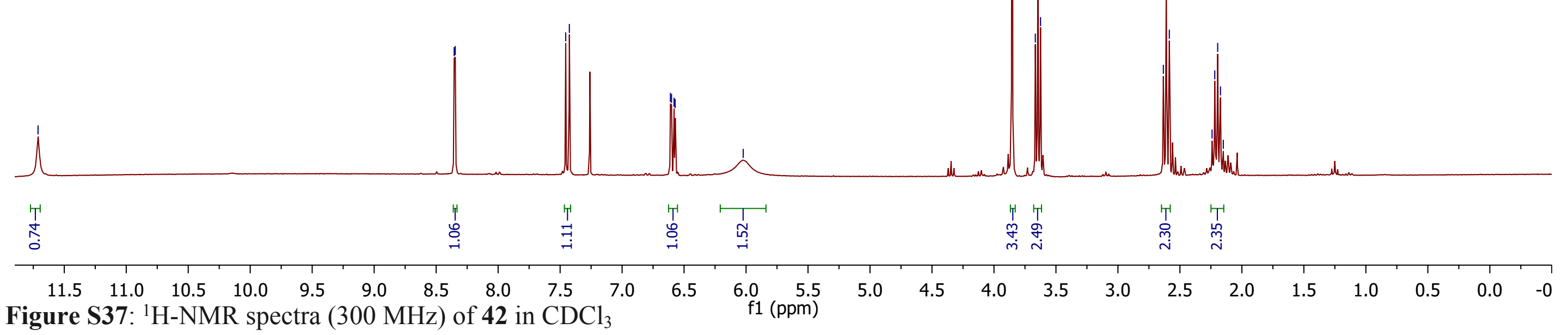



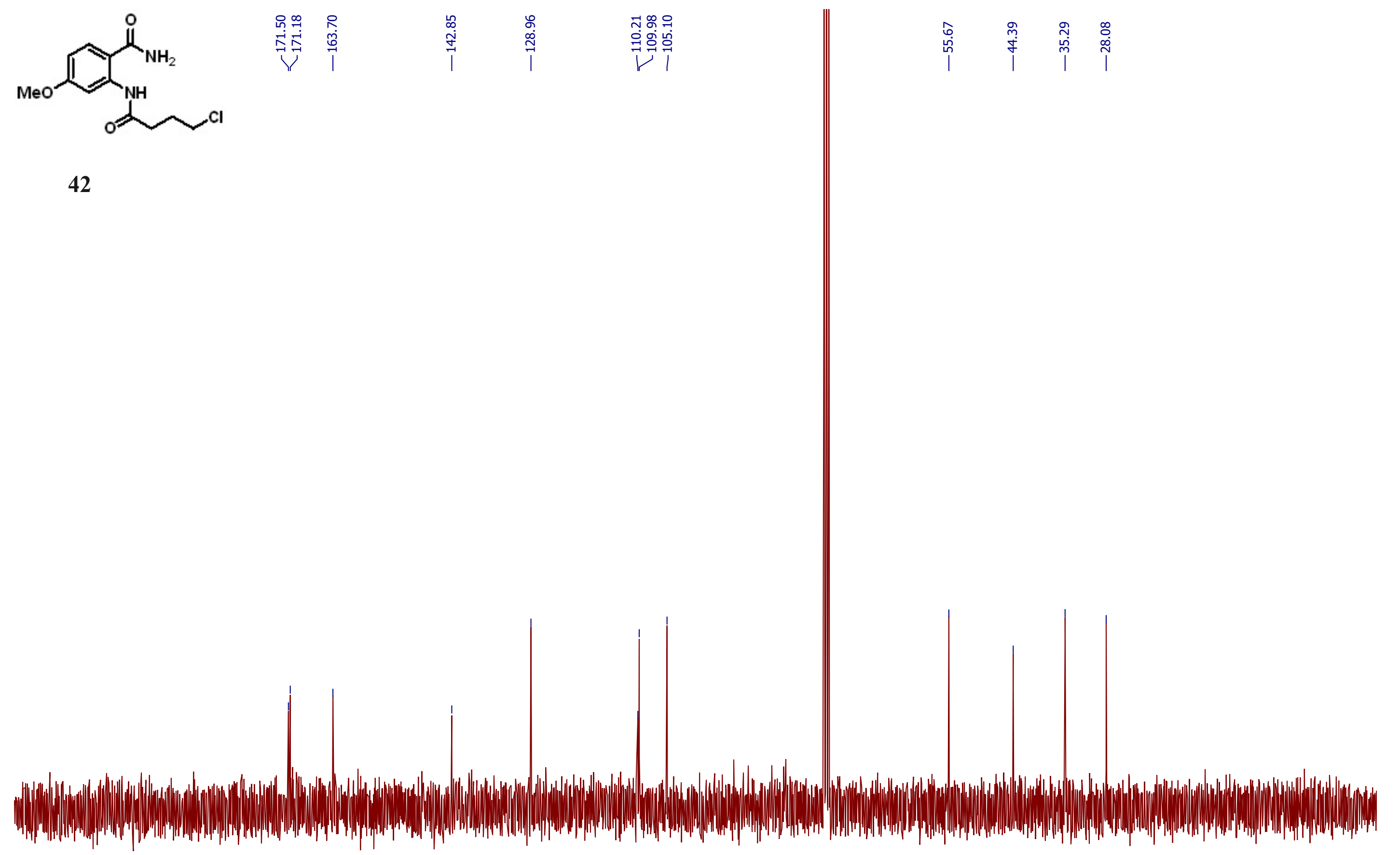

Figure S38: ${ }^{13} \mathrm{C}-\mathrm{NMR}$ spectra $(75 \mathrm{MHz})$ of 42 in $\mathrm{CDCl}_{3}$ 


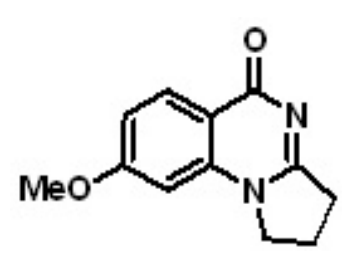

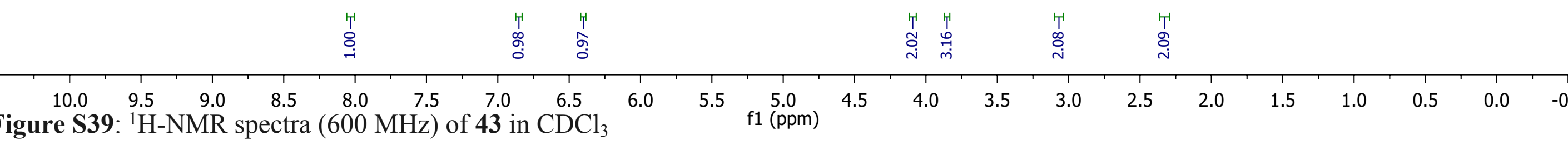




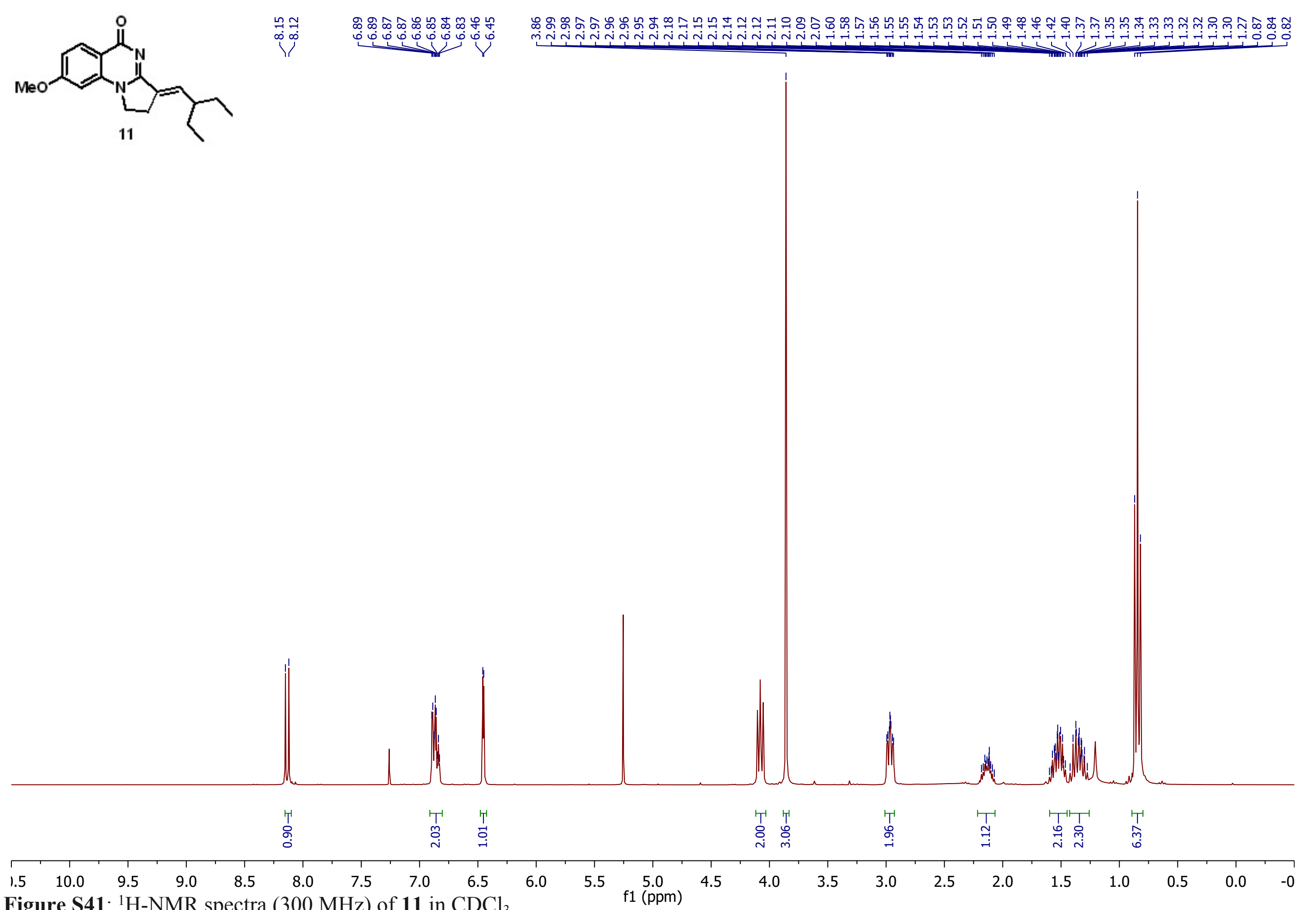

Figure S41: ${ }^{1} \mathrm{H}-\mathrm{NMR}$ spectra $(300 \mathrm{MHz})$ of 11 in $\mathrm{CDCl}_{3}$ 

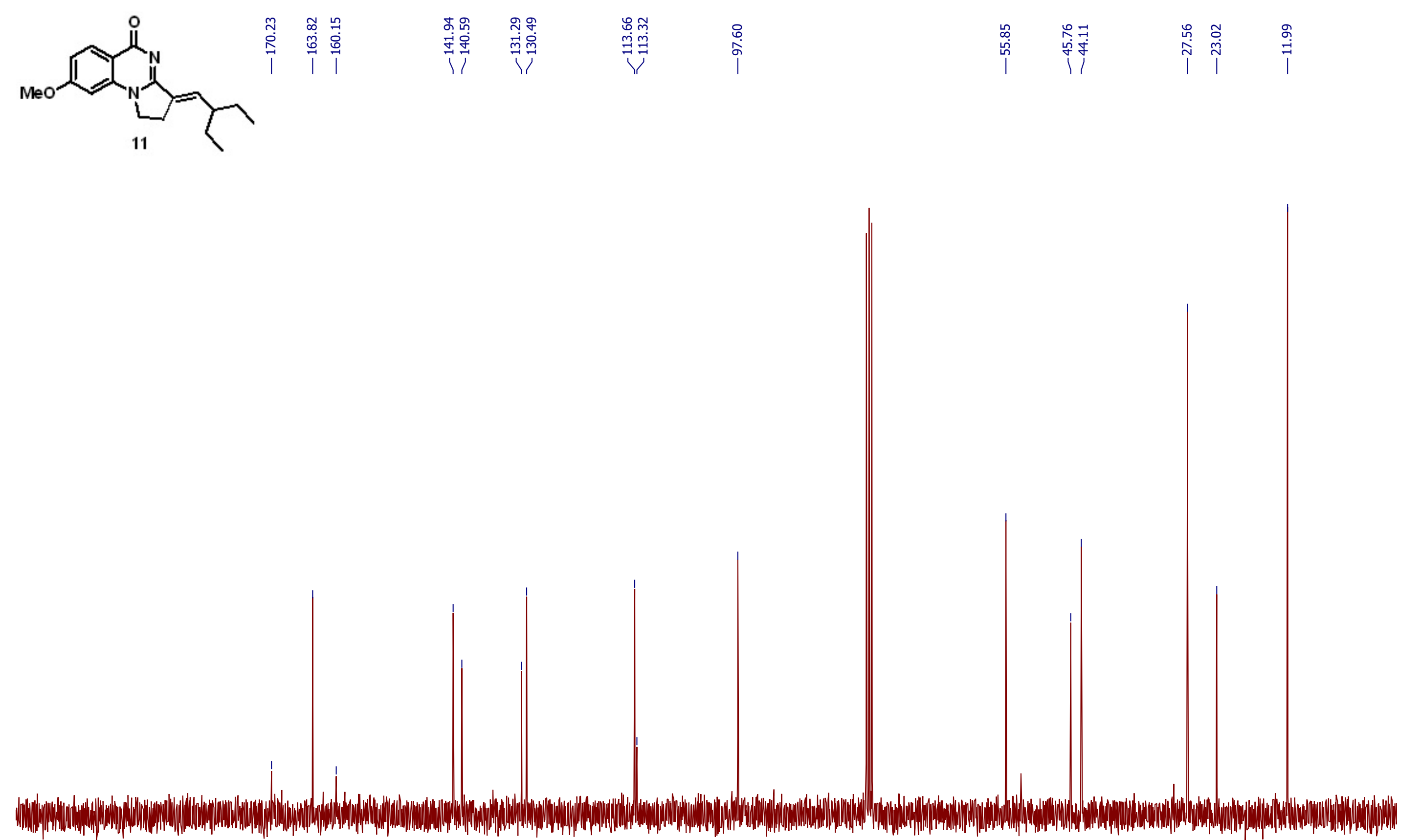

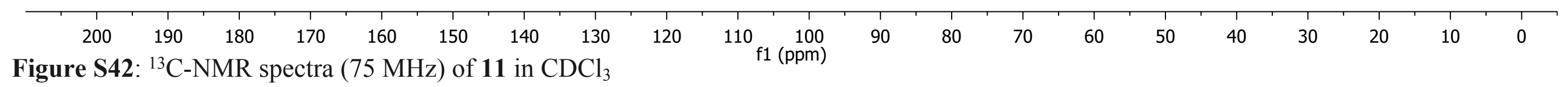



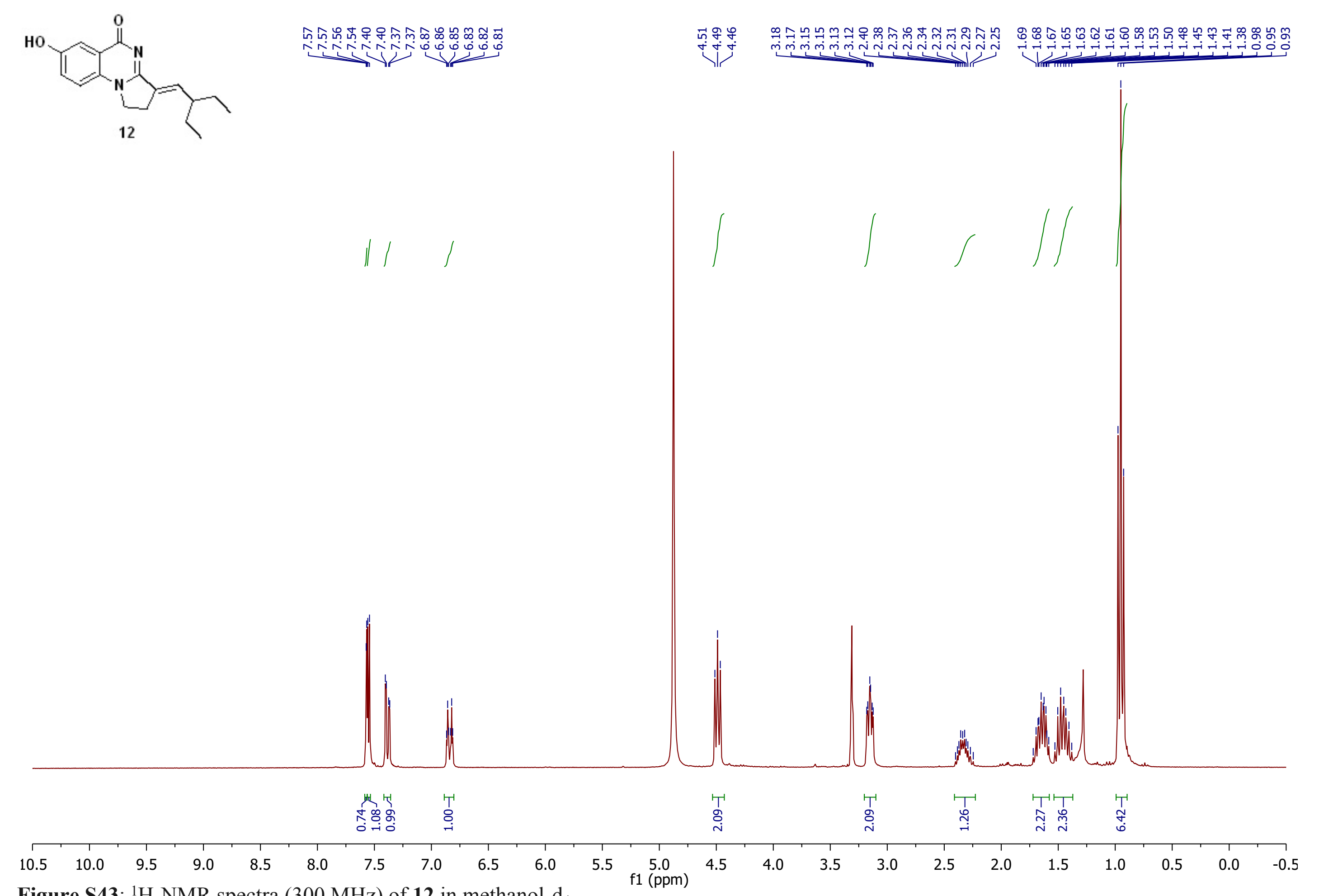

Figure S43: ${ }^{1} \mathrm{H}-\mathrm{NMR}$ spectra (300 MHz) of $\mathbf{1 2}$ in methanol- $\mathrm{d}_{4}$ 

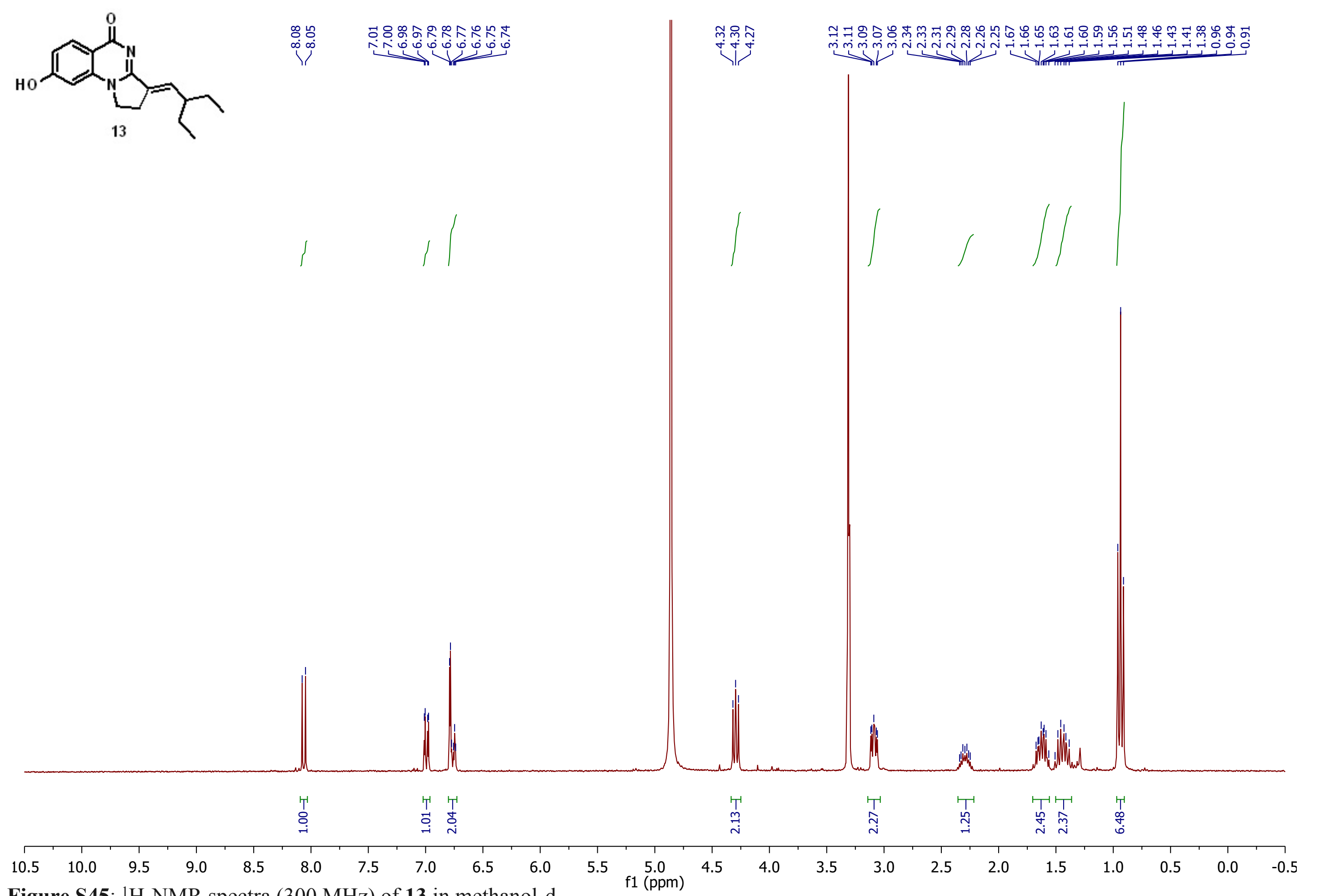

Figure S45: ${ }^{1} \mathrm{H}-\mathrm{NMR}$ spectra $(300 \mathrm{MHz})$ of $\mathbf{1 3}$ in methanol-d $\mathrm{d}_{4}$ 

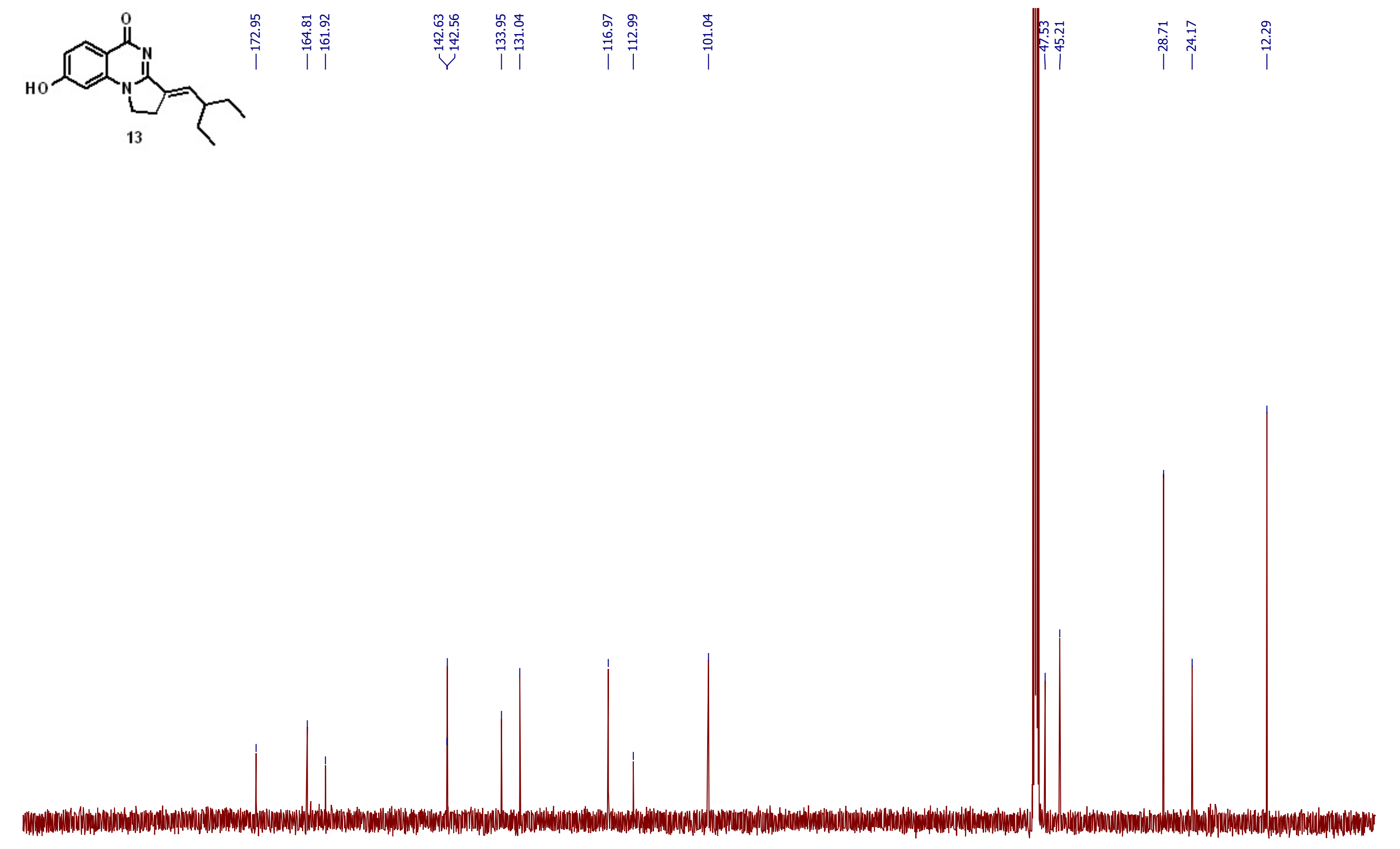

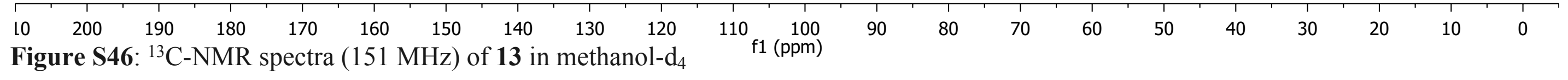



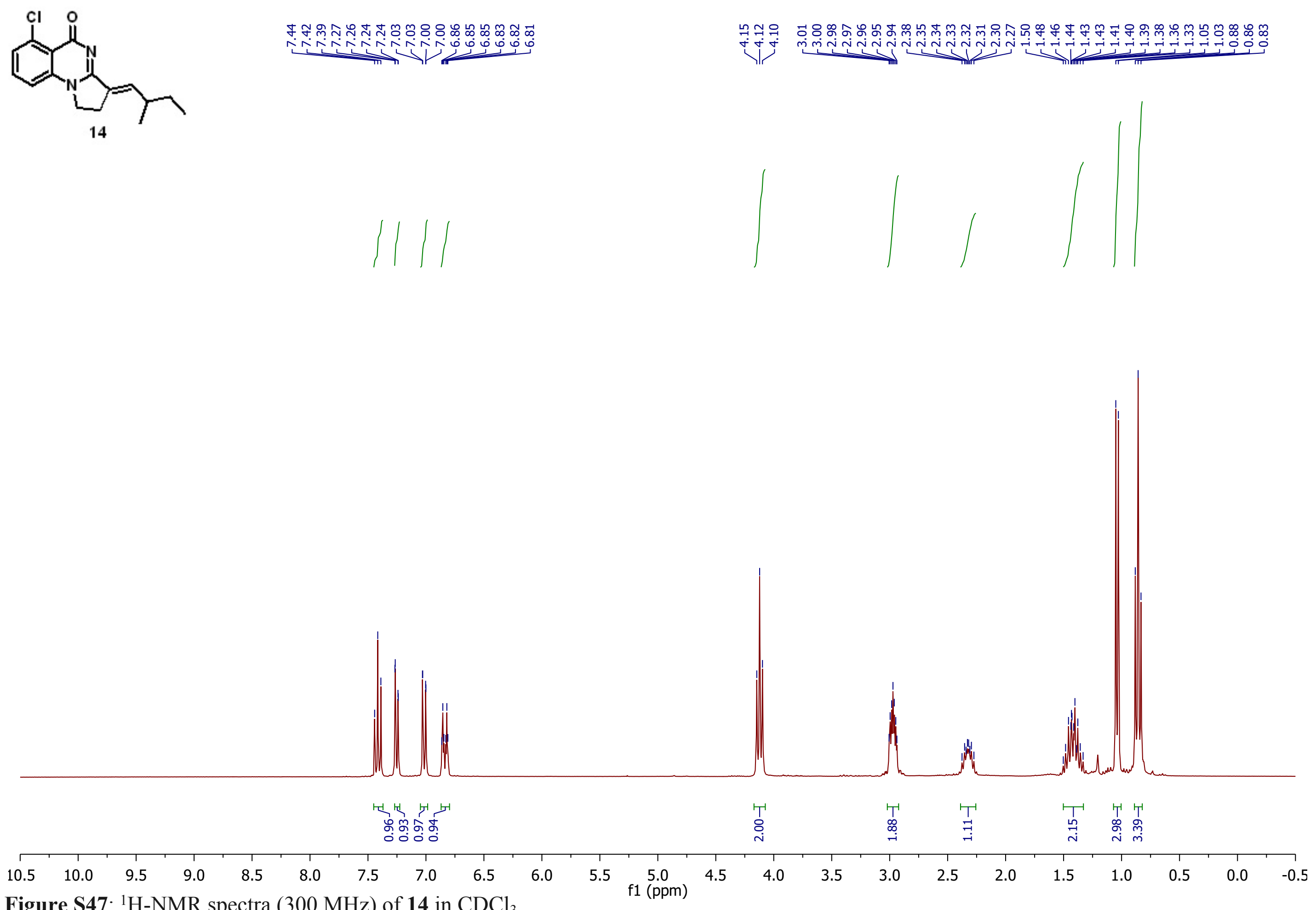

Figure S47: ${ }^{1} \mathrm{H}-\mathrm{NMR}$ spectra $(300 \mathrm{MHz})$ of 14 in $\mathrm{CDCl}_{3}$ 

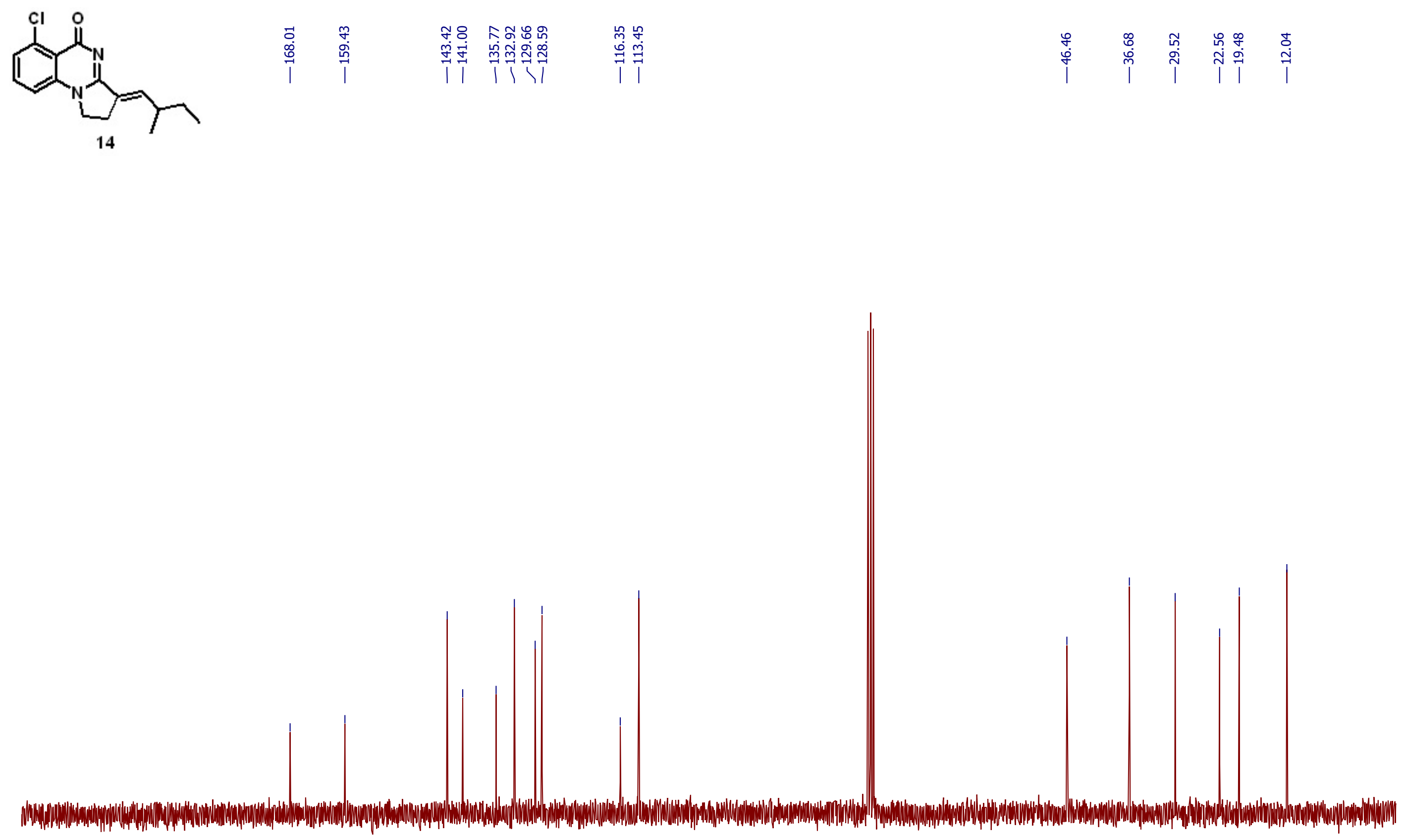

\begin{tabular}{|c|c|c|c|c|c|c|c|c|c|c|c|c|c|c|c|c|c|c|c|}
\hline 210 & 200 & 190 & 180 & 170 & 160 & 150 & 140 & 130 & 120 & $\begin{array}{r}110 \\
\mathrm{f} 1(\mathrm{ppm})\end{array}$ & 90 & 80 & 70 & 60 & 50 & 40 & 30 & 20 & 10 \\
\hline
\end{tabular}



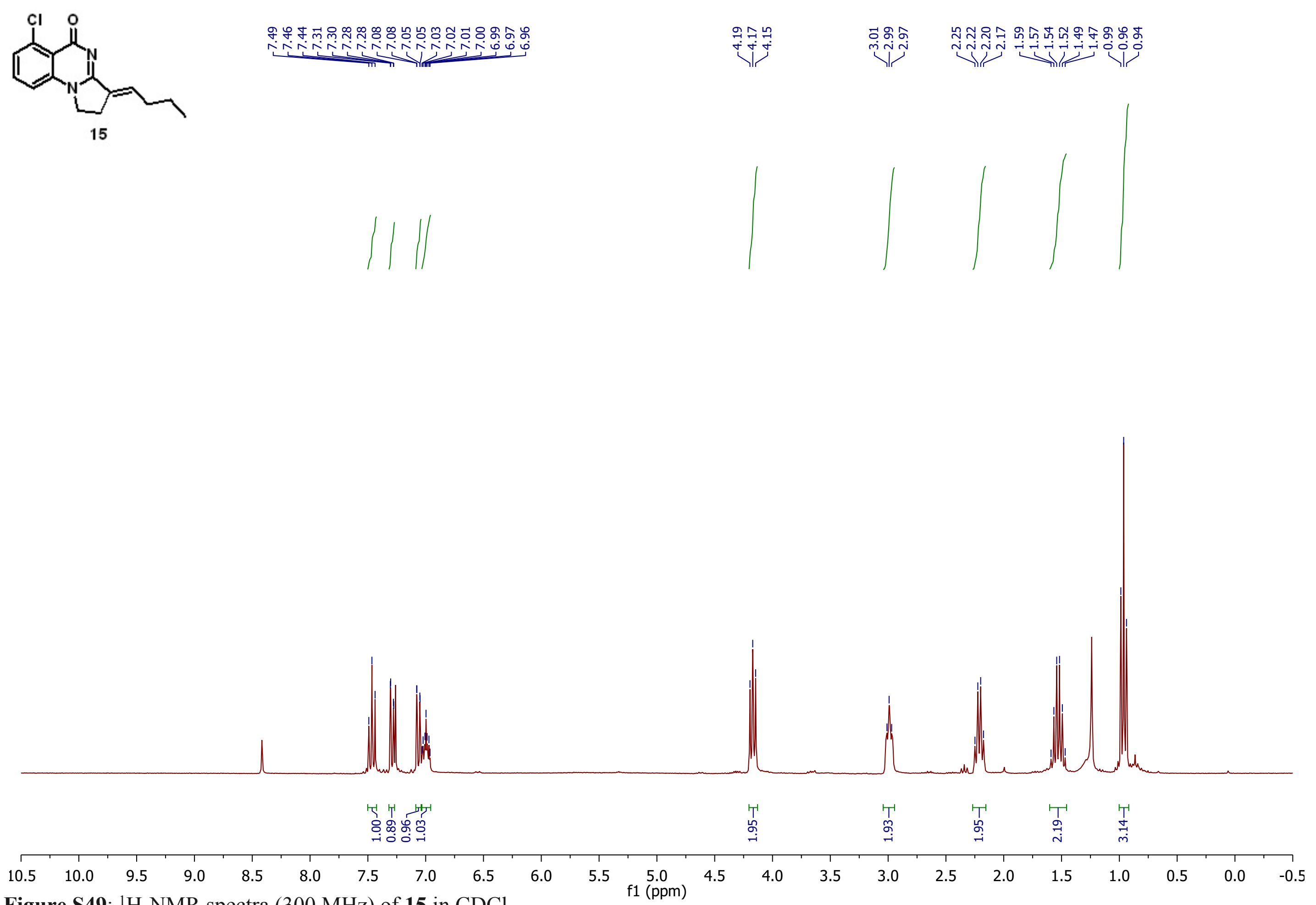

Figure S49: ${ }^{1} \mathrm{H}-\mathrm{NMR}$ spectra $(300 \mathrm{MHz})$ of $\mathbf{1 5}$ in $\mathrm{CDCl}_{3}$ 


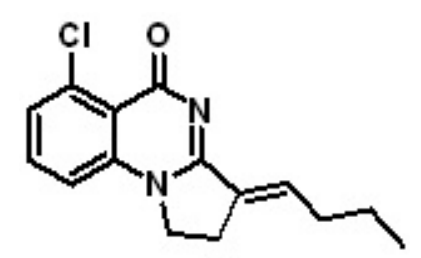

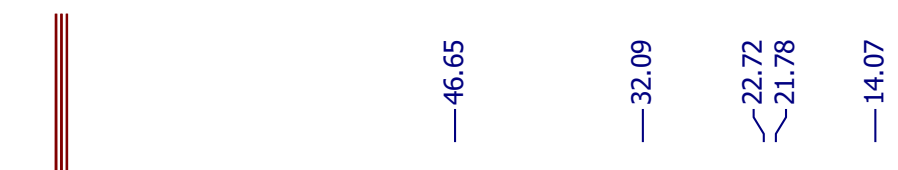

15

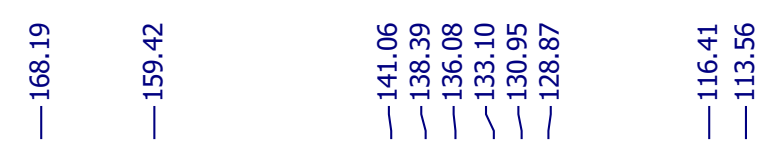

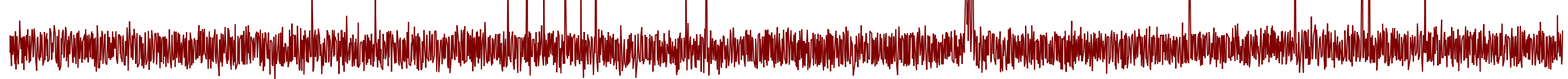

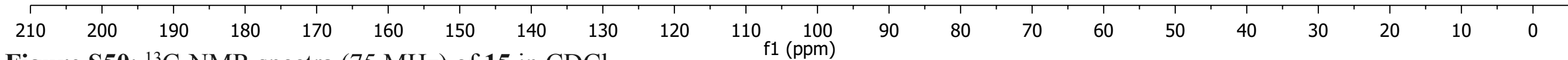

Figure S50: ${ }^{13} \mathrm{C}-\mathrm{NMR}$ spectra $(75 \mathrm{MHz})$ of $\mathbf{1 5}$ in $\mathrm{CDCl}_{3}$ 


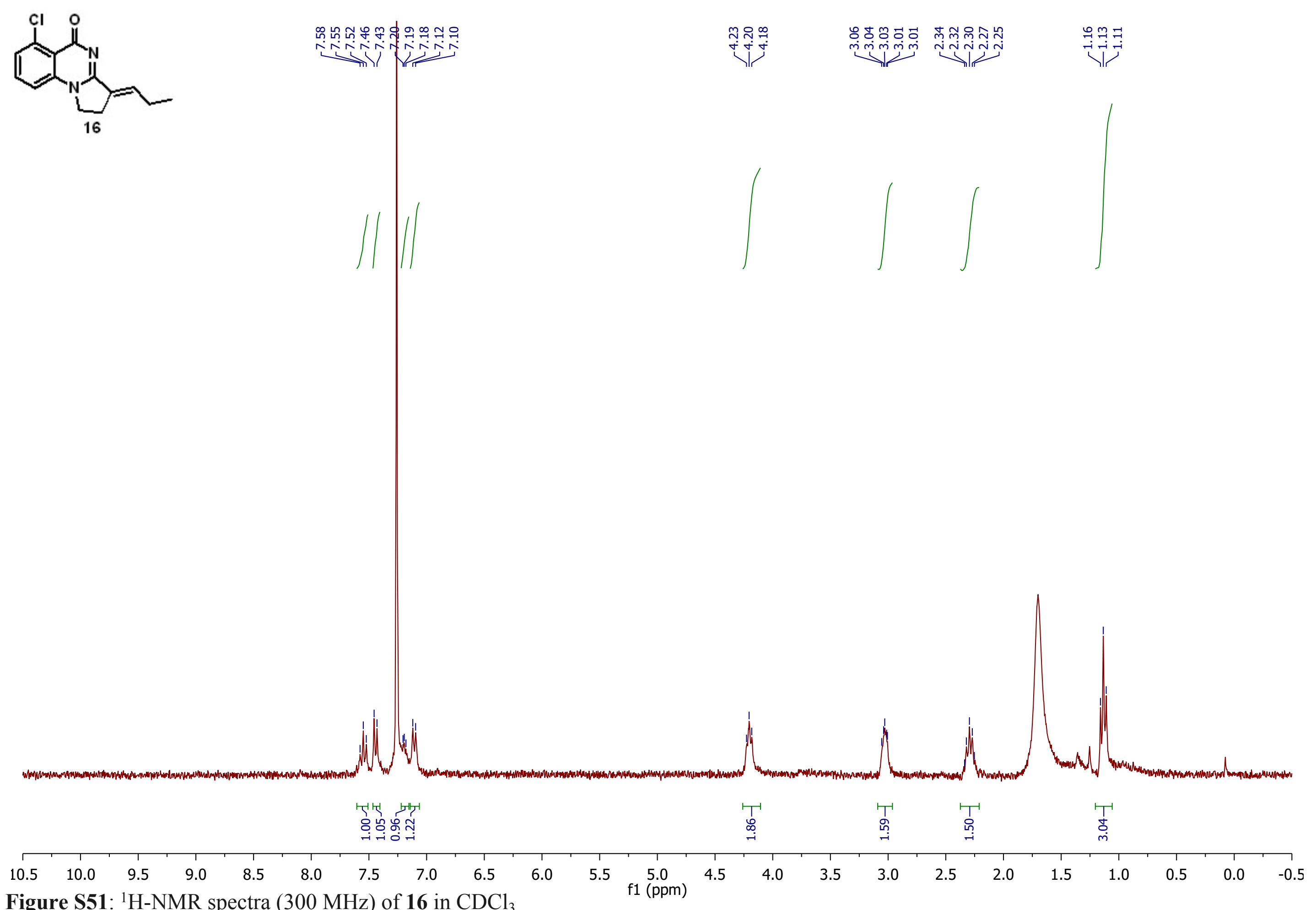

Figure S51: ${ }^{1} \mathrm{H}-\mathrm{NMR}$ spectra $(300 \mathrm{MHz})$ of 16 in $\mathrm{CDCl}_{3}$ 


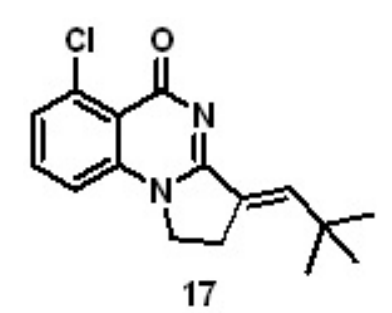

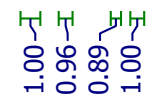




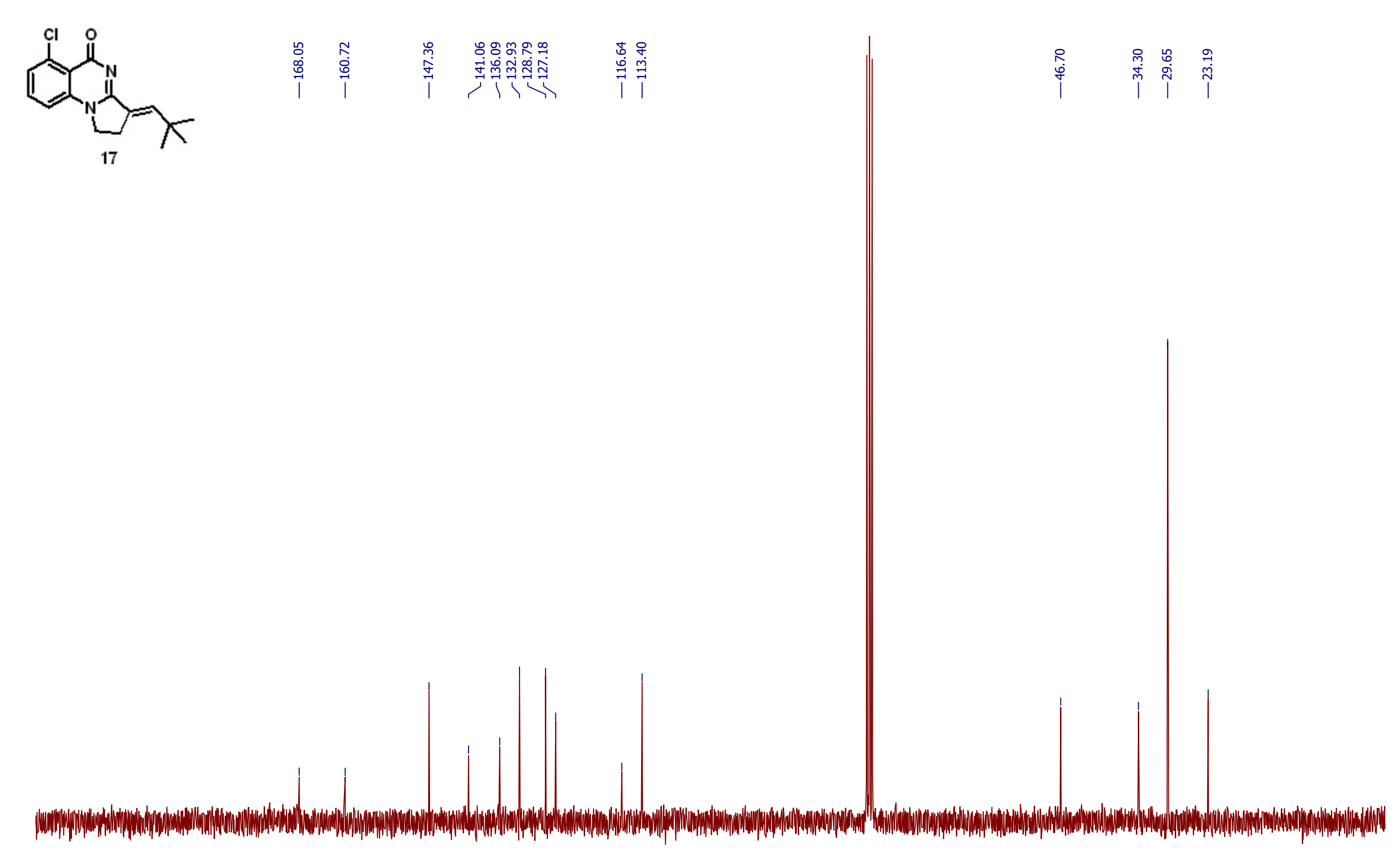

$\begin{array}{lllllllll}210 & 200 & 190 & 180 & 170 & 160 & 150 & 140 & 130 \\ \text { Figure S53: } & { }^{13} \mathrm{C}-\mathrm{NMR} \text { spectra } & (75 & \mathrm{MHz}) \text { of } \mathbf{1 7} \text { in } \mathrm{CDC}\end{array}$ 

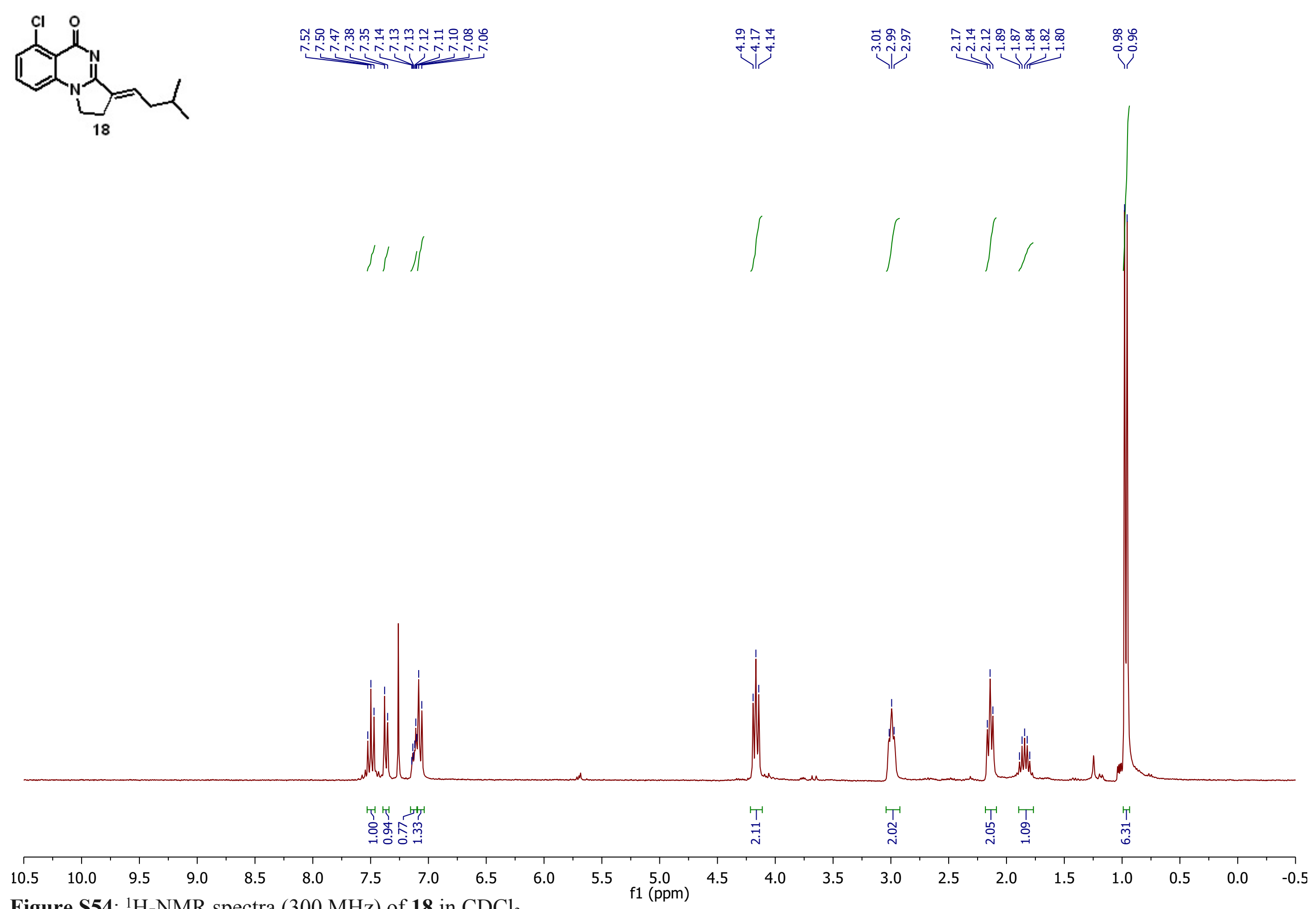

Figure S54: ${ }^{1} \mathrm{H}-\mathrm{NMR}$ spectra $(300 \mathrm{MHz})$ of $\mathbf{1 8}$ in $\mathrm{CDCl}_{3}$ 

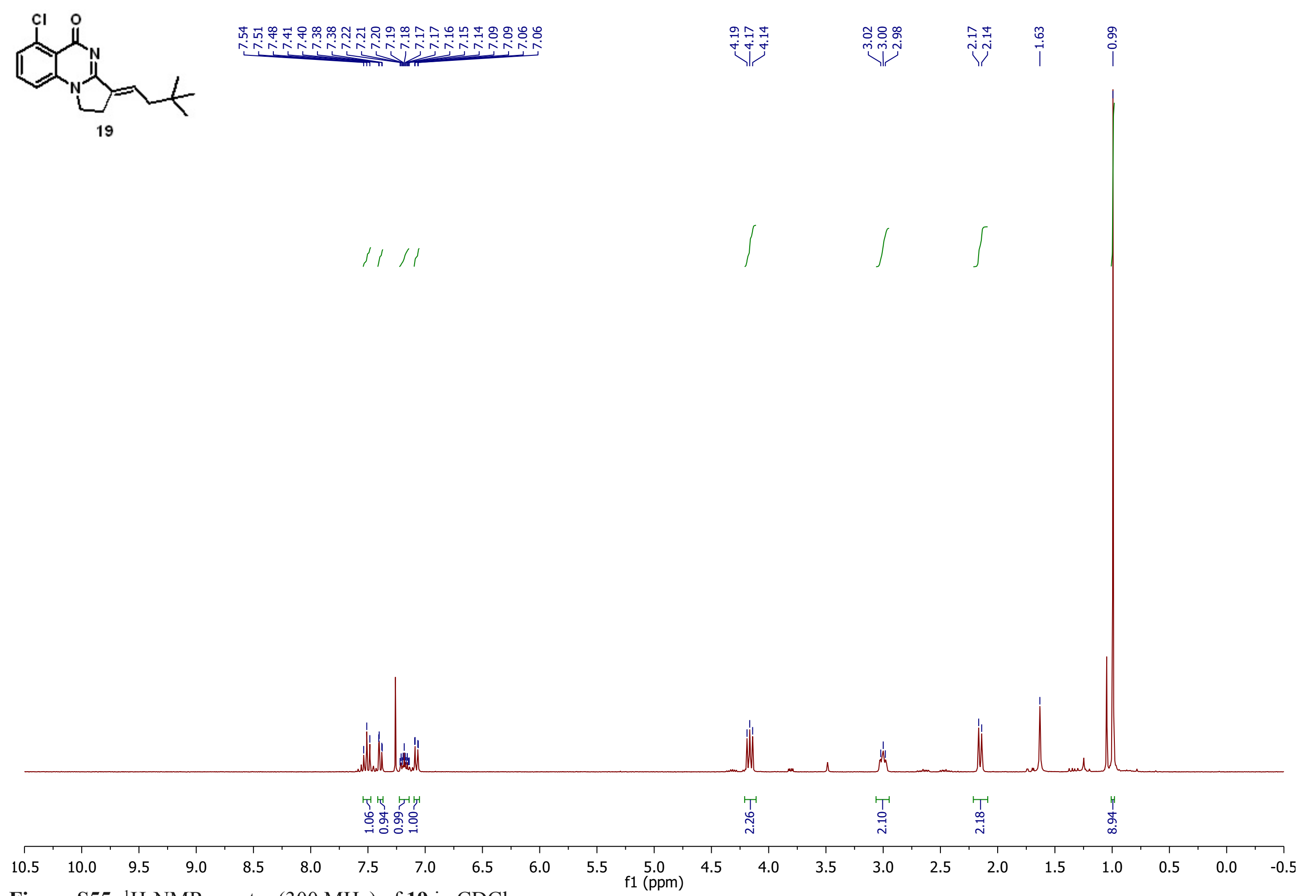

Figure S55: ${ }^{1} \mathrm{H}-\mathrm{NMR}$ spectra $(300 \mathrm{MHz})$ of 19 in $\mathrm{CDCl}_{3}$ 


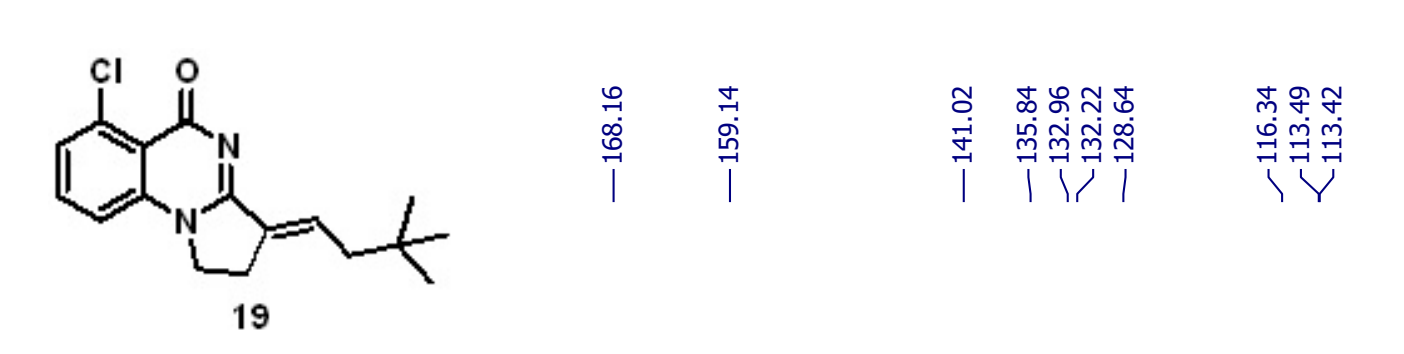

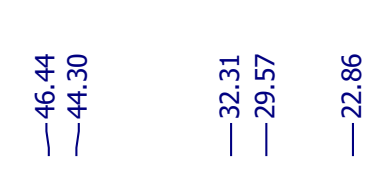




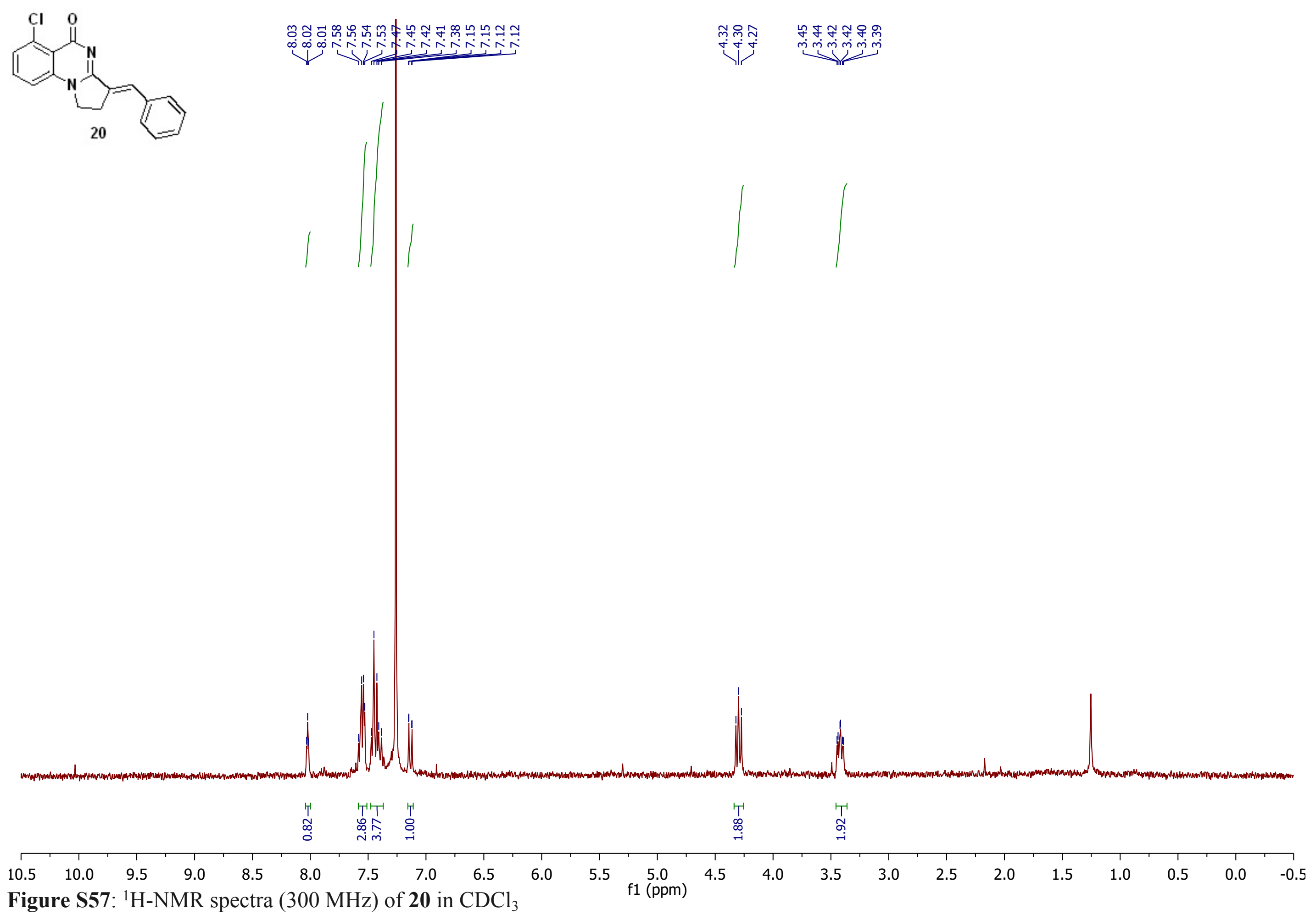




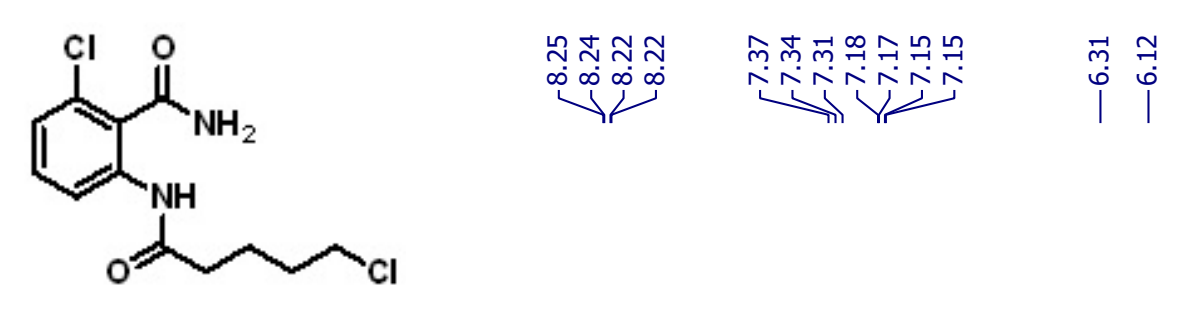

44

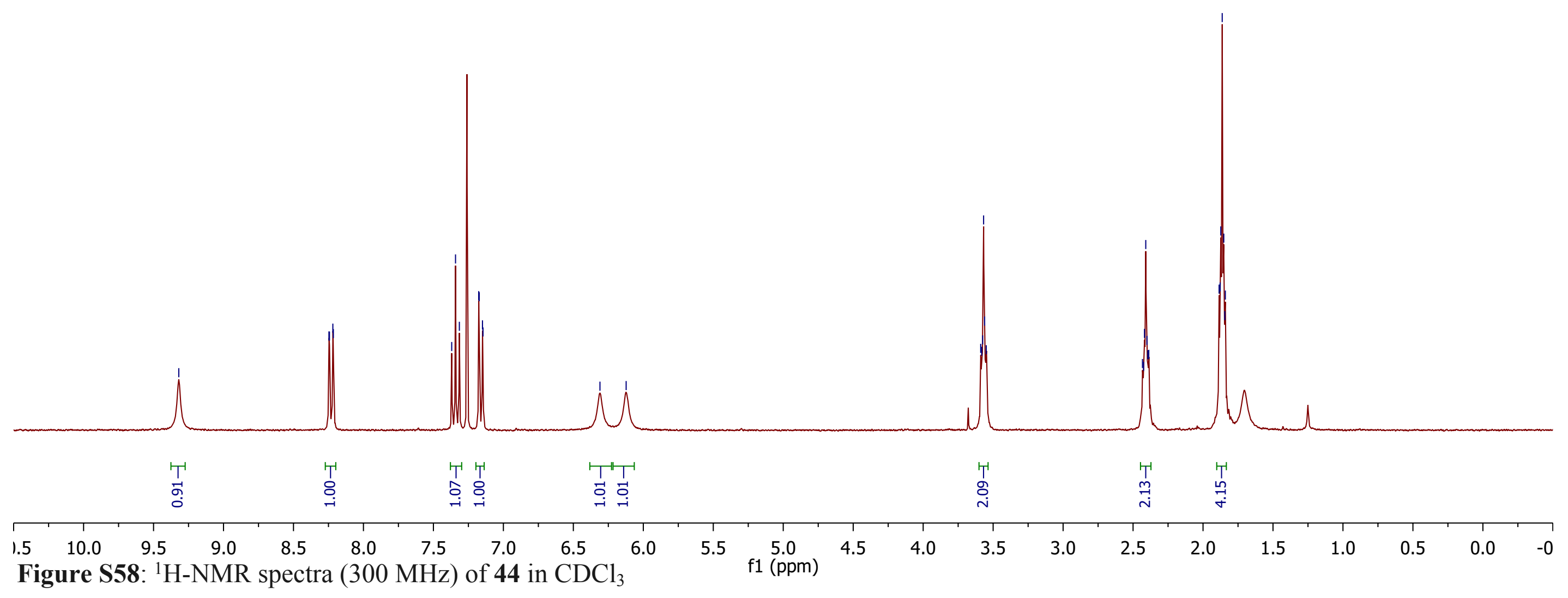



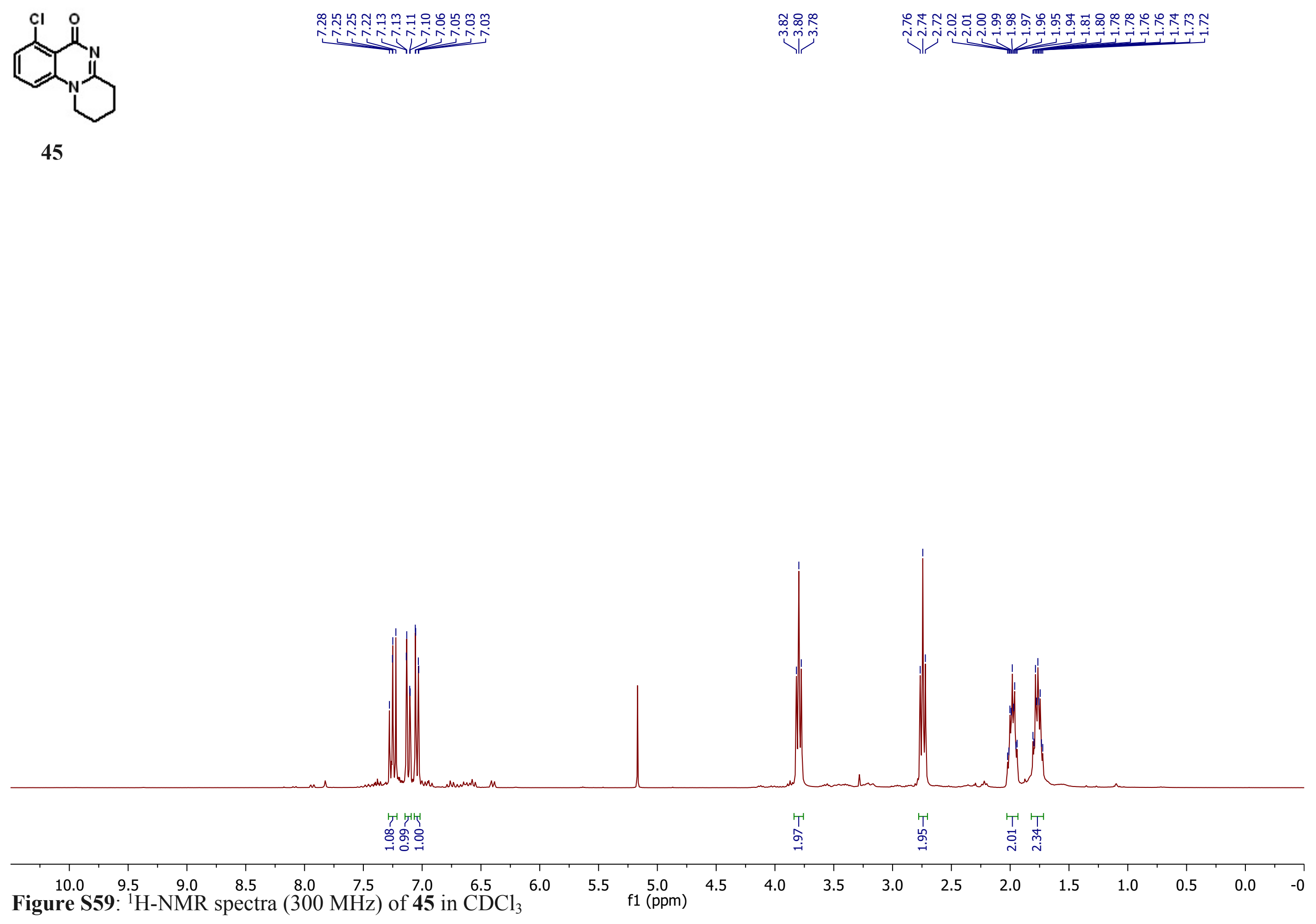

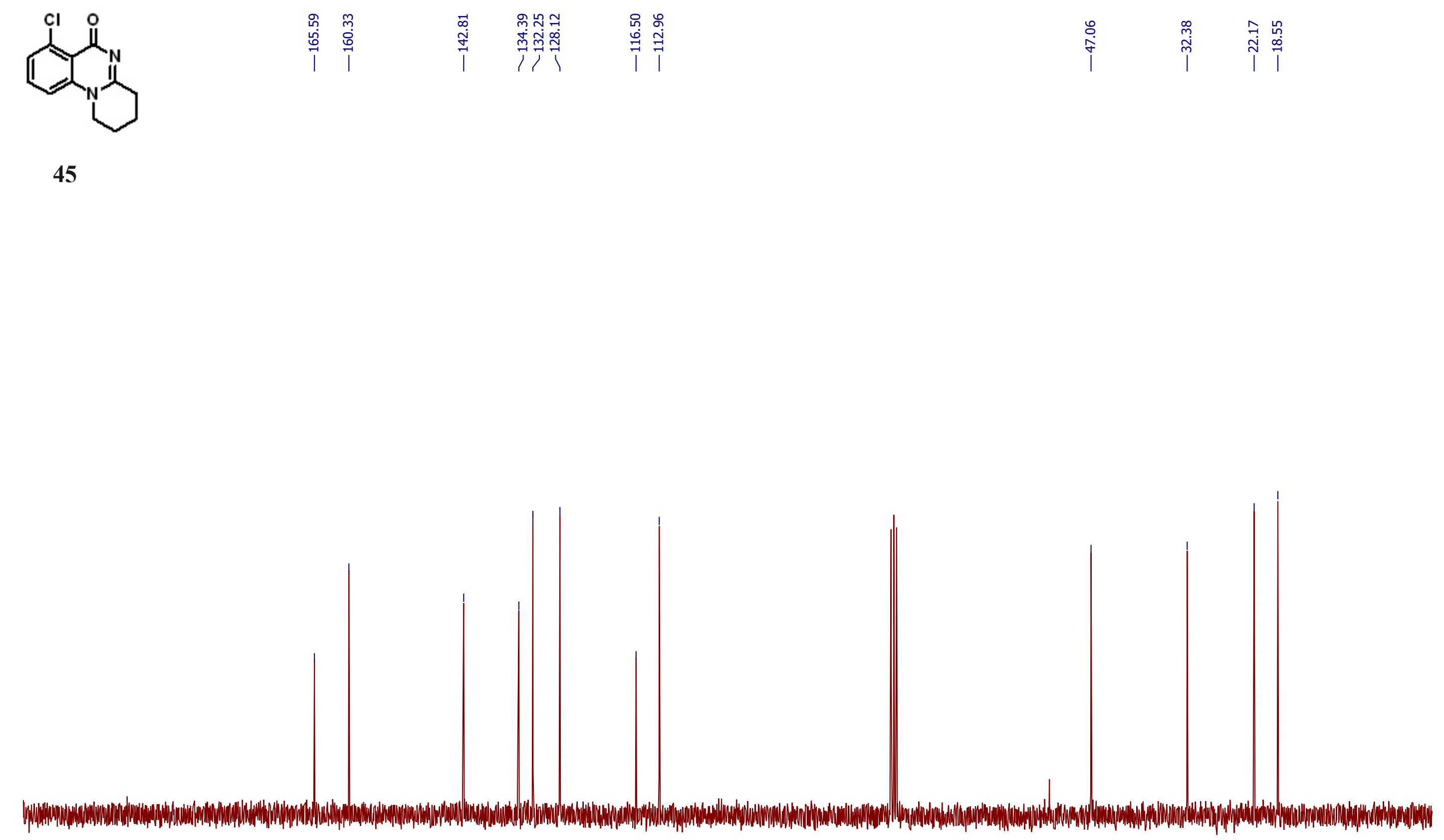

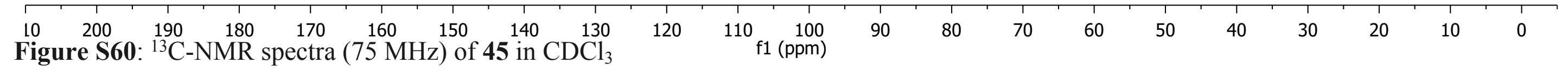



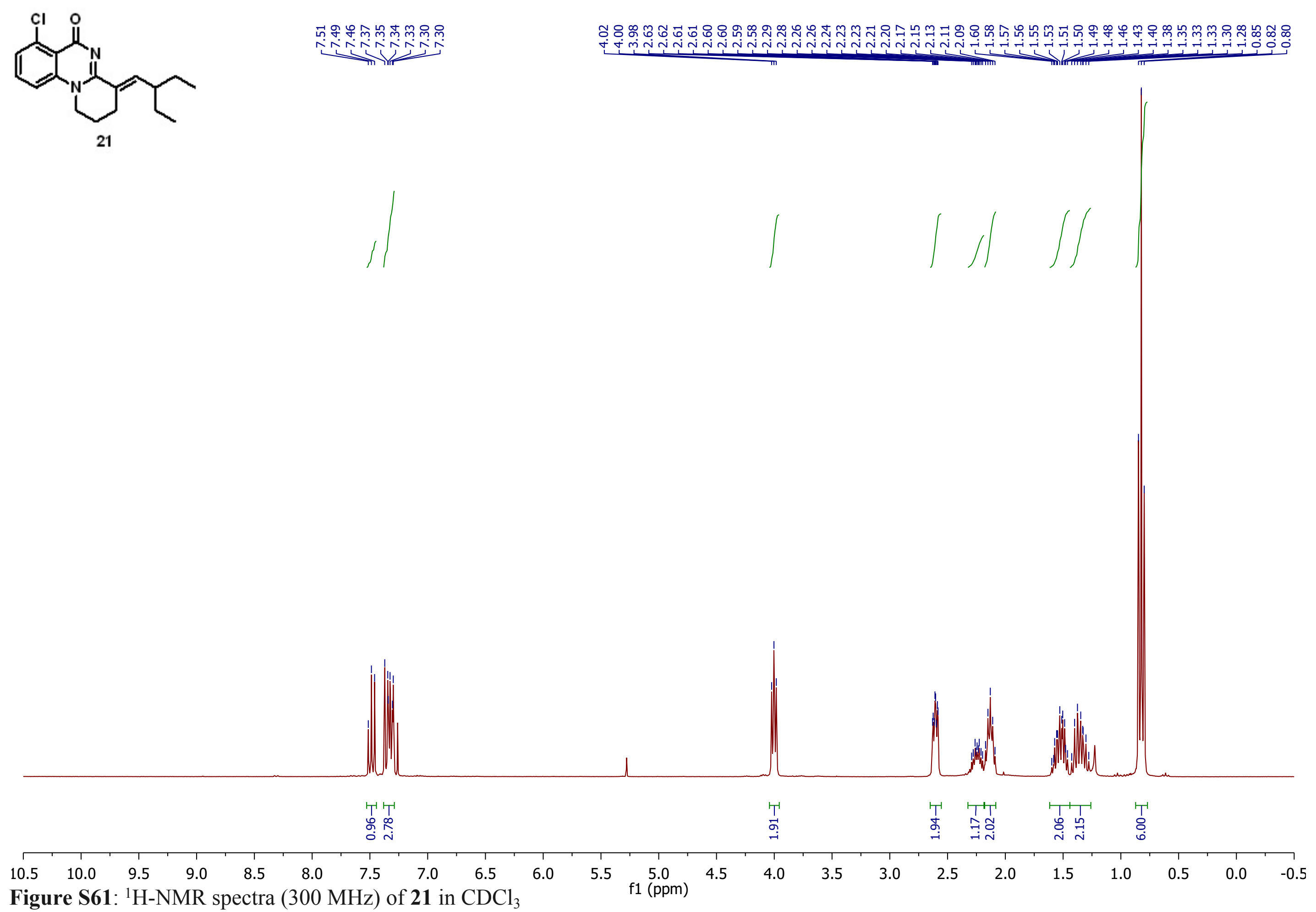


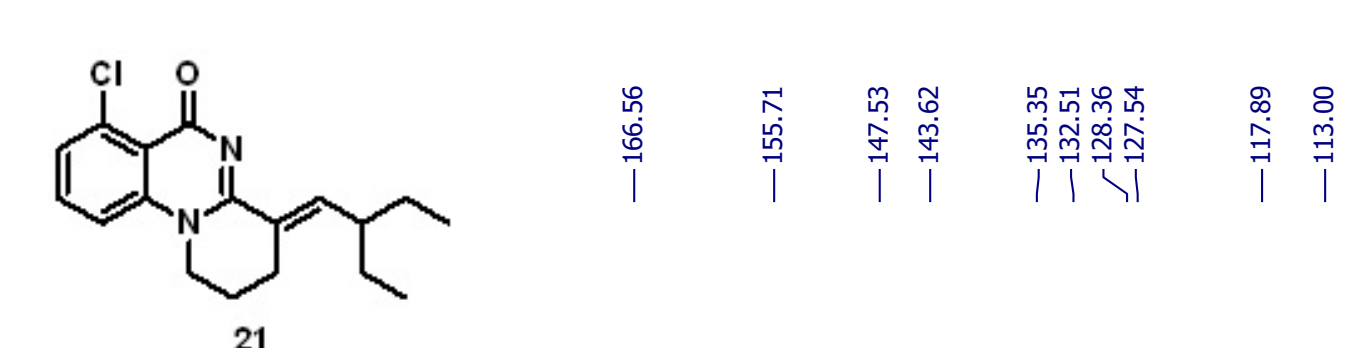

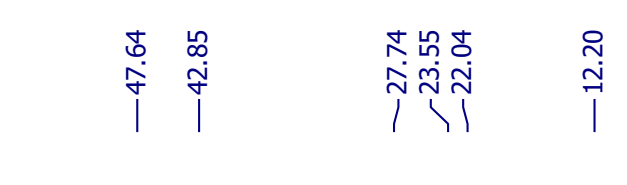

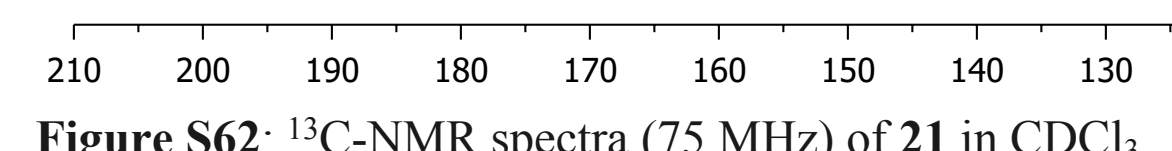




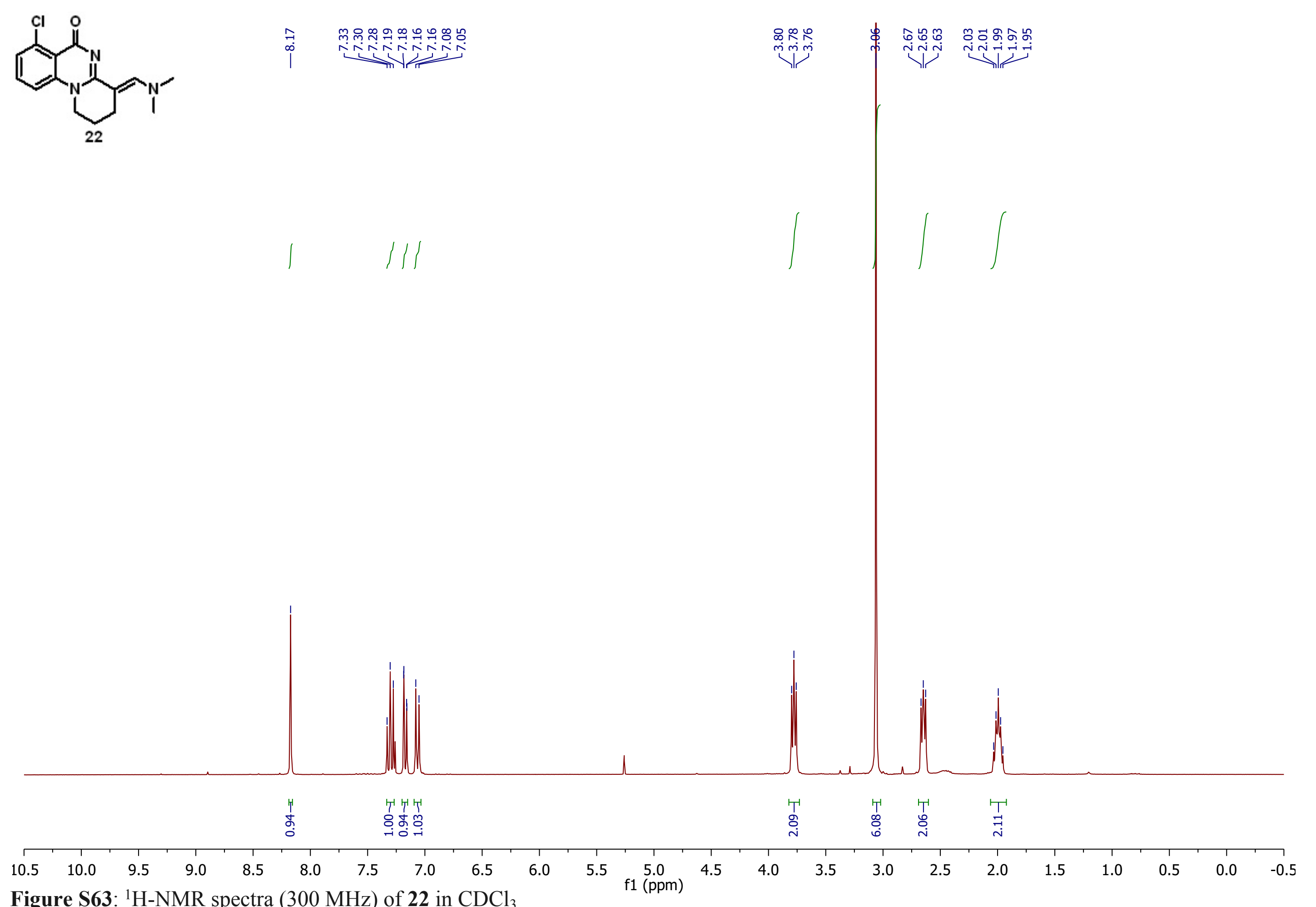




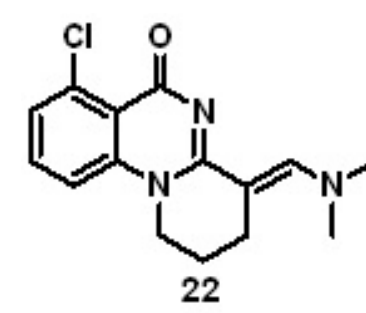

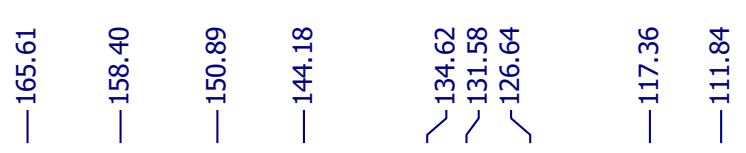

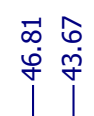

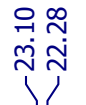

22

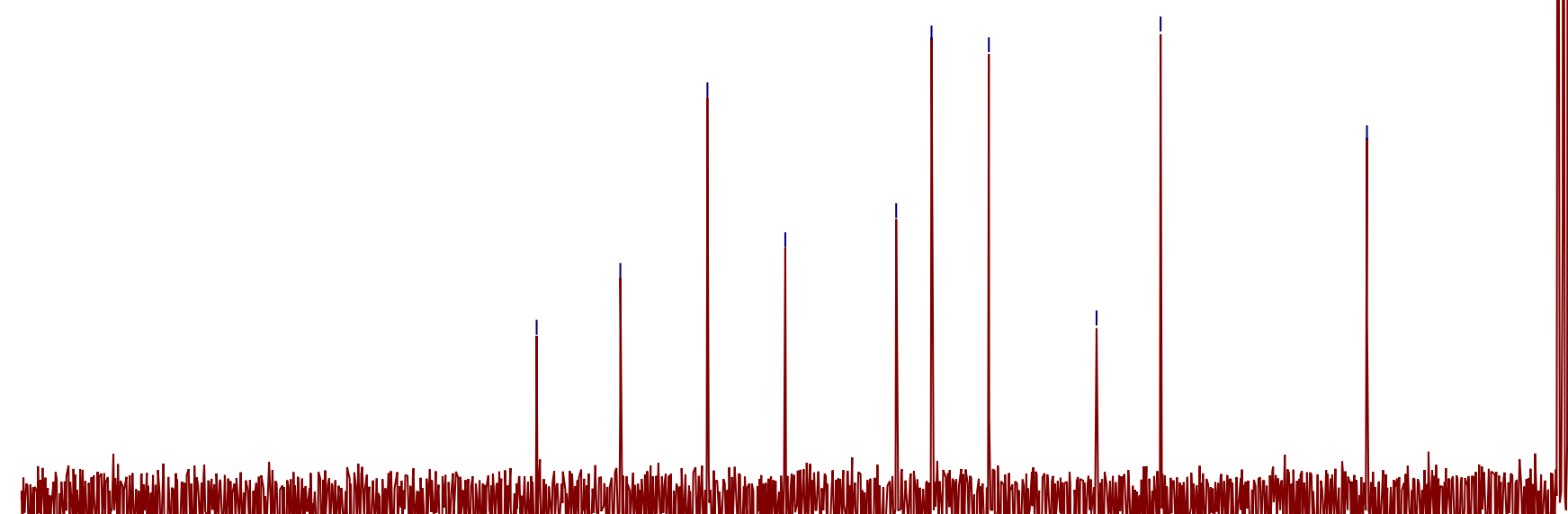
mind

\begin{tabular}{|c|c|c|c|c|c|c|c|c|c|c|c|c|c|c|c|c|c|c|c|c|}
\hline 210 & 200 & 190 & 180 & 170 & 160 & 150 & 140 & 130 & 120 & $\begin{array}{rr}110 & 100 \\
\mathrm{f} 1 & (\mathrm{ppm})\end{array}$ & 90 & 80 & 70 & 60 & 50 & 40 & 30 & 20 & 10 & 0 \\
\hline
\end{tabular}



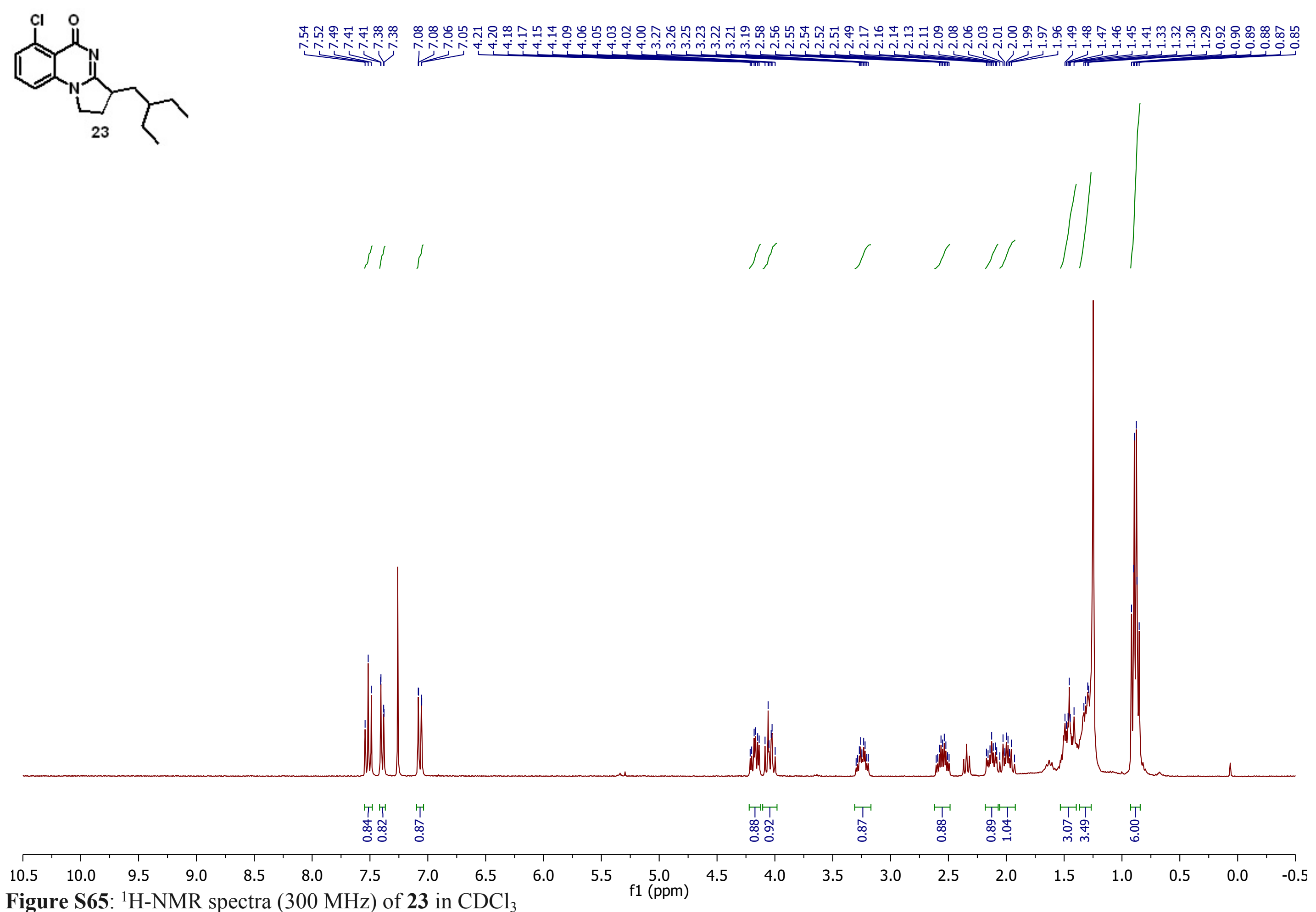

Figure S65: ${ }^{1} \mathrm{H}-\mathrm{NMR}$ spectra (300 MHz) of 23 in $\mathrm{CDCl}_{3}$ 


|



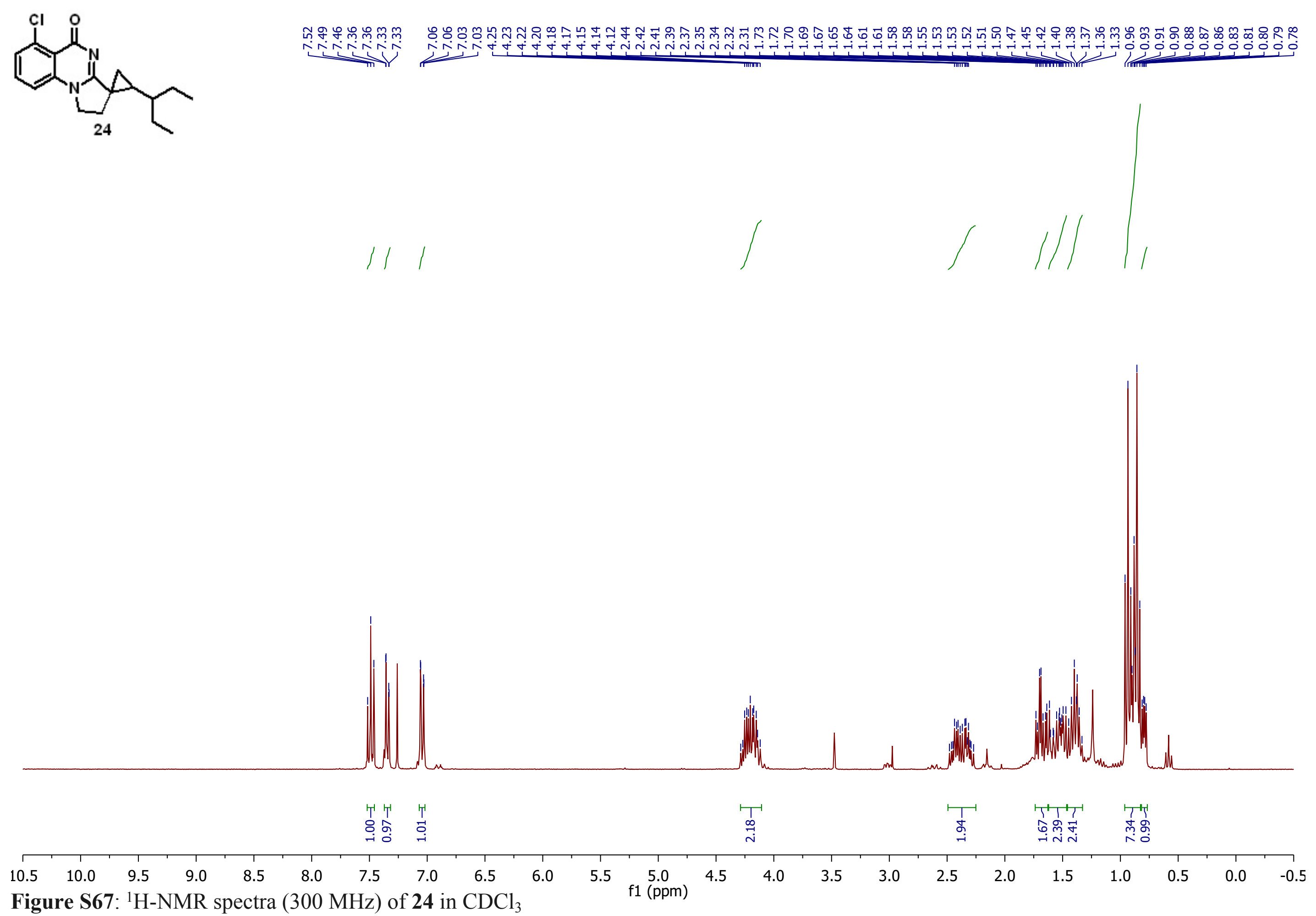


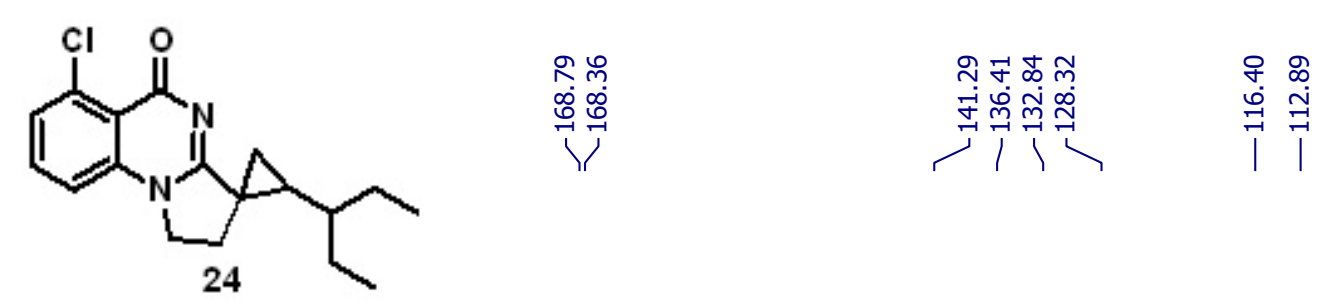

|

|

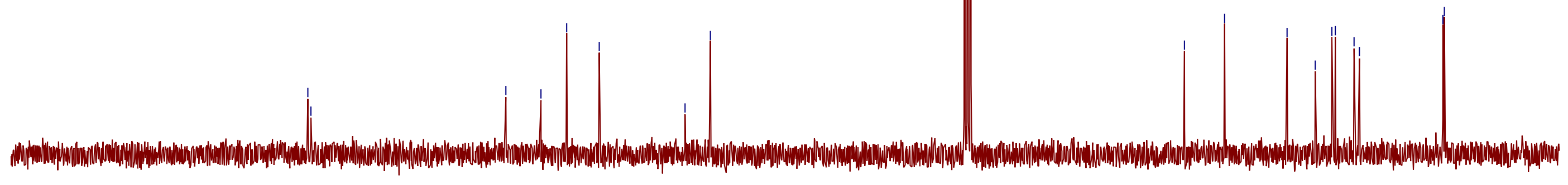

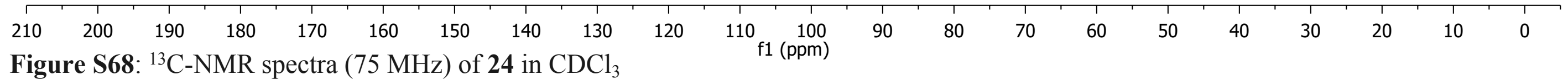




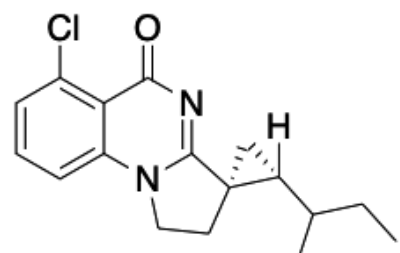

\section{rac-24}

purified by reverse phase preparative HPLC

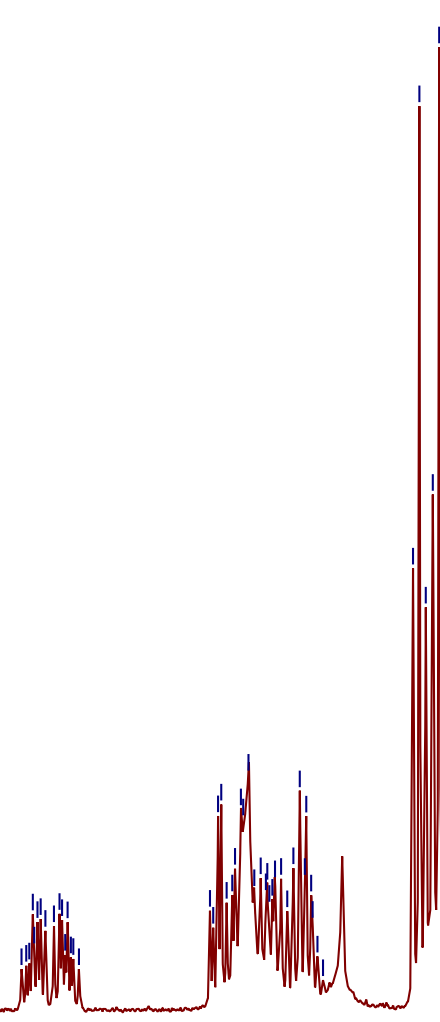

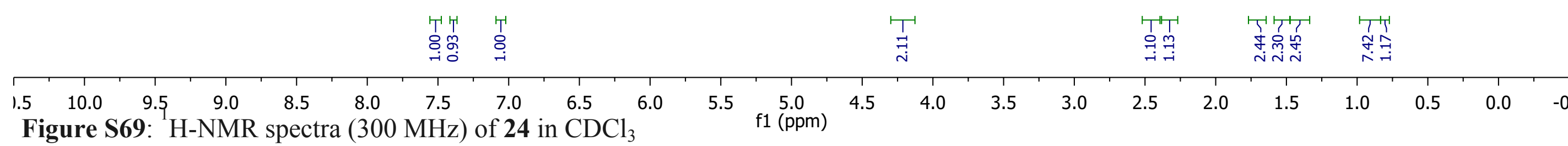

